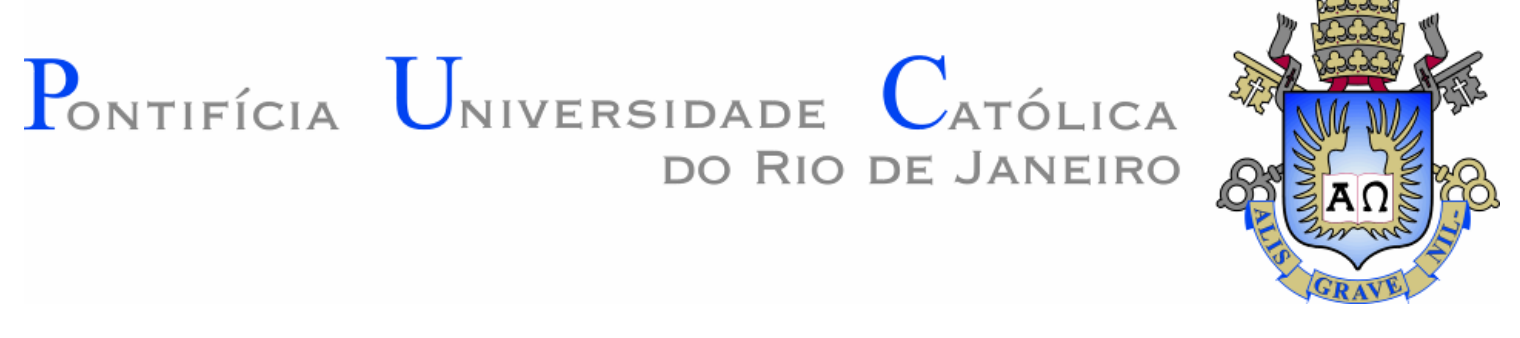

Rafael José Cavalieri Feital

\title{
Estudo numérico do processo de tamponamento de poços de petróleo
}

Dissertação apresentada como requisito parcial para a obtenção do grau de Mestre pelo Programa de Pós-Graduação em Engenharia Mecânica do Departamento de Engenharia Mecânica da PUC-Rio.

Orientadora: Prof. Mônica Feijó Naccache 


\section{Pontifícia Universidade Católica $_{\text {a }}$}

DO RIO DE JANEIRO

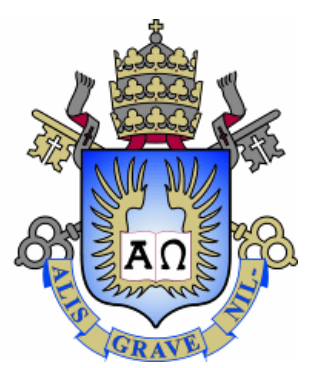

Rafael José Cavalieri Feital

\section{Estudo numérico do processo de tamponamento de poços de petróleo}

Dissertação apresentada como requisito parcial para a obtenção do grau de Mestre pelo Programa de Pós-Graduação em Engenharia Mecânica do Departamento de Engenharia Mecânica do Centro Técnico Científico da PUC-Rio. Aprovada pela Comissão Examinadora abaixo assinada.

Prof. Mônica Feijó Naccache

Orientadora

Departamento de Engenharia Mecânica - PUC-Rio

Prof. Paulo Roberto de Souza Mendes Departamento de Engenharia Mecânica - PUC-Rio

Dr. André Leibsohn Martins

Petróleo Brasileiro

Prof. José Eugenio Leal Coordenador Setorial do Centro Técnico Científico - PUC-Rio 
Todos os direitos reservados. É proibida a reprodução total ou parcial do trabalho sem autorização da universidade, do autor e do orientador.

\section{Rafael José Cavalieri Feital}

Graduou-se em Engenharia Química na PUC-Rio (Pontíficia Universidade Católica do Rio de Janeiro) em 2013. Escreveu um artigo que foi publicado em revista internacional (Journal Molecular Simulation / Journal of Experimental Nanoscience) em 2012 durante a Iniciação Científica na PUC-Rio, nomeado "Docking and Molecular Dynamics of new potential inhibitors of the Human Epidermal Receptor 2 (HER2)".

Ficha Catalográfica

Feital, Rafael José Cavalieri

Estudo numérico do processo de tamponamento de poços de petróleo / Rafael José Cavalieri Feital; orientadora: Mônica Feijó Naccache. - Rio de Janeiro PUC, Departamento de Engenharia Mecânica, 2015.

v., 109 f. : il. (color.) ; 29,7 cm

1. Dissertação (mestrado) - Pontifícia Universidade Católica do Rio de Janeiro, Departamento de Engenharia Mecânica.

Inclui referências bibliográficas.

1. Engenharia mecânica - Teses. 2. Tamponamento. 3. Viscoplasticidade. 4. Reologia. I. Naccache, Mônica Feijó. II. Pontifícia Universidade Católica do Rio de Janeiro. Departamento de Engenharia Mecânica. III. Título.

CDD: 621 


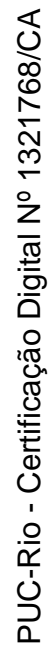

Para os meus pais, Myriam e Ricardo, pelo incentivo, estímulo e confiança. 


\section{Agradecimentos}

À minha orientadora Professora Mônica Feijó Naccache pelo incentivo e cooperação para a realização deste trabalho.

Ao CNPq e à PUC-Rio, pelos auxílios concedidos, sem os quais este trabalho não poderia ter sido realizado.

Aos meus pais, Ricardo José Feital e Myriam Cavalieri D'Oro Feital, pelo constante apoio, estímulo, educação, carinho e atenção.

Aos meus amigos da PUC-Rio.

Aos professores que fizeram parte da banca examinadora.

A todos os professores do Departamento pelos ensinamentos e cooperação.

A todos os familiares e amigos que me ajudaram e me incentivaram. 


\section{Resumo}

Feital, Rafael José Cavalieri; Naccache, Mônica Feijó. Estudo numérico do processo de tamponamento de poços de petróleo. Rio de Janeiro, 2015. 109p. Dissertação de Mestrado - Departamento de Engenharia Mecânica, Pontíficia Universidade Católica do Rio de Janeiro.

O tamponamento de poços de petróleo é analisado numericamente. Neste processo, um fluido mais denso (pasta de cimento) é colocado sobre outro menos denso (fluido de perfuração) em um poço vertical, resultando em uma situação de instabilidade. $\mathrm{O}$ escoamento resultante foi estudado de forma a avaliar se o isolamento do poço ocorreria até o momento da cura do cimento (entre 4 e 5 horas). O cimento foi modelado como fluido não-newtoniano e o fluido de perfuração foi considerado newtoniano em alguns casos e não-newtoniano nos demais casos. A solução do escoamento foi obtida numericamente, usando-se o programa ANSYS Fluent. As equações de conservação são resolvidas empregando-se o Método dos Volumes Finitos e o escoamento multifásico foi modelado utilizando-se o método Volume de Fluido. $\mathrm{O}$ comportamento viscoplástico não-newtoniano foi modelado empregando a equação constitutiva do fluido newtoniano generalizado, com a função de viscosidade Herschel-Bulkley. O sucesso da operação foi determinado pela combinação dos parâmetros reológicos e geométricos. O efeito dos parâmetros como a razão entre densidades e viscosidades foi investigado para uma geometria fixa (razão fixa entre o comprimento do tampão e o seu diâmetro). Além disso, a influência dessa mesma razão no processo também foi analisada enquanto outros parâmetros foram mantidos fixos. Foi demonstrado que o escoamento é muito instável e que os parâmetros estudados afetam consideravelmente a operação.

\section{Palavras-chave}

Viscoplástico; não-newtoniano; reologia; estabilidade; tamponamento de poços de petróleo; tensão; Herschel-Bulkley. 


\section{Abstract}

Feital, Rafael José Cavalieri; Naccache, Mônica Feijó (Advisor). Numerical study of oil well plugging process. Rio de Janeiro, 2015. 109p. MSc. Dissertation - Departamento de Engenharia Mecânica, Pontíficia Universidade Católica do Rio de Janeiro.

The plugging process of an oil well was analyzed numerically. In this process, the denser fluid is the cement plug, which was placed above the drilling fluid in a vertical well, resulting in an unstable situation. The cement plug was modeled as non-Newtonian and the drilling fluid was considered Newtonian in some cases and non-Newtonian in other cases. The flow solution is studied using the ANSYS Fluent program. The conservation equations were solved using the Finite Volume Method, and the multiphase flow was modeled with the Volume of Fluid method. The non-Newtonian viscoplastic behavior of the cement plug was modeled with the Generalized Newtonian Fluid constitutive equation, with the Herschel-Bulkley viscosity function. The success of the operation was determined by the combination of the governing rheological and geometric parameters. The effect of the governing parameters, such as the density ratio and the viscosity ratio, were investigated for a fixed geometry and a fixed ratio between the cement plug length and diameter. Furthermore, the influence of this ratio in the process was also analyzed while others governing parameters were fixed. It was shown that the flow is highly unstable, and that the governing parameters considerably affect the operation.

\section{Keywords}

Viscoplastic; non-newtonian; rheology; stability; oil well plugging; tension; Herschel-Bulkley. 


\section{Sumário}

1. Introdução 23

1.1. Motivação 23

1.2. Objetivo 25

2. Revisão Bibliográfica 26

3. Formulação Matemática 32

3.1. Equações Constitutivas 32

3.2. Problema 34

3.3. Adimensionalização 37

3.4. Método VOF 39

4. Metodologia 42

4.1. Pressão e Velocidade acopladas 43

4.2. Método baseado nos mínimos quadrados 45

4.3. Método Implícito de Primeira Ordem 47

4.4. Discretização Power-Law 48

4.5. Tensão Interfacial 49

4.6. Número de Courant 51

5. Teste de Malha (Validação) 52

5.1. Definição da Dimensão da Malha 52

5.2. Definição do Refinamento da Malha 56

5.3. Definição da Taxa de Cisalhamento Crítica 59

6. Resultados 64 
6.1. Influência da Razão de Aspecto 64

6.2. Influência da Razão Entre Densidades 67

6.3. Influência da Razão Entre Viscosidades 79

6.4. Influência da Razão Entre Tensões Limite de Escoamento 91

6.5. Influência da Razão Entre Índices de Comportamento 95

6.6. Influência da Tensão Interfacial 98

$\begin{array}{ll}\text { 7. Conclusão } & 102\end{array}$

7.1. Proposta para trabalhos futuros 104

$\begin{array}{ll}\text { 7.2. Observações } & 105\end{array}$

8. Referências bibliográficas 


\section{Lista de gráficos}

Gráfico 1 - Tensão de Cisalhamento vs. Taxa de Deformação

Gráfico 2 - Velocidade Interfacial vs. Tempo (Malhas $\mathrm{B}_{1}$ e $\mathrm{B}_{2}, \mathrm{~L}^{*}=$ 20, $\left.\rho_{R}=1,61, \eta_{R}=1,00\right)$

Gráfico 3 - Densidade da Mistura no topo vs. Tempo (Malhas $\mathrm{B}_{1} \mathrm{e}$ $\left.\mathrm{B}_{2}, \mathrm{~L}^{*}=20, \rho_{R}=1,61, \eta_{R}=1,00\right)$

Gráfico 4 - Velocidade Interfacial vs. Tempo (Malhas $\mathrm{C}_{1}$ e $\mathrm{C}_{2}$, $\mathrm{L}^{*}=$ 20, $\left.\rho_{R}=1,61, \eta_{R}=1,00\right)$

Gráfico 5 - Densidade da Mistura no topo vs. Tempo (Malhas $\mathrm{C}_{1} \mathrm{e}$ $\mathrm{C}_{2}, \mathrm{~L}^{*}=20, \rho_{R}=1,61, \eta_{R}=1,00$ )

Gráfico 6 - Velocidade Interfacial vs. Tempo (Malhas $B_{1}, A_{1}$ e $C_{1}$ )

Gráfico 7 - Densidade da Mistura no topo vs. Tempo (Malhas $B_{1}$, $A_{1}$ e $C_{1}$ )

Gráfico 8 - Tempos de Furo e Deposição vs. Refinamento $\left(\mathrm{L}^{*}=\right.$ 20, $\left.\rho_{R}=1,61, \eta_{R}=1,00\right)$

Gráfico 9 - Velocidade Terminal vs. Refinamento $\left(\mathrm{L}^{*}=20, \rho_{R}=\right.$ $\left.1,61, \eta_{R}=1,00\right)$

Gráfico 10 - Velocidade Interfacial vs. Tempo $\left(\mathrm{L}^{*}=10, \rho_{R}=1,20\right)$

Gráfico 11 - Densidade da mistura no Topo vs. Tempo $\left(\mathrm{L}^{*}=10\right.$, $\left.\rho_{R}=1,20\right)$

Gráfico 12 - Tempo de Furo vs. $\log \left(\frac{1}{\left(\dot{\gamma}_{c r}\right)_{R}}\right)$

Gráfico 13 - Tempo de Deposição vs. $\log \left(\frac{1}{\left(\dot{\gamma_{c r}}\right)_{R}}\right)$ 
Gráfico 14 - Velocidade Terminal vs. $\log \left(\frac{1}{\left(\dot{\gamma_{c r}}\right)_{R}}\right)$

Gráfico 15 - Velocidade Interfacial vs. Tempo $\left(\rho_{R}=1,20, \eta_{R}=\right.$ $1,00)$

Gráfico 16 - Densidade da mistura no topo vs. Tempo $\left(\rho_{R}=1,20\right.$, $\left.\eta_{R}=1,00\right)$

Gráfico 17 - Tempos de Furo e Deposição vs. Razão de Aspecto $\left(\rho_{R}=1,20, \eta_{R}=1,00\right)$

Gráfico 18 - Velocidade Terminal vs. Razão entre Densidades ( $L^{*}$ $=10, \eta_{R}=1,00$ )

Gráfico 19 - Velocidade Interfacial vs. Tempo $\left(\mathrm{L}^{*}=5, \eta_{R}=1,00\right)$

Gráfico 20 - Densidade da mistura no topo vs. Tempo $\left(\mathrm{L}^{*}=5, \eta_{R}\right.$ $=1,00$ )

Gráfico 21 - Tempos de furo e deposição vs. Razão entre Densidades para $\mathrm{L}^{*}=5$

Gráfico 22 - Velocidade Interfacial vs. Tempo $\left(\mathrm{L}^{*}=10, \eta_{R}=0,50\right)$

Gráfico 23 - Densidade da mistura no topo vs. Tempo $\left(\mathrm{L}^{*}=10, \eta_{R}\right.$ $=0,50$ )

Gráfico 24 - Tempos de furo e deposição vs. Razão entre Densidades $\left(\mathrm{L}^{*}=10, \eta_{R}=0,50\right)$

Gráfico 25 - Velocidade terminal vs. Razão entre Densidades ( $L^{*}$ $\left.=10, \eta_{R}=0,50\right)$

Gráfico 26 - Velocidade Interfacial vs. Tempo $\left(\mathrm{L}^{*}=10, \eta_{R}=0,75\right)$

Gráfico 27 - Densidade da mistura no topo vs. Tempo $\left(\mathrm{L}^{*}=10, \eta_{R}\right.$ $=0,75$ )

Gráfico 28 - Tempos de furo e deposição vs. Razão entre Densidades $\left(\mathrm{L}^{*}=10, \eta_{R}=0,75\right)$ 
Gráfico 29 - Velocidade Terminal vs. Razão entre Densidades ( $\mathrm{L}^{*}$ $\left.=10, \eta_{R}=0,75\right)$

Gráfico 30 - Velocidade Interfacial vs. Tempo $\left(\mathrm{L}^{*}=10, \eta_{R}=1,00\right)$

Gráfico 31 - Densidade da mistura no topo vs. Tempo $\left(\mathrm{L}^{*}=10, \eta_{R}\right.$ $=1,00)$

Gráfico 32 - Tempos de furo e deposição vs. Razão entre Densidades $\left(\mathrm{L}^{*}=10, \eta_{R}=1,00\right)$

Gráfico 33 - Velocidade Terminal vs. Razão entre Densidades ( $L^{*}$ $\left.=10, \eta_{R}=1,00\right)$

Gráfico 34 - Tempo de Furo vs. Razão entre Densidades

78

Gráfico 35 - Tempo de Deposição vs. Razão entre Densidades

78

Gráfico 36 - Velocidade Terminal vs. Razão entre Densidades

79

Gráfico 37 - Velocidade Interfacial vs. Tempo $\left(\mathrm{L}^{*}=10, \rho_{R}=1,05\right)$

Gráfico 38 - Densidade da mistura no topo vs. Tempo $\left(L^{*}=10\right.$, $\left.\rho_{R}=1,05\right)$

Gráfico 39 - Tempos de furo e deposição vs. Razão entre Viscosidades $\left(\mathrm{L}^{*}=10, \rho_{R}=1,05\right)$

Gráfico 40 - Velocidade Terminal vs. Razão entre Viscosidades $\left(\mathrm{L}^{*}=10, \rho_{R}=1,05\right)$

Gráfico 41 - Velocidade Interfacial vs. Tempo $\left(\mathrm{L}^{*}=10, \rho_{R}=1,20\right)$

Gráfico 42 - Densidade da mistura no topo vs. Tempo $\left(L^{*}=10\right.$, $\left.\rho_{R}=1,20\right)$

Gráfico 43 - Tempos de furo e deposição vs. Razão entre Viscosidades $\left(\mathrm{L}^{*}=10, \rho_{R}=1,20\right)$

Gráfico 44 - Velocidade Terminal vs. Razão entre Viscosidades $\left(\mathrm{L}^{*}=10, \rho_{R}=1,20\right)$

Gráfico 45 - Velocidade Interfacial vs. Tempo $\left(\mathrm{L}^{*}=10, \rho_{R}=1,31\right)$

Gráfico 46 - Densidade da mistura no topo vs. Tempo $\left(L^{*}=10\right.$, $\left.\rho_{R}=1,31\right)$ 
Gráfico 47 - Tempos de furo e deposição vs. Razão entre Viscosidades $\left(\mathrm{L}^{*}=10, \rho_{R}=1,31\right)$

Gráfico 48 - Velocidade Terminal vs. Razão entre Viscosidades $\left(\mathrm{L}^{*}=10, \rho_{R}=1,31\right)$

Gráfico 49 - Velocidade Interfacial vs. Tempo $\left(\mathrm{L}^{*}=10, \rho_{R}=1,61\right)$

Gráfico 50 - Densidade da mistura no topo vs. Tempo $\left(L^{*}=10\right.$, $\left.\rho_{R}=1,61\right)$

Gráfico 51 - Tempos de furo e deposição vs. Razão entre Viscosidades $\left(\mathrm{L}^{*}=10, \rho_{R}=1,61\right)$

Gráfico 52 - Velocidade Terminal vs. Razão entre Viscosidades $\left(\mathrm{L}^{*}=10, \rho_{R}=1,61\right)$

Gráfico 53 - Tempo de Furo vs. Razão entre Viscosidades

Gráfico 54 - Tempo de Deposição vs. Razão entre Viscosidades

Gráfico 55 - Velocidade Terminal vs. Razão entre Viscosidades

Gráfico 56 - Velocidade Interfacial vs. Tempo $\left(\mathrm{L}^{*}=10, \rho_{R}=1,20\right.$, $\left.\eta_{R}=1,00\right)$

Gráfico 57 - Densidade da mistura no topo vs. Tempo $\left(L^{*}=10\right.$, $\left.\rho_{R}=1,20, \eta_{R}=1,00\right)$

Gráfico 58 - Tempo de Furo e Deposição vs. Razão entre Tensões Limite

Gráfico 59 - Velocidade Terminal vs. Razão entre Tensões Limite

Gráfico 60 - Velocidade Interfacial vs. Tempo $\left(\mathrm{L}^{*}=10, \rho_{R}=1,20\right.$, $\left.\eta_{R}=1,00, \tau_{y_{R}}=1,00\right)$

Gráfico 61 - Densidade da mistura no topo vs. Tempo $\left(\mathrm{L}^{*}=10\right.$, $\left.\rho_{R}=1,20, \eta_{R}=1,00, \tau_{y_{R}}=1,00\right)$

Gráfico 62 - Tempo de Furo e Deposição vs. Razão entre Índices de Comportamento

Gráfico 63 - Velocidade Terminal vs. Razão entre Índices de Comportamento 
Gráfico 64 - Velocidade Interfacial vs. Tempo $\left(\mathrm{L}^{*}=10, \rho_{R}=1,05\right.$, $\left.\eta_{R}=0,50\right)$

Gráfico 65 - Densidade da mistura no topo vs. Tempo $\left(\mathrm{L}^{*}=10\right.$, $\left.\rho_{R}=1,05, \eta_{R}=0,50\right)$ 


\section{Lista de figuras}

Figura 1 - Tamponamento do poço de petróleo

Figura 2 - Visão bidimensional do tamponamento de poços de petróleo

Figura 3 - Variação no centróide das células na direção do vetor $r_{i}$

Figura 4 - Perfil do escoamento para $\rho_{R}=1,05$ e $\rho_{R}=1,61$ para $\eta_{R}=0,50$

Figura 5 - Perfil do escoamento para $\eta_{R}=0,50$ e $\eta_{R}=1,00$ para $\rho_{R}=1,05$

Figura 6 - Perfil do escoamento para $\tau_{y_{R}}=0,50$ e $\tau_{y_{R}}=2,00$

Figura 7 - Perfil do escoamento para $n_{R}=0,56$ e $n_{R}=1,00$ 


\section{Lista de tabelas}

Tabela 1 - Resultados das malhas $\mathrm{B}_{1}$ e $\mathrm{B}_{2}$

Tabela 2 - Resultados das malhas $\mathrm{C}_{1}$ e $\mathrm{C}_{2}$

Tabela 3 - Resultados das malhas $\mathrm{B}_{1}, \mathrm{~B}_{2}, \mathrm{C}_{1}$ e $\mathrm{C}_{2}$

Tabela 4 - Resultados das malhas 3D $\left(\mathrm{L}^{*}=20, \rho_{R}=1,61, \eta_{R}=\right.$ $1,00)$

Tabela 5 - Discrepâncias dos resultados em relação ao caso 5

Tabela 6 - Resultados para diferentes razões de aspecto 66

Tabela 7 - Tempos de furo e deposição para $L^{*}=5 \quad 69$

Tabela 8 - Velocidade Terminal e Tempos de furo e deposição $\left(L^{*}\right.$ $\left.=10, \eta_{R}=0,50\right)$

Tabela 9 - Velocidade Terminal e Tempos de furo e deposição ( $L^{*}$ $=10, \eta_{R}=0,75$ )

Tabela 10 - Velocidade Terminal e Tempos de furo e deposição $\left(\mathrm{L}^{*}=10, \eta_{R}=1,00\right)$

Tabela 11 - Resultados para diferentes razões entre densidades

Tabela 12 - Velocidade Terminal e Tempos de furo e deposição $\left(\mathrm{L}^{*}=10, \rho_{R}=1,05\right)$

Tabela 13 - Velocidade Terminal e Tempos de furo e deposição $\left(\mathrm{L}^{*}=10, \rho_{R}=1,20\right)$

Tabela 14 - Velocidade Terminal e Tempos de furo e deposição $\left(\mathrm{L}^{*}=10, \rho_{R}=1,31\right)$

Tabela 15 - Velocidade Terminal e Tempos de furo e deposição $\left(\mathrm{L}^{*}=10, \rho_{R}=1,61\right)$

Tabela 16 - Resultados para diferentes razões entre viscosidades

Tabela 17 - Resultados (Razão entre Tensões Limite de Escoamento)

Tabela 18 - Resultados (Razão entre Índices de Comportamento) 
Tabela 19 - Influência da tensão interfacial no tempo de furo 


\section{Lista de Equações}

(1) $\stackrel{\bar{\tau}}{\tau}=\eta \cdot \overline{\bar{D}}$

(2) $\overline{\bar{D}}=\frac{1}{2}\left(\nabla u+\nabla u^{T}\right)$

(3) $\gamma=\sqrt{\frac{1}{2} \overline{\bar{D}}: \overline{\bar{D}}}$

(4A) $\eta=\frac{\tau_{y}}{\dot{\gamma}}+K \dot{\gamma}^{n-1}, \tau>\tau_{y}$

(4B) $\eta=\infty, \tau<\tau_{y}$

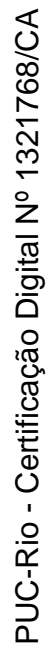

(5A) $\eta=\frac{\tau_{y}}{\dot{\gamma}}+K\left[\frac{\dot{\gamma}}{\dot{\gamma_{c r}}}\right]^{n-1} \rightarrow \dot{\gamma}>\dot{\gamma}_{c r}$

(5B) $\eta=\eta_{0}=\frac{\tau_{y}}{\dot{\gamma}}\left[\frac{2-\frac{\dot{\gamma}}{\dot{\gamma}_{c r}}}{\dot{\gamma}_{c r}}\right]+K\left[(2-n)+(n-1) \frac{\dot{\gamma}}{\dot{\gamma}_{c r}}\right] \rightarrow \dot{\gamma}<\dot{\gamma}_{c r}$ 33

(6) $\tau=\tau_{y}\left(1-e^{-m \gamma}\right)+K \dot{\gamma}^{n}$

(7) $\eta=K|\dot{\gamma}|^{\mathrm{n}-1}+\frac{\tau_{y}}{|\dot{\gamma}|}\left(1-e^{-m \mid \dot{|\gamma|}}\right)$

(8) $\eta(\dot{\gamma})=K \dot{\gamma}^{n-1}$

(9) $L_{w}=L+L_{d}+L_{u}$

(10) $\frac{\Delta P}{\rho_{2} g L}=1$ 
(11) $1-\frac{4 \tau}{\rho_{2} g D}-\frac{\Delta P}{\rho_{2} g L} \geq 0$

(12) $1-4 \tau^{*}-\Delta P^{*} \cdot \frac{D}{L} \geq 0$

(13) $4 \tau_{y}^{*}+\frac{\Delta P^{*}}{L^{*}}=1$

(14) $B o=\frac{\Delta \rho \cdot g \cdot D^{2}}{\sigma}$

(15) $C a=\frac{\eta_{1} \cdot V_{c a r}}{\sigma}$

(16) $\varphi=\varphi_{1} \alpha_{1}+\varphi_{2} \alpha_{2}$

(17) $\alpha_{1}+\alpha_{2}=1$

(18) $\frac{\partial \rho}{\partial t}+\rho\left(\frac{\partial u_{i}}{\partial x_{k}}+\frac{\partial u_{i}}{\partial x_{i}}\right)=0$

(19) $\frac{\partial \alpha_{i}}{\partial t}+u_{i} \frac{\partial \alpha_{i}}{\partial x_{j}}=0$

(20) $\frac{\partial\left(\rho u_{i}\right)}{\partial t}+\frac{\partial\left(\rho u_{i} u_{j}\right)}{\partial x_{i}}=-\frac{\partial P}{\partial x_{k}}+\frac{\partial}{\partial x_{i}}\left[\eta\left(\frac{\partial u_{i}}{\partial x_{k}}+\frac{\partial u_{i}}{\partial x_{i}}\right)\right]+\rho g_{k}$

(21) $\frac{\partial \rho^{*}}{\partial t^{*}}+\rho^{*}\left(\frac{\partial u_{i}^{*}}{\partial x_{k}^{*}}+\frac{\partial u_{i}^{*}}{\partial x_{i}^{*}}\right)=0$

(22) $\frac{\partial \alpha_{i}}{\partial t^{*}}+u_{i}{ }^{*} \frac{\partial \alpha_{i}}{\partial x_{j}{ }^{*}}=0$

(23) $\frac{\partial u_{i}^{*}}{\partial t^{*}}+\frac{\partial\left(u_{i}^{*} u_{j}^{*}\right)}{\partial x_{i}^{*}}=-\frac{\partial P^{*}}{\partial x_{k}{ }^{*}} \frac{\rho_{2}}{\rho}+\frac{1}{\operatorname{Re}} \frac{\rho_{2}}{\rho} \frac{\partial}{\partial x_{i}^{*}}\left[\eta^{*}\left(\frac{\partial u_{i}^{*}}{\partial x_{k}{ }^{*}}+\frac{\partial u_{i}^{*}}{\partial x_{i}^{*}}\right)\right]+1$

(24) $V=V_{n f}{ }^{*}+V_{f}$ 
(25) $P=P_{c 0}{ }^{*}+P_{c 0}{ }^{\prime}$

(26) $V_{f}{ }^{\prime}=d_{f}\left(P_{c 0}{ }^{\prime}-P_{c 1}{ }^{\prime}\right)$

(27) $d_{f}=\frac{A_{f}}{\left(a_{p, c 0}^{\prime}+a_{p, c 1}^{\prime}\right) / 2}$

(28) $a P^{\prime}=\sum_{i} a_{i} P_{i}^{\prime}+B$

(29) $B=\sum_{f}^{n} J_{f}^{*} A_{f}$

(30) $(\nabla \phi)_{c_{0}} . \Delta r_{i}=\left(\phi_{c_{i}}-\phi_{c_{0}}\right)$

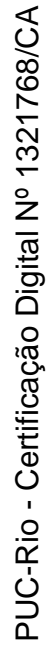

(31) $|J|(\nabla \phi)_{c_{0}}=\Delta \phi$

(32) $\left(\phi_{x}\right)_{c_{0}}=\sum_{i=1}^{n}\left[W^{x} i_{0}\left(\phi_{c_{i}}-\phi_{c_{0}}\right)\right]$

(33) $\left(\phi_{y}\right)_{c_{0}}=\sum_{i=1}^{n}\left[W^{y} i_{0}\left(\phi_{c_{i}}-\phi_{c_{0}}\right)\right]$

(34) $\left(\phi_{z}\right)_{c_{0}}=\sum_{i=1}^{n}\left[W^{z} i_{0}\left(\phi_{c_{i}}-\phi_{c_{0}}\right)\right]$

(35) $F_{i}=\left[-\nabla_{S} \bullet\left(h \bar{V}_{l}\right)+\frac{m_{S}}{\rho_{l}}\right]_{i}$

(36) $G_{i}=\left[-\frac{h \nabla_{S} P_{L}}{\rho_{l}}+\left[\bar{g}_{\tau}\right] h+\frac{3}{2 \rho_{l}} \bar{\tau}_{f_{s}}+\frac{\dot{q}}{\rho_{l}}-\nabla_{S} \bullet\left[h \bar{V}_{l} \bar{V}_{l}\right]\right]_{i}$ 
(38) $\left(\bar{V}_{l}\right)_{i+1}=\frac{\left(h \bar{V}_{l}\right)_{i}+G_{i} \Delta t}{h_{i+1}+\left[\frac{3 v_{l}}{h_{i+1}}\right] \Delta t}$

(39) $h_{i+1}^{0}=h_{i}+F_{i} \Delta t$

(40) $\left(\bar{V}_{l}\right)_{i+1}^{0}=\frac{\left(h \bar{V}_{l}\right)_{i}+G_{i} \Delta t}{h_{i+1}^{0}+\left[\frac{3 v_{l}}{h_{i+1}^{0}}\right] \Delta t}$

(41) $h_{i+1}^{n+1}=h_{i}+\left\{h_{i+1}^{n},\left(\bar{V}_{l}\right)_{i+1}^{n}\right\} F \Delta t$

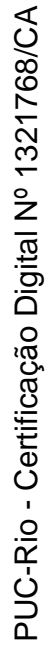

(42) $\left(\bar{V}_{l}\right)_{i+1}^{n+1}=\frac{\left(h \bar{V}_{l}\right)_{i}+\left\{h_{i+1}^{n},\left(\bar{V}_{l}\right)_{i+1}^{n}\right\} G \Delta t}{h_{i+1}^{n+1}+\left[\frac{3 v_{l}}{h_{i+1}^{n+1}}\right] \Delta t}$

(43) $\left|h_{i+1}^{n+1}-h_{i+1}^{n}\right| \leq \epsilon$

(44) $\left|\left[u_{\alpha}\right]_{i+1}^{n+1}-\left[u_{\alpha}\right]_{i+1}^{n}\right| \leq \epsilon$

(45) $\frac{\partial}{\partial x}(\rho u \phi)=\frac{\partial}{\partial x} \Gamma \frac{\partial \phi}{\partial x}$

(46) $\frac{\phi(x)-\phi_{0}}{\phi_{L}-\phi_{0}}=\frac{e^{\left[\frac{x}{L}\right] P e}-1}{e^{P e}-1}$

(47) $P e=\frac{\rho u L}{\Gamma}$

(48) $T=\sigma(I-n \otimes n) \mid \vec{n}$ 
(49) $|\vec{n}|=\nabla \alpha$

(50) $\hat{n}=\frac{\vec{n}}{|->|}$

(51) $T=\sigma(|\nabla \alpha|) I-\frac{\nabla \alpha \otimes \nabla \alpha}{|\nabla \alpha|}$

(52) $F_{C S S}=\nabla \cdot T$

(53) $C=u_{x} \frac{\Delta t}{\Delta x}+u_{y} \frac{\Delta t}{\Delta y}+u_{z} \frac{\Delta t}{\Delta z}$

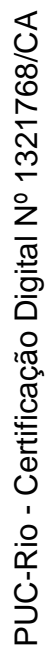




\section{Introdução}

\subsection{Motivação}

O processo de tamponamento de poços de petróleo tem sido amplamente utilizado na indústria petrolífera, principalmente quando se deseja efetuar o abandono definitivo ou temporário e a recompletação de um poço. Este processo consiste no bombeamento de um determinado volume de pasta de cimento para o poço com a finalidade de tamponar um trecho deste poço. O cimento é posicionado sobre a lama de perfuração. Pelo fato do cimento ser mais denso do que a lama de perfuração, gera-se uma situação instável que pode resultar no escoamento do cimento antes da sua cura, e a posterior contaminação do mesmo pelo fluido de perfuração, que pode resultar na falha da operação. O comportamento mecânico dos dois materiais, que são em geral Não-Newtonianos, a geometria e as condições de operação determinam o sucesso da operação.

Com o intuito de melhorar o processo de tamponamento, alguns artifícios vêm sendo utilizados pela indústria do petróleo. Um deles é a utilização de aditivos químicos à composição do cimento, que têm a função de aperfeiçoar a vedação do poço. Alguns são empregados para reduzir a perda de água enquanto outros são adicionados ao cimento com a finalidade de reduzir a sua densidade e, desta forma, minimizar as chances de perda do cimento por causa da alta permeabilidade ou formações de baixa fratura de gradiente ${ }^{[1]}$.

Além dos aditivos, os tampões mecânicos também podem ser aplicados no poço para facilitar o tamponamento. Eles são utilizados em alguns poços para reduzir o volume de tampão necessário para o tamponamento e também para adicionar uma proteção ao poço da formação de pressão. Exemplos de tampões mecânicos são os tampões-ponte, que fornecem uma vedação sólida e completa do reservatório reduzindo, desta forma, as chances de contaminação do cimento pela água ou pelo gás pressurizados e o tampão-retentor (retentor de cimento), que é 
muito usado quando se pretende tamponar zonas altamente pressurizadas que precisam ser comprimidas pelo cimento antes do tamponamento ${ }^{[2]}$.

A estabilidade do escoamento no processo de tamponamento do poço depende do comportamento mecânico dos fluidos. Se ambos os fluidos forem Newtonianos o processo é sempre instável pelo fato de haver diferença entre densidades da pasta de cimento e do fluido de perfuração. Porém, se os fluidos forem viscoplásticos existirão situações estáveis, sem deslocamento. Materiais viscoplásticos são aqueles que possuem tensão-limite de escoamento, abaixo da qual o material se comporta como um sólido (com viscosidade infinita ou muito elevada). Acima da tensão limite de escoamento o fluido escoa com comportamento pseudoplástico, com a viscosidade caindo com o aumento da taxa de cisalhamento, ou Newtoniano.

No processo de tamponamento o que ocorre na prática é a aplicação de um elevado fator de segurança para garantir que não ocorra a contaminação do poço. Assim, em geral são utilizadas razões de aspecto (razão entre o comprimento do tampão e o seu diâmetro) muito elevadas, para garantir que o fluido de perfuração não perfure o topo do tampão antes do tempo de cura do cimento. Este grande fator de segurança é causado pela ausência de uma análise detalhada que determine uma razão de aspecto ótima, e gera um desperdício de tampão, aumentando os custos de operação. Além disso, muitas vezes o tamponamento é feito utilizando materiais de baixa qualidade e empregando métodos precários e, conseqüentemente, muitos poços que não são devidamente tamponados podem resultar em problemas ambientais, principalmente no que diz respeito à canalização de gás durante a cimentação do poço. Portanto, um maior investimento na tecnologia deste processo iria contribuir de forma significativa para a sua otimização. 


\subsection{Objetivo}

Este trabalho tem como finalidade análise numérica do processo de tamponamento de poços, visando a sua otimização. Em primeiro lugar, deseja-se determinar a menor de aspecto para a qual não haverá a contaminação do cimento pelo fluido de perfuração antes do seu tempo de cura evitando, desta forma, um gasto desnecessário de tampão. O estudo será feito em dimensões menores do que as reais. Tendo-se definido esta razão "ótima", pode-se fazer uma extrapolação de dados desta razão para o caso real (razão de aspecto numericamente próxima a 200).

Além disso, outro objetivo é a investigação paramétrica, ou melhor, a análise da influência que alguns parâmetros exercem no processo do tamponamento de poços de petróleo, isto é, na velocidade com a qual a interface entre os fluidos se move, no tempo de contaminação ("tempo de furo", ou seja, o tempo em que o fluido de perfuração contamina o cimento, encostando no topo do poço) e no tempo em que o tampão leva para se depositar no fundo do poço. Dentre os parâmetros de interesse pode-se citar a razão entre as densidades dos dois fluidos (fluido de perfuração e tampão), a razão entre as suas viscosidades, a razão entre as suas tensões-limite de escoamento, a razão entre os seus índices de potência e a tensão interfacial.

A partir da solução das equações de conservação são obtidas as distribuições de velocidade e pressão no escoamento. A partir daí, obtém-se a velocidade da interface e os tempos de contaminação (quando o fluido de perfuração "fura" o topo do tampão). Nos casos em que houve a deposição completa, a relação entre o tempo de deposição do tampão e os parâmetros empregados também foi investigada. 


\section{Revisão Bibliográfica}

Existem vários estudos numéricos e experimentais que lidam com tamponamento de poços de petróleo. Alguns estão diretamente relacionados (Abdu, Naccache e Mendes ${ }^{[3]}$; Kerswell ${ }^{[4]}$; Beckett et al. ${ }^{[5]}$ ) enquanto que outros (Meiburg et al. ${ }^{[12]}$ ) tratam de situações um pouco diferentes embora também apresentem um vínculo considerável com esse tópico.

Um dos estudos numéricos foi realizado por Abdu, Naccache e Mendes ${ }^{[3]}$. A geometria empregada foi um cilindro vertical contendo dois fluidos: o tampão e o fluido de perfuração, sendo que o tampão se situava inicialmente acima do fluido de perfuração. O trabalho consistiu na investigação dos efeitos que determinados parâmetros como a razão entre densidades dos dois fluidos envolvidos e razão entre viscosidades pudessem exercer sobre a operação. $\mathrm{Na}$ maioria dos casos analisados, o tampão tinha um comprimento numericamente igual ao seu diâmetro ao passo que, em outros casos, este comprimento era quatro vezes maior do que o diâmetro. Alguns casos incluíam apenas fluidos newtonianos enquanto que, em outros casos, apenas o tampão era nãonewtoniano, comportando-se como um fluido viscoplástico e seguindo o modelo Herschel-Bulkley, o qual será discutido mais adiante (seção 3.1). Apenas dois valores foram utilizados para as tensões-limite de escoamento. A razão entre densidades foi consideravelmente baixa e mantida em uma faixa de 1,2 até 1,8 ao passo que a razão entre viscosidades variou de 0,5 até 2,0 . Uma das conclusões consistiu no fato de os tempos de contaminação e deposição do cimento serem diretamente proporcionais aos respectivos valores da tensão-limite de escoamento, visto que a resistência ao escoamento se torna maior conforme esta tensão aumenta. Além disso, notou-se que, para a faixa de razões de aspecto analisadas, estas razões não exerciam influência significativa no processo de tamponamento. Como uma proposta para futuros estudos, sugeriu-se a utilização de razões de aspecto maiores além da análise de outros parâmetros reológicos.

No estudo feito por Kerswell ${ }^{[4]}$, os dois fluidos são considerados incompressíveis e imiscíveis entre si. O duto cilíndrico é vertical e a dinâmica dos 
fluidos ocorre pela diferença de densidades deles, o que significa que o fluido mais pesado se localiza inicialmente na parte superior do tubo ao passo que o fluido menos denso se situa na parte inferior. O objetivo do trabalho é determinar qual o escoamento que maximizará a taxa de fluxo volumétrico quando apenas uma interface separa os dois fluidos. Foram supostas duas possibilidades de configurações: a primeira é denominada "lado por lado", de acordo com a qual a interface começa e termina na parede do tubo, enquanto que na segunda configuração, nomeada "excêntrica", o fluido mais viscoso está cercado pelo fluido menos viscoso e, desta forma, a interface é um círculo completo. Kerswell concluiu principalmente que o escoamento que otimiza a taxa de fluxo volumétrico em todos os gradientes de pressão possíveis é sempre axissimétrico. Além disso, foi determinado que o escoamento "lado por lado" é o mais eficiente para uma específica razão entre viscosidades (razão inferior a 4,60). Para uma razão entre viscosidades superior a 4,60, a melhor solução é a excêntrica.

Beckett et al. ${ }^{[5]}$ publicaram um estudo experimental do fluxo entre dois fluidos newtonianos em um tubo vertical de comprimento igual a 1 metro e diâmetro igual a 38,4 milímetros. Um deles é o xarope dourado, que é o mais denso e o mais viscoso, enquanto que o outro fluido é uma solução de xarope dourado diluído em água, sendo o mais leve e também o menos viscoso. O estudo baseou-se na exploração dos possíveis regimes de escoamento para baixos Números de Reynolds. A interface foi considerada um círculo ou um arco de circunferência com curvatura constante na seção transversal do tubo, ao passo que o fluxo volumétrico líquido foi considerado nulo e a faixa de razões entre viscosidades dos dois líquidos foi extensa (de 2 a 1180). A conclusão principal consistiu no fato de os escoamentos estudados apresentarem apenas dois regimes de escoamento: escoamento axissimétrico de núcleo anular, no qual o fluido menos viscoso ocupou um núcleo cilíndrico ao passo que o fluido mais denso escoou no anel tubular, e o escoamento lado por lado, escoamento em que os dois fluidos estão em contato com o tubo e existe apenas uma interface entre eles. Foi observado que para uma razão entre viscosidades maior ou igual a 75 , o escoamento axissimétrico de núcleo anelar prevalecia, enquanto que somente o escoamento lado por lado existia para uma razão entre viscosidades menor ou 
igual a 117. Para uma razão entre viscosidades entre 5 e 59, os dois escoamentos coexistiam. O perfil de velocidades obtido mostrou que o escoamento axissimétrico de núcleo anular é o que melhor descreve a formulação de Huppert \& Hallworth. Além disso, os resultados experimentais indicaram que a taxa máxima de fluxo volumétrico não depende do tipo de regime, assim como os valores experimentais da taxa de fluxo volumétrico são muito menores (duas casas decimais a menos) do que os valores obtidos da literatura quando as razões de viscosidades são elevadas. Também foi determinada uma expressão para o fluxo volumétrico, a qual obedece ao modelo de viscosidade Power-Law.

Um outro estudo importante trata da cimentação do poço em um duto inclinado (Frigaard e Scherzer ${ }^{[6]}$ ) envolvendo dois fluidos incompressíveis e miscíveis (embora não completamente misturados) entre si do tipo Bingham. Enquanto o fluido mais denso se situa inicialmente na parte superior do duto, o fluido mais leve se localiza na parte inferior. As forças interfaciais são ignoradas assim como a transferência de massa nas interfaces entre os dois fluidos. Este artigo consiste na investigação paramétrica das soluções em relação ao gradiente de pressão axial. Além disso, é empregado um método para regularizar a minimização da dissipação viscosa, o qual resolve o problema de minimização utilizando equações diferenciais parciais elípticas. O interessante é que esse método, apesar de aplicado para fluidos Bingham, também pode ser empregado em fluidos Herschel-Bulkley, por exemplo. Os resultados numéricos obtidos demonstram que o tipo de algoritmo utilizado é capaz de resolver uma grande quantidade de problemas com aplicações práticas.

Sweeney, Kerswell e Mullin ${ }^{[7]}$ estudaram a instabilidade Rayleigh-Taylor (instabilidade da interface entre dois fluidos com densidades distintas que ocorre quando o fluido mais pesado se move devido à pressão exercida pelo fluido mais leve) em uma situação envolvendo dois fluidos viscosos incompressíveis e imiscíveis entre si em um cilindro vertical finito sendo que o fluido mais pesado se situa inicialmente em cima do fluido menos denso (cada um ocupando metade do cilindro). O problema teve como parâmetros a razão entre densidades, a razão entre viscosidades e a razão de aspecto (razão entre o comprimento do tampão e o 
seu diâmetro) além da tensão superficial entre os fluidos e do número de Reynolds. Uma das conclusões a que os três autores chegaram consistiu no fato de que a instabilidade "ótima" corresponde a uma geometria axissimétrica e o comprimento de onda é numericamente igual a 1, indicando um escoamento inicial "lado por lado". Além disso, a discrepância entre a análise teórica (predita) da estabilidade linear próxima à interface e o caso real é relativamente pequena.

Calvert, Heathman e Griffith ${ }^{[8]}$ também tiveram como objetivo o aperfeiçoamento do tamponamento e a sua integridade, focando no estudo da influência da inclinação do poço no processo, ressaltando que a configuração de poço estudada não foi só a inclinada, mas também as configurações vertical e horizontal. Além deste parâmetro, também foram analisados os efeitos do diâmetro do poço, das razões entre densidades dos dois fluidos e das suas propriedades reológicas. Foi concluído que o sucesso da operação é função da inclinação do poço, do diâmetro do poço, da razão entre as tensões-limite de escoamento dos dois fluidos e da diferença entre densidades dos fluidos. Além disso, a situação de estabilidade melhora conforme a configuração do poço se aproxima da configuração horizontal. Quanto ao poço vertical, a instabilidade do tampão é causada pela "espiralização" do cimento através da lama, ao passo que a instabilidade no poço inclinado é gerada pelo Efeito Boycott ou pela extrusão.

Harestad et al. ${ }^{[9]}$ abordam os problemas que causam a falha do tamponamento e analisam os casos bem-sucedidos do plugue da pasta de cimento, além de apresentar um teste piloto mostrando a eficiência de uma ferramenta que impeça a pasta de cimento de escapar do poço ao comparar os resultados envolvendo essa ferramenta com os resultados correspondentes à ausência dessa ferramenta eficiente. Na presença da ferramenta, apenas uma pequena parcela de fluido de perfuração escoava em direção à superfície. Na ausência da ferramenta, essa parcela era muito mais expressiva, indicando um desequilíbrio de fluidos. Quanto aos fatores que prejudicam o processo de tamponamento de poços, foram citados: a remoção insuficiente do fluido de perfuração no local que será tamponado pelo cimento, visto que este fluido pode subir durante o processo, o que dificultaria a obtenção de uma barreira hidráulica; o escoamento de um 
volume limitado de lama a uma baixa vazão antes da cimentação aumentando, desta forma, os riscos de falha do tamponamento; o baixo volume de cimento bombeado a fim de evitar-se o desperdício; parâmetros do poço incorretos; o movimento descendente da pasta de cimento, enquanto o fluido de perfuração, menos denso e localizado inicialmente logo abaixo dele, sobe em sentido exatamente oposto.

A estabilidade do cimento durante o processo de tamponamento é bastante explorada por Crawshaw e Frigaard ${ }^{[10]}$. O trabalho apresenta resultados tanto experimentais como teóricos com uma estimativa das respectivas tensões-limite de escoamento dos dois fluidos necessárias para que a pasta de cimento seja estável em quaisquer condições geométricas do duto, como o diâmetro e a inclinação além da diferença entre densidades dos dois fluidos. Os experimentos mostram que o modelo é conservativo, o que foi discutido no decorrer do estudo por meio de suposições feitas para cada caso. As discrepâncias entre os resultados téoricos e experimentais se devem, primeiramente, à adoção do modelo Bingham (no caso teórico), desconsiderando a dependência da tensão de cisalhamento com o tempo, por exemplo. Além disso, foi suposto a imiscibilidade dos fluidos, o que na realidade pode influenciar principalmente no bombeamento de cimento.

Smith, Beirute e Holman ${ }^{[1]}$ sugeriram uma técnica que aprimorasse o processo do tamponamento de poços de petróleo. Foi realizado um estudo experimental para analisar o problema de instabilidade relacionado ao tamponamento, sendo o cimento o fluido mais denso e sendo a lama o fluido menos pesado, agindo, portanto, como um fluido de perfuração. Nos experimentos, foram utilizados tubos de acrílico como invólucro e tubos de cobre como tubos de perfuração. Os resultados experimentais demonstraram que a ferramenta proposta poderia aumentar consideravelmente as chances de um tamponamento qualitativo de cimento na profundidade de poço desejada, visto que essa ferramenta foi capaz de criar uma interface estável entre o cimento e a lama além de gerar uma distribuição uniforme de fluidos no poço. Além disso, ela minimizou a canalização da pasta de cimento, contribuindo para uma maior limpeza do poço e possibilitando, desta forma, a obtenção de um tampão mais 
forte e de mais qualidade. Vale ressaltar que um dos autores recomendou o emprego de menos dispersantes, uma vez que por causa deles, a pasta de cimento e a lama ficavam muito diluídos, dificultando a estabilidade do tampão. Uma outra observação importante foi a incompatibilidade entre cimento e lama ao serem misturados, os quais tendiam a formar um gel, que contribuía para a estabilidade do tampão. Além disso, foi observado que a adição de cimentos tixotrópicos muito viscosos e com alta tensão limite de escoamento também contribuía para a estabilidade do plugue. Para finalizar, duas conclusões do trabalho consistiram nos fatos de a interface entre os dois fluidos ser um fator determinante do sucesso da operação e de a inclusão de dispersantes gerar uma diluição maior da mistura entre a pasta de cimento e a lama além de gerar também uma maior instabilidade sendo recomendado, portanto, o uso mínimo de dispersantes.

Divergindo um pouco dos estudos apresentados previamente, Meiburg et al. ${ }^{[12]}$ analisaram a influência da variação das viscosidades de dois fluidos miscíveis entre si situados em um tubo vertical capilar com o fluido mais denso situado na parte superior do duto no início do processo. A análise é baseada nas equações tridimensionais de Stokes além de uma equação de convecção-difusão para o campo de concentração utilizando coordenadas cilíndricas. A densidade da mistura foi definida como uma função linear da concentração do fluido mais denso ao passo que a viscosidade da mistura foi modelada como uma função exponencial proporcional à concentração do fluido mais pesado. Os resultados obtidos mostraram que, no caso de a razão entre viscosidades ser unitária, as perturbações estáveis no escoamento ocorriam até um determinado Número de Rayleigh ( $\mathrm{Ra}=920$, sendo Ra o Número de Rayleigh) e denominado, por isso, de Número de Rayleigh Crítico. Para esta mesma razão, é demonstrado através das relações de dispersão que as perturbações mais instáveis ocorrem para um número de onda azimutal igual a 1. É observado que, para um alto número de Rayleigh (superior a $10^{5}$ ), o modo mais instável deixa de ser o azimutal e passa a ser as perturbações axissimétricas. 


\section{Formulação Matemática}

\subsection{Equações Constitutivas}

Os fluidos não-newtonianos puramente viscosos são descritos pela equação constitutiva para um fluido newtoniano generalizado, dada pela seguinte expressão:

$\bar{\tau}=\eta \cdot \overline{\bar{D}}$

sendo $\overline{\bar{D}}$ o Tensor Taxa de Deformação, que é a parte simétrica do gradiente de velocidade sendo, portanto, expresso como:

$$
\overline{\bar{D}}=\frac{1}{2}\left(\nabla u+\nabla u^{T}\right)
$$

A magnitude da taxa de deformação, $\gamma$, pode ser definida em função de $\overline{\bar{D}}$ da seguinte forma:

$$
\gamma=\sqrt{\frac{1}{2} \overline{\bar{D}}: \overline{\bar{D}}}
$$

O modelo que rege o comportamento viscoso dos dois fluidos é o de Herschel-Bulkley. A viscosidade é dada pela seguinte equação:

$$
\begin{aligned}
& \eta=\frac{\tau_{y}}{\dot{\gamma}}+K \dot{\gamma}^{n-1}, \tau>\tau_{y} \\
& \eta=\infty, \tau<\tau_{y}
\end{aligned}
$$


onde $n$ é o índice de comportamento ou índice de potência, $\tau_{y}$ é tensão-limite de escoamento na parede, $\dot{\gamma}$ é a taxa de cisalhamento, Ké o índice de consistência e $\dot{\gamma}_{c r} \leq \dot{\gamma}_{c a r}$, sendo $\dot{\gamma}_{c r}$ a taxa de cisalhamento crítica.

No software ANSYS Fluent, é apresentada uma adaptação do modelo Herschel-Bulkley, mostrada a seguir:

$\eta=\frac{\tau_{y}}{\dot{\gamma}}+K\left[\frac{\dot{\gamma}}{\gamma_{c r}}\right]^{n-1} \rightarrow \dot{\gamma}>\dot{\gamma}_{c r}$

$\eta=\eta_{0}=\frac{\tau_{y}}{\dot{\gamma}}\left[\frac{2-\frac{\dot{\gamma}}{\dot{\gamma}_{c r}}}{\dot{\gamma}_{c r}}\right]+K\left[(2-n)+(n-1) \frac{\dot{\gamma}}{\dot{\gamma}_{c r}}\right] \rightarrow \dot{\gamma}<\dot{\gamma}_{c r}$

sendo $\eta_{0}$ uma viscosidade muito alta.

Na figura abaixo, visualizamos a variação da tensão de cisalhamento com a taxa de deformação seguindo o modelo Herschel-Bulkley (para $n>1$, o fluido será dilatante; para $0<\mathrm{n}<1$, o fluido será pseudoplástico; para $\mathrm{n}=1$, o fluido será Bingham):

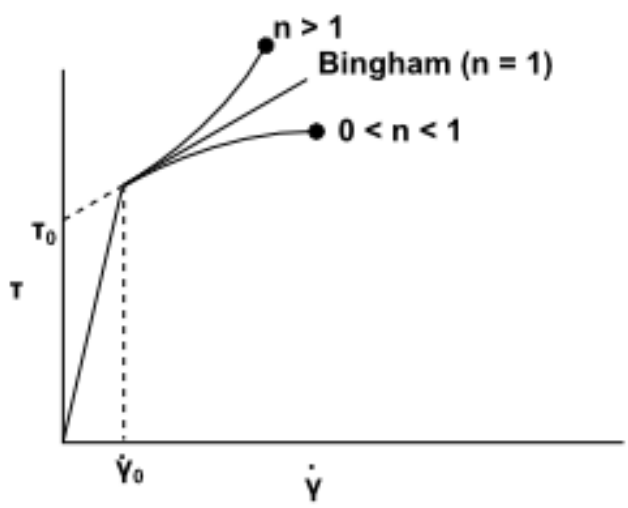

Gráfico 1 - Tensão de Cisalhamento vs. Taxa de Deformação 
É evidente que, quando a tensão de cisalhamento, $\tau$, é menor do que a tensão-limite de escoamento, $\tau_{y}$, haverá uma descontinuidade, o que causará uma instabilidade na simulação numérica, visto que $\gamma=0$. A fim de evitar esse problema de instabilidade causado pela descontinuidade, Papanastasiou ${ }^{[13]}$ propôs um modelo modificado ao introduzir um parâmetro material, que controla o fator de estresse, modelo este denominado Herschel-Bulkley - Papanastasiou, representado abaixo:

$\tau=\tau_{y}\left(1-e^{-m \gamma}\right)+K \dot{\gamma}^{n}$, sendo "m" o fator de estresse.

Portanto, a viscosidade aparente é dada por:

$$
\eta=K|\dot{\gamma}|^{\mathrm{n}-1}+\frac{\tau_{y}}{|\dot{\gamma}|}\left(1-e^{-m|\dot{\gamma}|}\right)
$$

Vale ressaltar um tipo particular de modelo, denominado Power-Law. Este modelo é definido pela seguinte equação:

$$
\eta(\dot{\gamma})=K \dot{\gamma}^{n-1}
$$

\subsection{Problema}

$\mathrm{Na}$ figura abaixo (Fig. 1), podemos visualizar a figura equivalente ao processo de tamponamento. O fluido 2 (cinza-escuro) é a pasta de cimento, sendo o fluido mais denso, ao passo que o fluido de perfuração é o fluido 1 (cinza-claro), que é o fluido menos pesado. Como a densidade do fluido 2 é superior à densidade do fluido 1 , o fluido 2 desce enquanto que o fluido 1 realiza um movimento ascendente. O processo é finalizado no momento em que não há mais 
instabilidade, isto é, quando o fluido 1 se localiza em cima do fluido 2, configurando uma situação oposta ao início do processo.

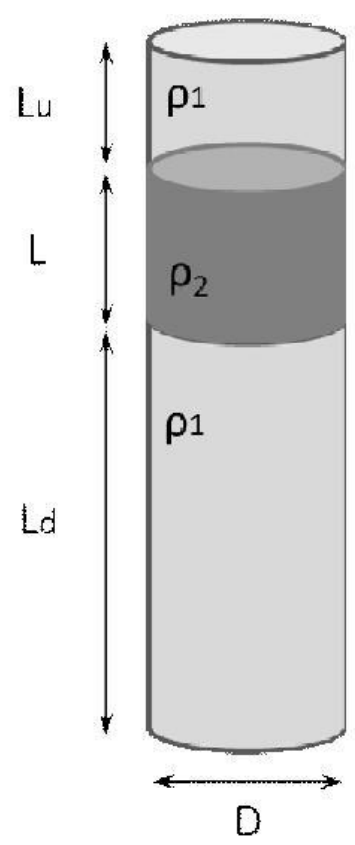

Figura 1 - Tamponamento do poço de petróleo

É valido ressaltar que, na situação analisada, o comprimento do poço é definido como:

$L_{w}=L+L_{d}+L_{u}$

Considerando $\mathrm{L}_{\mathrm{u}}=0$ (portanto, $\mathrm{L}_{\mathrm{w}}=\mathrm{L}+\mathrm{L}_{\mathrm{d}}$ ) e $\mathrm{L}=\mathrm{L}_{\mathrm{d}}$, temos que $\mathrm{L}_{\mathrm{w}}=2 \mathrm{~L}$. Além disso, $\mathrm{D}=1$ metro em todos os casos estudados. A razão de aspecto é representada por $L^{*}=\frac{L}{D}$. Além disso, $\rho_{1}$ e $\rho_{2}$ equivalem, respectivamente, às densidades do fluido de perfuração e do tampão, assim como $\eta_{1}$ e $\eta_{2}$ correspondem às suas respectivas viscosidades.

Supondo inicialmente que o fluido 2 é menos denso do que o fluido 1 , o fluido 2 efetuaria um movimento ascendente, ao passo que o fluido 1 escoaria 
para baixo, resultando em uma configuração segundo a qual o fluido 2 permaneceria indefinidamente em cima do fluido 1, visto que a sua densidade é menor. Efetuando um balanço de forças (situação estática) para essa configuração, teremos que:

$$
\frac{\Delta P}{\rho_{2} g L}=1
$$

sendo $\Delta P$ a diferença de pressão entre o topo do tampão (coincidente com o topo do tubo) e a sua superfície inferior.

Agora, supondo o contrário, ou seja, considerando que o fluido 2 é mais pesado do que o fluido 1, o tampão se deslocaria para baixo e, por conservação de massa, o fluido 1 se moveria para cima. Porém, se o tampão for viscoplástico, mesmo que ele seja mais pesado do que o fluido de perfuração, ele só escoaria para baixo se o seu peso superasse a força gerada pela sua tensão limite de escoamento na parede. $\mathrm{O}$ balanço de forças que representa a situação na qual o tampão consegue se mover em movimento descendente é o seguinte (desprezando $\left.\mathrm{L}_{\mathrm{u}}\right)$ :

$$
1-\frac{4 \tau}{\rho_{2} g D}-\frac{\Delta P}{\rho_{2} g L} \geq 0
$$

Vale lembrar que $\Delta P=P_{B}-P_{A}$, sendo $P_{B}$ a pressão atuante na superfície inferior do tampão e $P_{A}$ a pressão atuante na superfície superior do tampão. Caso $\mathrm{L}_{\mathrm{u}}$ fosse considerado, $\Delta P=P_{B}-\left(P_{A}+\rho_{1} g L_{u}\right)$.

De forma resumida, o balanço de forças mostrado acima representa o escoamento do tampão caso o seu peso supere a força gerada pela tensão de escoamento na parede.

Em termos adimensionais, temos que: 
$1-4 \tau^{*}-\Delta P^{*} \cdot \frac{D}{L} \geq 0$

Vale lembrar que, de acordo com a equação acima, três situações podem ocorrer:

a) Se a tensão de escoamento for numericamente superior ao peso do tampão, o cimento não escoará $\left(4 \tau_{y}^{*}>1\right.$ e $\left.\Delta \mathrm{P}^{*}=0\right)$.

b) Caso a tensão de escoamento seja menor do que o peso do tampão, o cimento escoará quando $\tau=\tau_{y}$, e o balanço de forças inicialmente será:

$4 \tau_{y}^{*}+\frac{\Delta P^{*}}{L^{*}}=1$

c) Se a tensão de escoamento é nula (ou se houver deslizamento na parede), a tensão de cisalhamento na parede também será nula e, portanto:

$\Delta P^{*}=L^{*}$

\subsection{Adimensionalização}

Adiante, pode-se visualizar a Fig. 2, que representa bidimensionalmente a configuração inicial do processo de tamponamento: 


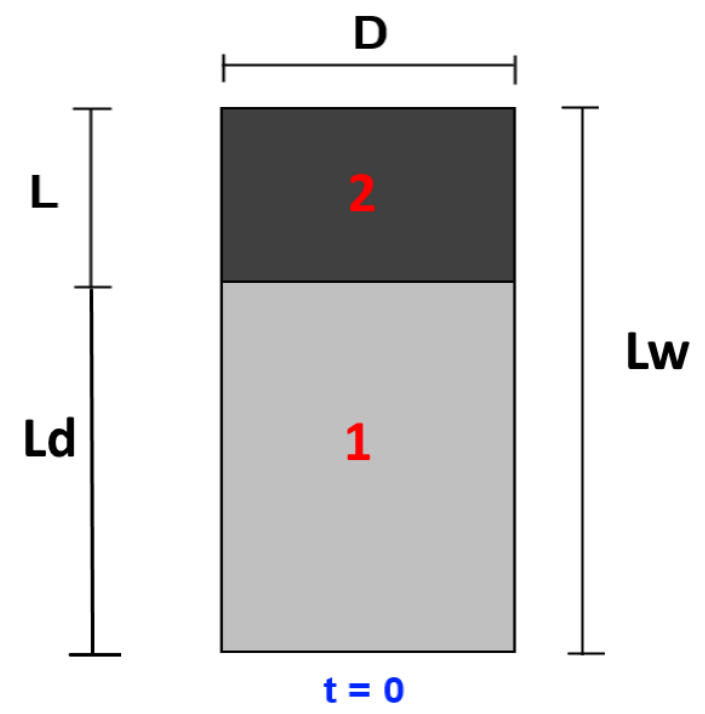

Figura 2 - Visão bidimensional do processo de tamponamento de poços de petróleo

Um parâmetro que deve ser estudado é a tensão superficial presente na interface entre os dois fluidos. Esta tensão é gerada pelas forças de atração entre as moléculas de um fluido, sendo simbolizada pela letra $\sigma$. A seguir, são mostrados dois parâmetros adimensionais que relacionam as principais forças atuantes no fluido de perfuração (forças gravitacionais, forças geradas pela tensão interfacial e forças viscosas):

$$
B o=\frac{\Delta \rho \cdot g \cdot D^{2}}{\sigma}
$$

sendo $B o$ a relação entre as forças gravitacionais e as forças geradas pela tensão interfacial atuantes no fluido de perfuração. Bo é conhecido cientificamente como Número de Bond. $\Delta \rho$ é a diferença entre as densidades dos dois fluidos.

$$
C a=\frac{\eta_{1} \cdot V_{c a r}}{\sigma}
$$

sendo $C a$ a relação entre as forças viscosas e as forças resultantes da tensão na interface que atuam no fluido de perfuração. $C a$ é mais conhecido na literatura como Número de Capilaridade. Além disso, $V_{c a r}$ representa a velocidade característica, sendo $V_{c a r}=\sqrt{g D}$. 
Adimensionalizando os parâmetros, considerando que a taxa de cisalhamento característica é dada por $\dot{\gamma}_{c a r}=\frac{V_{c a r}}{D}=\frac{\sqrt{g D}}{D}$ a uma viscosidade $\eta_{c a r}$ e a razão entre os índices de comportamento (ou razão entre os índices de potência) de cada fluido é simbolizada por $n_{R}$, temos que:

$$
\begin{aligned}
& t^{*}=\left(t-t_{0}\right) \dot{\gamma}_{c a r} \\
& u_{i}^{*}=\frac{u_{i}}{V_{c a r}} \\
& \Delta \rho^{*}=\frac{\Delta \rho D V_{c a r}}{\eta_{c a r}} \\
& \operatorname{Re}=\frac{\rho_{2} D V_{c a r}}{\eta_{c a r}} \\
& \eta^{*}=\frac{\eta}{\eta_{c a r}} \\
& x^{*}=\frac{x}{D} \\
& \tau^{*}=\frac{\tau}{\rho_{2} g D} \\
& \tau_{y_{R}}=\frac{\tau_{y_{2}}}{\tau_{y_{1}}} \\
& \rho_{R}=\frac{\rho_{2}}{\rho_{1}} \\
& \eta_{R}=\frac{\eta_{2}}{\eta_{1}} \\
& n_{R}=\frac{n_{2}}{n_{1}} \\
& P^{*}=\frac{P}{\rho_{2} g D}
\end{aligned}
$$

\subsection{Método VOF}

O método Volume de Fluido, mais conhecido como VOF (Volume of Fluid), pode modelar 2 ou mais fluidos imiscíveis ao resolver um sistema de equações de momento e localizar onde cada um dos fluidos imiscíveis entre si possui a fração volumétrica desejada. Por exemplo, ele pode localizar a interface entre dois fluidos, isto é, a região onde dois fluidos apresentam fração volumétrica igual a 0,5. Essa localização da(s) interface(s) entre cada fase é representada pela equação de continuidade para a fração volumétrica de uma das fases. Vale lembrar que a fração volumétrica de um fluido é a razão entre o volume que esse fluido ocupa e o volume que a mistura ocupa, sendo simbolizada pela letra $\alpha$.

Exemplos de aplicações do VOF são o movimento de grandes bolhas em um líquido, o movimento de um líquido após uma quebra de barragem e a predição de um rompimento de jato, isto é, a desintegração de um líquido/gás 
devido às forças turbulentas agindo tanto na superfície do jato quanto dentro do próprio jato.

O método VOF é composto pelo sistema de equações abaixo:

\section{Equação para o cálculo das propriedades da mistura:}

$\varphi=\varphi_{1} \alpha_{1}+\varphi_{2} \alpha_{2}$

sendo $\varphi$ uma propriedade da mistura formada pelos 2 fluidos. $O$ índice 1 é referente ao fluido que está inicialmente embaixo, isto é, o fluido de perfuração, enquanto que o índice 2 se refere ao tampão, sendo $\alpha$ a fração volumétrica.

Equação de Restrição:

$\alpha_{1}+\alpha_{2}=1$

\section{Equação de Continuidade:}

$\frac{\partial \rho}{\partial t}+\rho\left(\frac{\partial u_{i}}{\partial x_{k}}+\frac{\partial u_{i}}{\partial x_{i}}\right)=0$

sendo $\rho$ a densidade, $u$ a velocidade, $t$ o tempo e $x$ a coordenada. Além disso, $i$ representa a fase ou o fluido $(\mathrm{i}=1$ ou $\mathrm{i}=2$ no caso de dois fluidos $)$.

$\frac{\partial \alpha_{i}}{\partial t}+u_{i} \frac{\partial \alpha_{i}}{\partial x_{j}}=0$

\section{Equação da Conservação de Momento:}

O método VOF assume que todos os fluidos (fases) tem a mesma velocidade: 
$\frac{\partial\left(\rho u_{i}\right)}{\partial t}+\frac{\partial\left(\rho u_{i} u_{j}\right)}{\partial x_{i}}=-\frac{\partial P}{\partial x_{k}}+\frac{\partial}{\partial x_{i}}\left[\eta\left(\frac{\partial u_{i}}{\partial x_{k}}+\frac{\partial u_{i}}{\partial x_{i}}\right)\right]+\rho g_{k}$

sendo $\eta$ a viscosidade, $P$ a pressão e $g$ a aceleração da gravidade.

Desta forma, podemos também adimensionalizar as equações acima, obtendo o seguinte conjunto de equações:

$\frac{\partial \rho^{*}}{\partial t^{*}}+\rho^{*}\left(\frac{\partial u_{i}^{*}}{\partial x_{k}^{*}}+\frac{\partial u_{i}^{*}}{\partial x_{i}^{*}}\right)=0$

$\frac{\partial \alpha_{i}}{\partial t^{*}}+u_{i}^{*} \frac{\partial \alpha_{i}}{\partial x_{j}^{*}}=0$

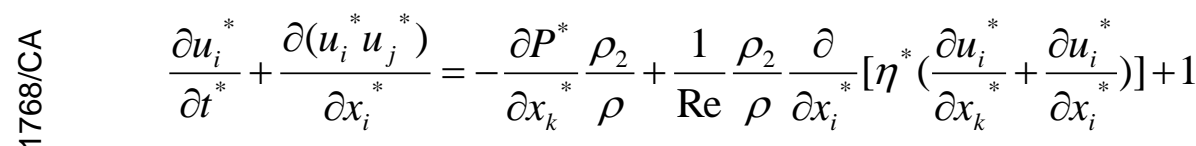

As condições de contorno são as seguintes: a velocidade inicial no topo do poço é nula, não há deslizamento e a parede não é permeável. 


\section{Metodologia}

Foram utilizados 2 softwares. Primeiramente, o ICEM CFD foi empregado com a finalidade de construir 2 tipos de geometria: retangular (bidimensional) e cilíndrica/tubular (tridimensional). Em seguida, o software ANSYS Fluent foi usado para a simulação do processo de tamponamento envolvendo os dois fluidos (tampão e fluido de perfuração).

Os métodos implementados no ANSYS Fluent são o Volume de Fluido, modelo multifásico mais conhecido como VOF (Volume of Fluid), e o Método dos Volumes Finitos, também conhecido como FVM (Finite Volume Method). O Método dos Volumes Finitos foi utilizado com a finalidade de resolver as equações diferenciais do modelo VOF em cada ponto nodal da malha ao transformá-las em equações algébricas, discretizando-as. Vale lembrar que o limite de tolerância para a convergência foi fixado em $1 \cdot 10^{-5}$ tanto para a continuidade como para as velocidades nos eixos cartesianos.

O Fluent apresenta diversas possibilidades para simulações numéricas. O esquema de discretização da equação de momentum utilizado foi o Power Law. Além disso, foram utilizados para a discretização espacial o gradiente baseado na célula de mínimos quadrados (Least Squares Cell Based). A formulação transiente adotada foi a formulação de Primeira Ordem Implícita (First Order Implicit) ${ }^{[14]}$.

O método PRESTO ${ }^{[15]}$ ("Pressure Staggering Option”) para a discretização da equação de pressão foi utilizado no Fluent visto que ele gera uma solução mais acurada e estável visto que os erros de interpolação e suposições do gradiente de pressão nas condições de contorno são evitados além de impedir um elevado e imprevisível aumento da velocidade nas proximidades da malha. Tal método consiste em uma interpolação da pressão ao utilizar um balanço de continuidade discreto em um volume de controle deslocado em relação à face a fim de determinar a pressão, sendo um método que requer um elevado custo computacional. Além disso, PRESTO é um dos dois únicos métodos utilizados para o modelo VOF. 
A formulação utilizada no Fluent para a determinação da interface entre os fluidos foi a Reconstrução Geométrica ${ }^{[16]}$ (Geo-Reconstruct), que representa a reconstrução da interface entre os fluidos utilizando uma aproximação linear, sendo a formulação mais acurada do Fluent e aplicada para malhas nãoestruturadas. Primeiramente, a posição linear da interface em relação ao centro de cada célula parcialmente preenchida é calculada com base na fração volumétrica na célula. Em seguida, é empregada a representação computacional linear da interface que, em conjunto com as informações sobre o campo de velocidades normais e tangenciais na face, calcula a quantidade de fluido proveniente da advecção através de cada face. Logo depois, a fração volumétrica em cada célula é calculada ao empregar um balanço de fluxos calculado nas etapas anteriores. De forma resumida, a Reconstrução Geométrica supõe que a interface entre os fluidos tem uma inclinação linear com cada célula, usando essa distorção linear para calcular a advecção do fluido através da face da célula.

\subsection{Pressão e Velocidade acopladas}

Um dos algoritmos utilizado no acoplamento das equações de conservação de massa e momentum é o SIMPLE ${ }^{[17]}$ ("Semi-Implicit Pressure Linked Equations"), desenvolvido por Patankar $(1980)^{[18]}$ Ele se baseia na premissa de que a velocidade proveniente da equação de conservação da quantidade de movimento só satisfará a equação de conservação de massa caso o perfil de pressões esteja correto, o que significa que a pressão necessita de correção (para garantir a conservação de massa) da mesma forma que a velocidade. Primeiramente, o campo de pressão é estimado, não estando necessariamente correto. Com isso, valores de velocidade nos eixos cartesianos são obtidos ao resolver-se a equação de conservação de momento.

$$
V=V_{n f}{ }^{*}+V_{f}
$$


$P=P_{c 0}^{*}+P_{c 0}$

$V_{f}^{\prime}=d_{f}\left(P_{c 0}^{\prime}-P_{c 1}^{\prime}\right)$

$d_{f}=\frac{A_{f}}{\left(a_{p, c 0}^{\prime}+a_{p, c 1}^{\prime}\right) / 2}$

Nas equações acima, $\mathbf{P}_{\mathbf{c 0}}{ }^{*}$ representa o "chute" dado em relação ao perfil de pressão na célula $\mathbf{c}_{\mathbf{0}}$, ao passo que $\mathbf{P}_{\mathbf{c} 0}{ }^{\prime}$ é a correção da pressão nesta mesma célula, da mesma forma que $\mathbf{V}_{\mathbf{n f}}{ }^{*}$ representa o "chute" dado em relação ao campo de velocidades na face da célula e $\mathbf{V}_{\mathbf{f}}^{\prime}$ é a correção da velocidade na célula. $\mathbf{A}_{\mathbf{f}}$ representa a área transversal e a representa o fator de relaxamento para a pressão.

O algoritmo PISO ${ }^{[19]}$ ("Pressure-Implicit with Splitting of Operators"), desenvolvido por Issa (1986) ${ }^{[20]}$, é outro algoritmo utilizado pelo Fluent, sendo fortemente recomendado para todos os fluxos transientes e é considerado uma extensão do algoritmo SIMPLE. Este algoritmo consiste em gerar uma solução mais aproximada da correção da pressão do que o algoritmo SIMPLE e os demais algoritmos ao empregar dois níveis de correção ("Skeweness Correction" e "Neighbor Correction"), podendo manter um cálculo estável para um passo de tempo elevado e para um fator de relaxamento inferior a 1,0 tanto para o momento quanto para a pressão. A vantagem dele em relação aos algoritmos SIMPLE e SIMPLEC é baseada no fato de a convergência por passo de tempo ser alcançada com um número consideravelmente menor de iterações apesar de o tempo requerido para uma iteração ser maior. $\mathrm{O}$ algoritmo PISO foi o algoritmo utilizado nas simulações realizadas no Fluent. Abaixo, são apresentadas as equações deste algoritmo, assim como uma descrição mais detalhada do algoritmo:

$a P^{\prime}=\sum_{i} a_{i} P_{i}^{\prime}+B$ 
$B=\sum_{f}^{n} J_{f}^{*} A_{f}$

$\mathbf{B}$ é a taxa de fluxo líquido na célula da malha, $\mathbf{J}_{\mathbf{f}}$ é o fluxo facial corrigido, $\mathbf{A}_{\mathbf{f}}$ é a área da face da célula. Além disso, $\mathbf{n}$ representa o número de faces, ao passo que f representa o índice da face.

O algoritmo PISO se baseia na seguinte seqüência de etapas: primeiramente, as condições de contorno são definidas e as equações de momento discretizadas são resolvidas obtendo-se um perfil de velocidades. Em seguida, a equação de correção da pressão é resolvida, obtendo-se até esta etapa valores de pressão e velocidade. O próximo passo consiste na solução da segunda equação de correção da pressão, tendo como resultado novos valores de pressão e velocidade. A seguir, todas as outras equações de transporte discretizadas são resolvidas. Caso ocorra convergência, o processo é finalizado. Caso contrário, o processo é reiniciado.

\subsection{Método baseado nos mínimos quadrados}

Este método consiste em determinar o gradiente da célula $\left(\nabla \phi_{0}=\phi_{x} \hat{i}+\phi_{y} \hat{j}+\phi_{z} \hat{k}\right)$ ao resolver um problema de minimização para o sistema não-quadrado da matriz de coeficientes $(|J|)$ em um sentido de mínimos quadrados, resultando em uma solução que varia linearmente. A equação ${ }^{[21]}$ que representa a modificação dos valores de célula entre as células $c_{0}$ e $c_{i}$ na direção do vetor $r_{i}$ (partindo do centróide da célula $c_{0}$ em direção ao centróide da célula posterior, $\mathrm{c}_{\mathrm{i}}$ ) é a seguinte:

$$
(\nabla \phi)_{c_{0}} \cdot \Delta r_{i}=\left(\phi_{c_{i}}-\phi_{c_{0}}\right)
$$

Analogamente, para uma célula muito próxima à célula $\mathrm{c}_{0}$, temos a seguinte equação: 
$|J|(\nabla \phi)_{c_{0}}=\Delta \phi$

Abaixo, podemos visualizar a Fig. 3, que ilustra as células $c_{0}$ e $c_{i}$ assim como o vetor $r_{i}$ :

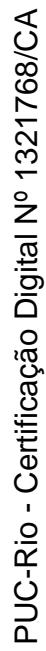

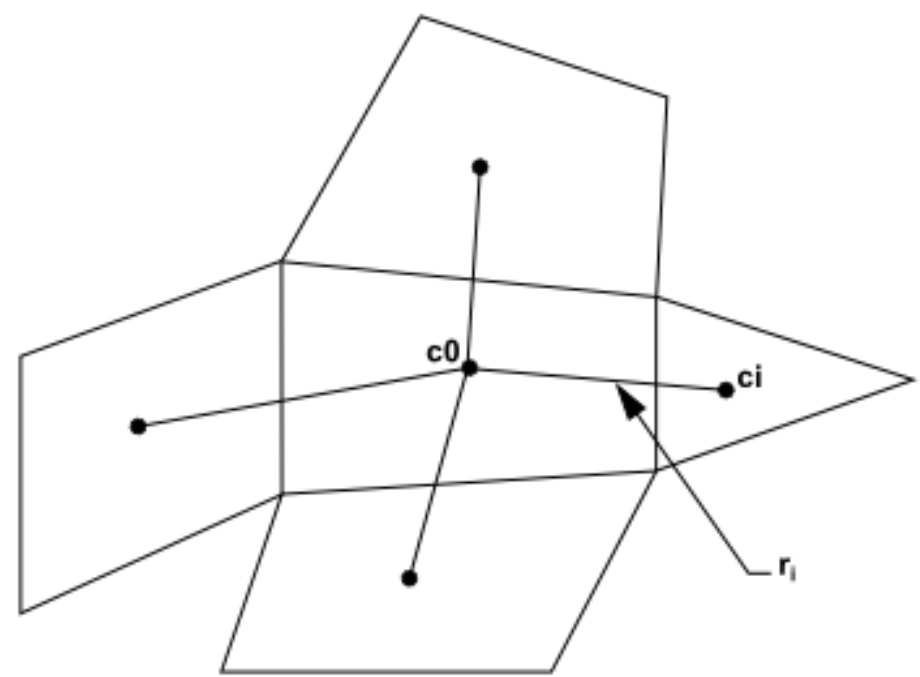

Figura 3 - Variação no centróide das células $\mathrm{c}_{0} \mathrm{e} \mathrm{c}_{\mathrm{i}}$ na direção do vetor $\mathrm{r}_{\mathrm{i}}$

O gradiente no centróide da célula é calculado da seguinte forma:

$\left(\phi_{x}\right)_{c_{0}}=\sum_{i=1}^{n}\left[W^{x}{ }_{i_{0}}\left(\phi_{c_{i}}-\phi_{c_{0}}\right)\right]$

$\left(\phi_{y}\right)_{c_{0}}=\sum_{i=1}^{n}\left[W^{y}{ }_{i_{0}}\left(\phi_{c_{i}}-\phi_{c_{0}}\right)\right]$

$\left(\phi_{z}\right)_{c_{0}}=\sum_{i=1}^{n}\left[W_{i_{0}}^{z}\left(\phi_{c_{i}}-\phi_{c_{0}}\right)\right]$

Vale ressaltar que $\left[c_{i}-c_{0}\right]$ corresponde ao vetor de diferença $\Delta \phi$, ao passo que o vetor $W=\left[W^{x}{ }_{i_{0}}, W^{y}{ }_{i_{0}}, W^{z}{ }_{i_{0}}\right]$ representa o Peso na forma vetorial. É importante lembrar que este método requer um custo computacional inferior aos métodos similares como o gradiente baseado no nó apesar de ter uma precisão inferior no caso de malhas irregulares e não-estruturadas. 


\subsection{Método Implícito de Primeira Ordem}

Definindo F e G abaixo e considerando o subscrito i relacionado ao passo de tempo anterior, temos o seguinte ${ }^{[22]}$ :

$$
\begin{aligned}
F_{i} & =\left[-\nabla_{S} \bullet\left(h \bar{V}_{l}\right)+\frac{m_{S}}{\rho_{l}}\right]_{i} \\
G_{i} & =\left[-\frac{h \nabla_{S} P_{L}}{\rho_{l}}+\left[\bar{g}_{\tau}^{-}\right] h+\frac{3}{2 \rho_{l}} \bar{\tau}_{f_{s}}+\frac{\dot{q}}{\rho_{l}}-\nabla_{S} \bullet\left[h \bar{V}_{l} \bar{V}_{l}\right]\right]_{i}
\end{aligned}
$$

De acordo com o método explícito de primeira ordem, primeiramente, os valores da altura do filme, $h_{i}$, são computados com base nos valores de $\mathbf{F}_{\mathrm{i}}$. Em seguida, os valores da velocidade vetorial são computados baseados nos valores de $\mathbf{G}_{\mathbf{i}}$.

$h_{i+1}=h_{i}+F_{i} \Delta t$

$\left(\bar{V}_{l}\right)_{i+1}=\frac{\left(h \bar{V}_{l}\right)_{i}+G_{i} \Delta t}{h_{i+1}+\left[\frac{3 v_{l}}{h_{i+1}}\right] \Delta t}$

Para melhorar a eficiência do método explícito, o método implícito ${ }^{[23]}$ é empregado como um preditor e corretor (o superscrito $\mathbf{0}$ indica a primeira iteração do passo de tempo "i+1"), segundo o qual os valores de $\mathbf{F}$ e $\mathbf{G}$ são atualizados durante o processo iterativo:

\section{Preditor:}

$h_{i+1}^{0}=h_{i}+F_{i} \Delta t$ 


$$
\left(\bar{V}_{l}\right)_{i+1}^{0}=\frac{\left(h \bar{V}_{l}\right)_{i}+G_{i} \Delta t}{h_{i+1}^{0}+\left[\frac{3 v_{l}}{h_{i+1}^{0}}\right] \Delta t}
$$

Corretor: Os valores atuais da altura e da velocidade vetorial são utilizados para atualizar os valores de $\mathbf{F}$ e $\mathbf{G}$, sendo recomputados logo em seguida. O superscrito $\mathbf{n}+\mathbf{1}$ se refere ao número atual de iterações enquanto que $\mathbf{u}_{\boldsymbol{\alpha}}$ simboliza cada componente do vetor velocidade, $\mathbf{V}_{\mathbf{l}}$. Vale ressaltar que $\boldsymbol{\varepsilon}$ é o valor a partir do qual ocorre a convergência.

$$
h_{i+1}^{n+1}=h_{i}+\left\{h_{i+1}^{n},\left(\bar{V}_{l}\right)_{i+1}^{n}\right\} F \Delta t
$$

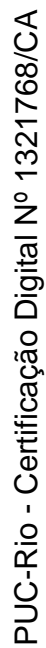

$$
\left(\bar{V}_{l}\right)_{i+1}^{n+1}=\frac{\left(h \bar{V}_{l}\right)_{i}+\left\{h_{i+1}^{n},\left(\bar{V}_{l}\right)_{i+1}^{n}\right\} G \Delta t}{h_{i+1}^{n+1}+\left[\frac{3 v_{l}}{h_{i+1}^{n+1}}\right] \Delta t}
$$

$\left|h_{i+1}^{n+1}-h_{i+1}^{n}\right| \leq \epsilon$

$$
\left|\left[u_{\alpha}\right]_{i+1}^{n+1}-\left[u_{\alpha}\right]_{i+1}^{n}\right| \leq \epsilon
$$

\subsection{Discretização Power-Law}

Esta discretização usa a solução exata ${ }^{[24]}$ para uma equação unidimensional da equação convecção-difusão para interpolar o valor de face $\phi$, sendo $\rho, u$ e $\Gamma$ parâmetros independentes do intervalo espacial, $\partial x$. 
$\frac{\partial}{\partial x}(\rho u \phi)=\frac{\partial}{\partial x} \Gamma \frac{\partial \phi}{\partial x}$

Integrando-se a equação acima, temos a seguinte equação, a qual nos mostra a relação entre a variação de $\phi$ com a coordenada espacial, $x$. Pe representa o número de Péclet, número adimensional definido como a razão entre a taxa de advecção de uma grandeza física e o fluxo à taxa de difusão desta mesma grandeza por um gradiente apropriado.

$\frac{\phi(x)-\phi_{0}}{\phi_{L}-\phi_{0}}=\frac{e^{\left[\frac{x}{L}\right] P e}-1}{e^{P e}-1}$

Abaixo, visualizamos as condições de contorno para a equação acima.

$\phi_{0}=\left.\phi\right|_{x=0}$

$\phi_{L}=\left.\phi\right|_{x=L}$

O número de Péclet é expresso por:

$$
P e=\frac{\rho u L}{\Gamma}
$$

\subsection{Tensão Interfacial}

A tensão superficial ou interfacial, que é um resultado da força atrativa e molecular de cada fluido, pode ser configurada utilizando dois modelos no Fluent $^{[25]}$ : o modelo de Força Superficial Contínua (The Continuum Surface Force Model ou CSF) e o modelo Tensão Superficial Contínua (The Continuum Surface Stress Model ou CSS). 
O primeiro modelo é aplicado quando a superfície estudada é curva. Como superfícies com raios de curvatura não se aplicam ao estudo paramétrico realizado posteriormente, o segundo modelo (CSS) foi empregado. Neste método, o tensor Tensão Superficial é representado por:

$$
T=\sigma(I-\hat{n} \otimes \hat{n})|\vec{n}|
$$

sendo que:

$|\vec{n}|=\nabla \alpha$

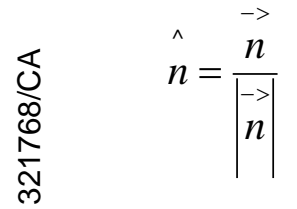

$T=\sigma(|\nabla \alpha|) I-\frac{\nabla \alpha \otimes \nabla \alpha}{|\nabla \alpha|}$

Para finalizar, a força resultante da tensão superficial é dada por:

$$
F_{C S S}=\nabla \cdot T
$$




\subsection{Número de Courant}

O Número de Courant (Courant-Friedrich-Levy ou CFL) é um número adimensional empregado com a finalidade de garantir a estabilidade numérica em escoamentos transiente e definido pela equação abaixo (no caso de uma geometria tridimensional) ${ }^{[26]}$ :

$C=u_{x} \frac{\Delta t}{\Delta x}+u_{y} \frac{\Delta t}{\Delta y}+u_{z} \frac{\Delta t}{\Delta z}$

sendo $u$ a velocidade e $\Delta t$ o passo de tempo. $\Delta x, \Delta y$ e $\Delta z$ representam os comprimentos paralelos a eixos ortogonais que formam o volume finito da malha. Este parâmetro adimensional é um dos parâmetros que afeta a convergência para um passo de tempo específico. A condição de convergência é dada por:

$C \leq C_{\text {máx }}$

sendo $C_{\text {máx }}$ o maior Número de Courant para que a convergência ocorra. Esse número depende do método utilizado para resolver a equação e principalmente do fato de o método ser explícito ou implícito. O método explícito é mais sensível à instabilidade e, portanto, $C_{\text {máx }}$ é menor nesse caso do que no caso em que o método é implícito.

Para uma geometria plana, o Número de Courant pode ser expresso pela seguinte equação:

$C=u_{x} \frac{\Delta t}{\Delta x}+u_{y} \frac{\Delta t}{\Delta y}$

Para calcular esse número adimensional, o programa ANSYS Fluent divide o volume de cada célula da malha em uma região próxima à interface do fluido pela soma dos fluxos que "saem" de uma determinada célula. O tempo resultante representa o tempo que levaria para o fluido sair totalmente da célula. 


\section{Teste de Malha (Validação)}

\subsection{Definição da Dimensão da Malha}

Primeiramente, foi criada uma malha tridimensional com 506760 pontos nodais, denominada "malha original" (malha $A_{1}$ ), para a qual os dois fluidos foram considerados newtonianos (água e um fluido mais denso) com as seguintes propriedades relativas: $\rho_{R}=1,61$ e $\eta_{R}=1,00$. A razão de aspecto foi fixada em um valor igual a 20. Configurou-se o passo de tempo de forma que o número de Courant fosse igual a 0,25 em todos os casos (o próprio Fluent pode ajustar automaticamente o passo de tempo para manter o número de Courant desejado constante através da opção "Time Step Variable"). Além disso, o limite de tolerância da convergência para cada passo de tempo foi mantido em $1,0 \cdot 10^{-5}$ tanto para a continuidade como para as velocidades em cada eixo.

A seguir, foi efetuada uma comparação entre dois pares de casos: o primeiro par de casos consistiu em uma malha tridimensional (malha $\mathrm{B}_{1}$ ) com $25 \%$ de pontos nodais a menos do que a malha $\mathrm{A}_{1}$ e uma malha bidimensional (malha $\mathrm{B}_{2}$ ) resultante de um "corte" efetuado na malha tridimensional sendo, desta forma, uma seção plana que passa pelo centro do topo circular da malha 3D. O segundo par de casos foi caracterizado por uma malha tridimensional (denominada malha $\mathrm{C}_{1}$ ) com $25 \%$ de pontos nodais a mais do que a malha $\mathrm{A}_{1} \mathrm{e}$ uma malha $2 \mathrm{D}$ (malha $\mathrm{C}_{2}$ ) criada analogamente à malha $\mathrm{B}_{2}$ sendo que, desta vez, o "corte" foi realizado na malha $\mathrm{C}_{1}$. A finalidade da comparação foi simplesmente definir a dimensão da malha (bidimensional ou tridimensional) que seria utilizada nas etapas seguintes (definição do refinamento da malha, determinação da taxa de cisalhamento crítica dos fluidos não-newtonianos e investigação paramétrica).

No melhor cenário, os resultados (velocidades da interface entre o tampão e o fluido de perfuração além dos tempos de furo) seriam similares para cada par de casos, possibilitando o uso da malha bidimensional nos casos posteriores, o que economizaria consideravelmente o tempo da simulação de cada caso, já que o 
tempo que o Método dos Volumes Finitos levaria um tempo significativamente menor para resolver cada equação de conservação do modelo VOF em cada ponto nodal da malha do que em uma malha tridimensional (pelo fato de a quantidade de pontos nodais em dois planos ser muito inferior ao número de pontos nodais em três planos).

Abaixo, pode-se visualizar os gráficos que mostram a dependência da velocidade da interface entre o tampão e o fluido de perfuração em relação ao tempo, assim como a relação entre a densidade da mistura no topo e o tempo. A primeira comparação foi efetuada entre as malhas $\mathrm{B}_{1}$ e $\mathrm{B}_{2}$ :

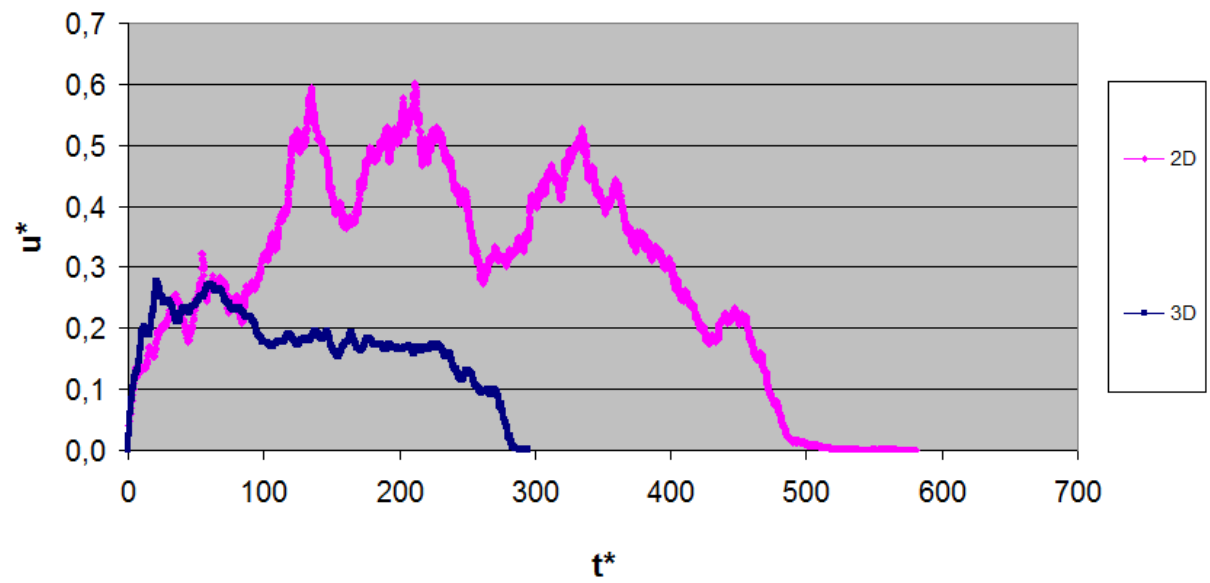

Gráfico 2 - Velocidade Interfacial vs. Tempo (Malhas $\mathrm{B}_{1}$ e $\mathrm{B}_{2}, \mathrm{~L}^{*}=20, \rho_{R}=1,61, \eta_{R}=1,00$ ) 


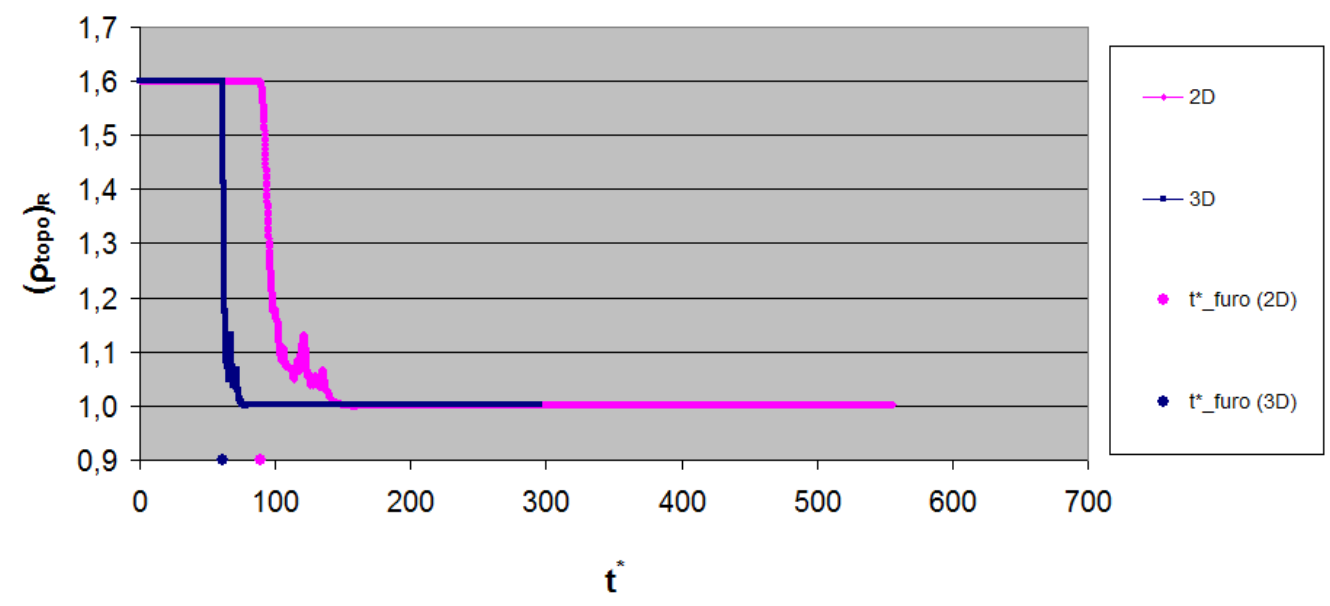

Gráfico 3 - Densidade da Mistura no topo vs. Tempo (Malhas $\mathrm{B}_{1}$ e $\mathrm{B}_{2}, \mathrm{~L}^{*}=20, \rho_{R}=1,61, \eta_{R}=$ $1,00)$

Os resultados numéricos das malhas $\mathrm{B}_{1}$ e $\mathrm{B}_{2}$ como a velocidade terminal e os tempos de furo e deposição são apresentados na tabela a seguir. Além disso, as discrepâncias dos resultados das malhas bidimensionais em relação às respectivas malhas tridimensionais também são mostrados na tabela:

\begin{tabular}{|c|c|c|c|c|c|}
\hline Dimensão da Malha & Malha & $t^{*}{ }_{\text {furo }}$ & $t^{*}{ }_{\text {deposição }}$ & $\varepsilon_{\text {furo }}(\%)$ & $\varepsilon_{\text {dep }}(\%)$ \\
\hline 2D & $\mathrm{B}_{2}$ & 88,74 & 581,06 & 45,30 & 97,13 \\
\hline 3D & $\mathrm{B}_{1}$ & 61,07 & 294,76 & - & - \\
\hline
\end{tabular}

Tabela 1 - Resultados das malhas $\mathrm{B}_{1}$ e $\mathrm{B}_{2}$

Após a comparação entre as malhas $\mathrm{B}_{1}$ e $\mathrm{B}_{2}$, foi realizada a comparação entre os resultados das malhas $\mathrm{C}_{1}$ e $\mathrm{C}_{2}$, mostrada a seguir: 


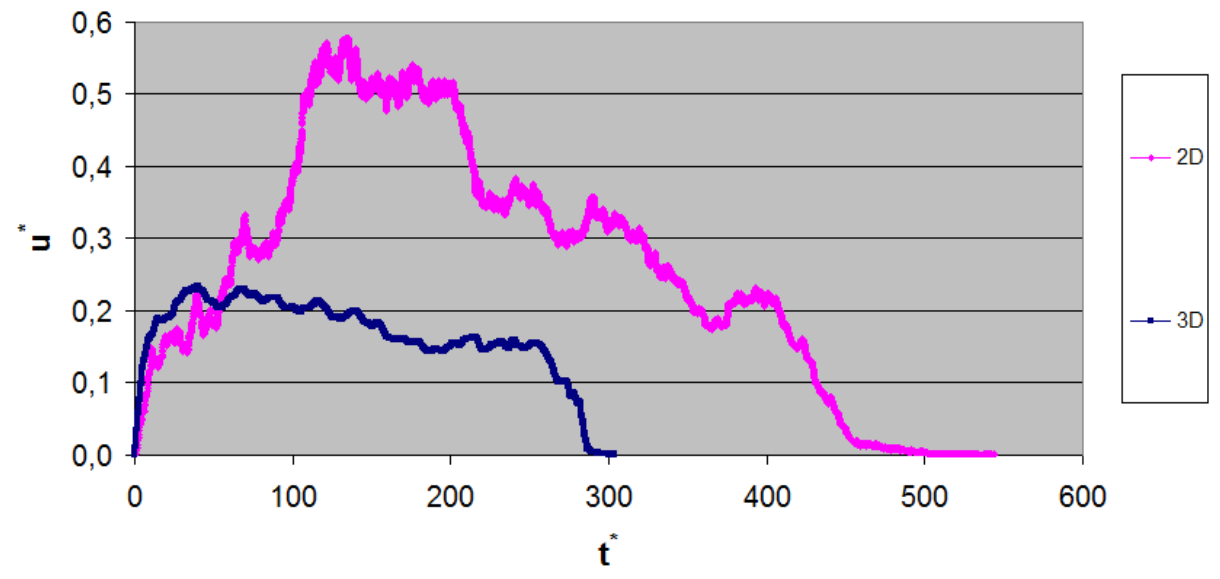

Gráfico 4 - Velocidade Interfacial vs. Tempo (Malhas $\mathrm{C}_{1}$ e $\mathrm{C}_{2}, \mathrm{~L}^{*}=20, \rho_{R}=1,61, \eta_{R}=1,00$ )

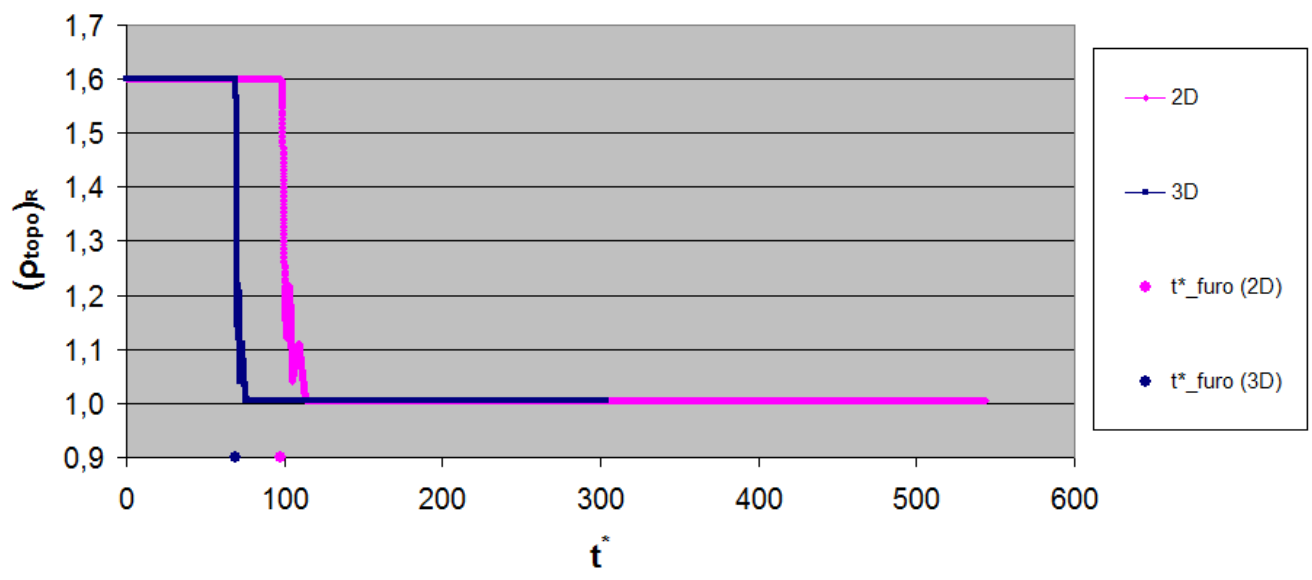

Gráfico 5 - Densidade da Mistura no topo vs. Tempo (Malhas $\mathrm{C}_{1}$ e $\mathrm{C}_{2}, \mathrm{~L}^{*}=20, \rho_{R}=1,61, \eta_{R}=$ $1,00)$

A seguir, são apresentados os resultados das malhas $\mathrm{C}_{1}$ e $\mathrm{C}_{2}$ além das discrepâncias dos resultados das malhas bidimensionais em relação às respectivas malhas tridimensionais:

\begin{tabular}{|c|c|c|c|c|c|}
\hline Dimensão da Malha & Malha & $t^{*}{ }_{\text {furo }}$ & $t^{*}{ }_{\text {deposição }}$ & $\varepsilon_{\text {furo }}(\%)$ & $\varepsilon_{\text {dep }}(\%)$ \\
\hline 2D & $\mathrm{C}_{2}$ & 97,90 & 598,36 & 41,25 & 96,85 \\
\hline 3D & $\mathrm{C}_{1}$ & 69,31 & 303,96 & - & - \\
\hline
\end{tabular}

Tabela 2 - Resultados das malhas $\mathrm{C}_{1}$ e $\mathrm{C}_{2}$ 
A tabela seguinte mostra os resultados das quatro malhas assim como as discrepâncias da malha $\mathrm{B}_{2}$ em relação à malha $\mathrm{B}_{1}$ assim como da malha $\mathrm{C}_{2} \mathrm{em}$ relação à malha $\mathrm{C}_{1}$ :

\begin{tabular}{|c|c|c|c|c|c|}
\hline Dimensão da Malha & Malha & $t^{*}{ }_{\text {furo }}$ & $t^{*}{ }_{\text {deposição }}$ & $\varepsilon_{\text {furo }}(\%)$ & $\varepsilon_{\text {dep }}(\%)$ \\
\hline 2D & $\mathrm{B}_{2}$ & 88,74 & 581,06 & 45,30 & 97,13 \\
\hline 3D & $\mathrm{B}_{1}$ & 61,07 & 294,76 & - & - \\
\hline 2D & $\mathrm{C}_{2}$ & 97,90 & 598,36 & 41,25 & 96,85 \\
\hline 3D & $\mathrm{C}_{1}$ & 69,31 & 303,96 & - & - \\
\hline
\end{tabular}

Tabela 3 - Resultados das malhas $\mathrm{B}_{1}, \mathrm{~B}_{2}, \mathrm{C}_{1}$ e $\mathrm{C}_{2}$

Como pode ser observado, as discrepâncias dos tempos de furo e deposição para cada par de malhas foram muito elevadas. Conseqüentemente, a opção de utilizar-se a malha bidimensional nas próximas etapas ficou comprometida, decidindo-se trabalhar com a malha tridimensional.

\subsection{Definição do Refinamento da Malha}

O próximo passo foi a definição do refinamento da malha. Para isso, as malhas tridimensionais $\left(\mathrm{A}_{1}, \mathrm{~B}_{1}\right.$ e $\left.\mathrm{C}_{1}\right)$ foram comparadas da seguinte forma: as três malhas foram simuladas simultaneamente e os resultados obtidos da simulação como a velocidade da interface entre os fluidos e os tempos de furo foram utilizados para efeitos de comparação.

Como houve uma discrepância notável entre os resultados (velocidades terminais e tempos de furo e deposição) das malhas $\mathrm{C}_{1}$ e $\mathrm{B}_{1}\left(\mathrm{~B}_{1}\right.$ é a malha menos refinada e $\mathrm{C}_{1}$ é a malha mais refinada) mas não houve discrepâncias consideráveis entre os resultados das malhas $A_{1}$ e $C_{1}\left(A_{1}\right.$ é menos refinada do que $C_{1}$ e mais refinada do que $B_{1}$ ), decidiu-se trabalhar com a malha $A_{1}$ nos casos posteriores. Os gráficos e a tabela a seguir apresentam os resultados e a discrepância dos resultados das malhas menos refinadas $\left(\mathrm{A}_{1}\right.$ e $\left.\mathrm{B}_{1}\right)$ em relação à malha mais refinada $\left(\mathrm{C}_{1}\right)$ : 


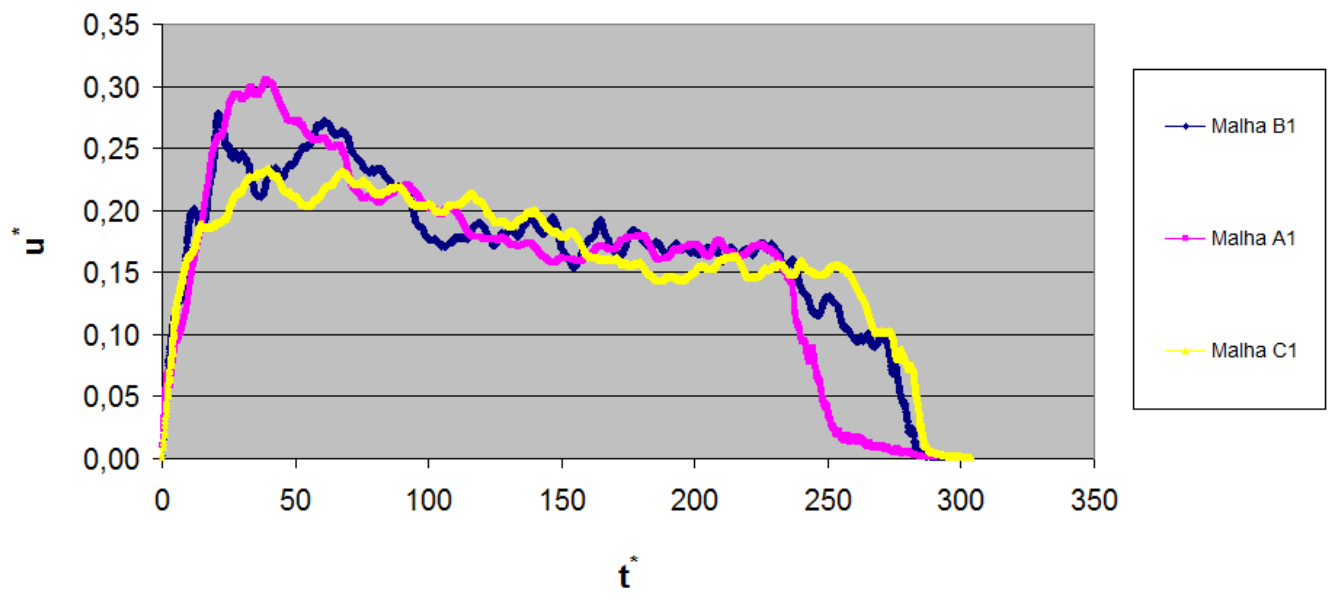

Gráfico 6 - Velocidade Interfacial vs. Tempo (Malhas $B_{1}, A_{1}$ e $C_{1}$ )

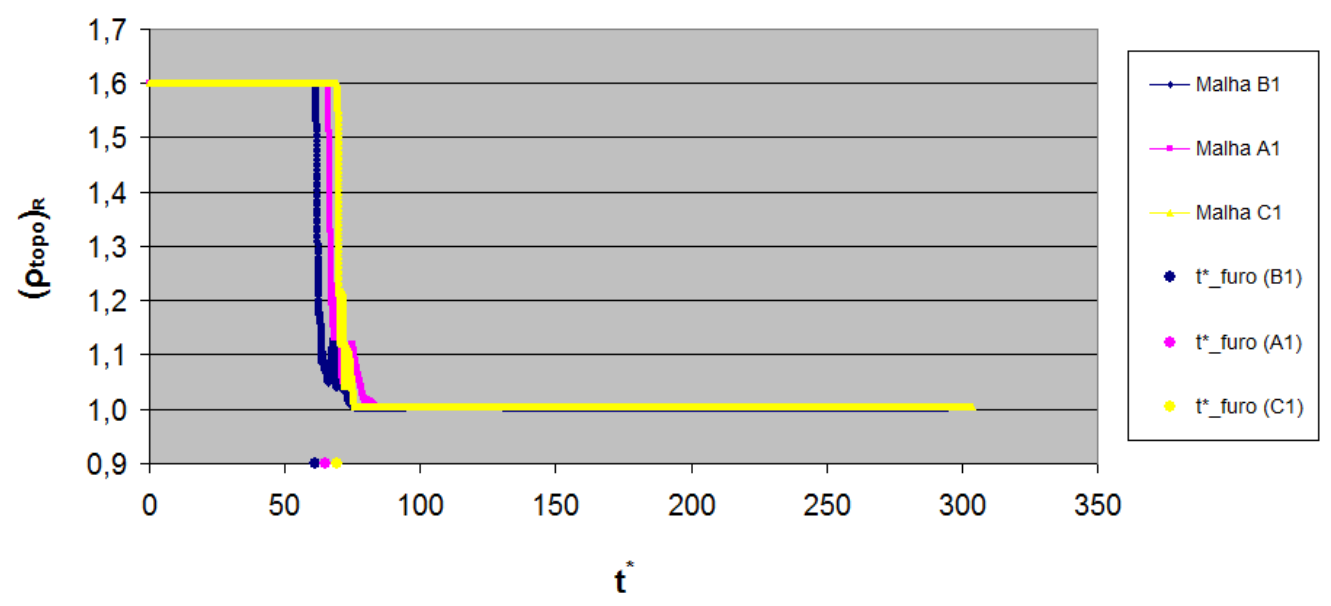

Gráfico 7 - Densidade da Mistura no topo vs. Tempo (Malhas $B_{1}, A_{1}$ e $C_{1}$ )

\begin{tabular}{|c|c|c|c|c|c|c|c|}
\hline \% Refinamento em relação à malha A1 & Malhas & $t^{*}{ }_{\text {furo }}$ & $t^{*}{ }_{\text {deposição }}$ & $u_{t}{ }^{*}$ & $\varepsilon_{\text {furo }}(\%)$ & $\varepsilon_{\text {dep }}(\%)$ & $\mathcal{E}_{u_{t}^{*}}(\%)$ \\
\hline-25 & $\mathrm{~B}_{1}$ & 61,11 & 275,85 & 0,169 & 11,84 & 9,25 & 7,64 \\
\hline $\mathbf{0}$ & $\mathbf{A}_{1}$ & $\mathbf{6 5 , 8 7}$ & $\mathbf{2 9 7 , 4 0}$ & $\mathbf{0 , 1 6 6}$ & $\mathbf{4 , 9 7}$ & $\mathbf{2 , 1 6}$ & $\mathbf{5 , 7 3}$ \\
\hline+25 & $\mathrm{C}_{1}$ & 69,31 & 303,96 & 0,157 & - & - & - \\
\hline
\end{tabular}

Tabela 4 - Resultados das malhas tridimensionais $\left(\mathrm{L}^{*}=20, \rho_{R}=1,61, \eta_{R}=1,00\right)$ 
A seguir, são mostrados dois gráficos que ilustram a dependência dos tempos de furo e deposição e da velocidade terminal (quando o regime é praticamente permanente) em relação ao grau de refinamento da malha:

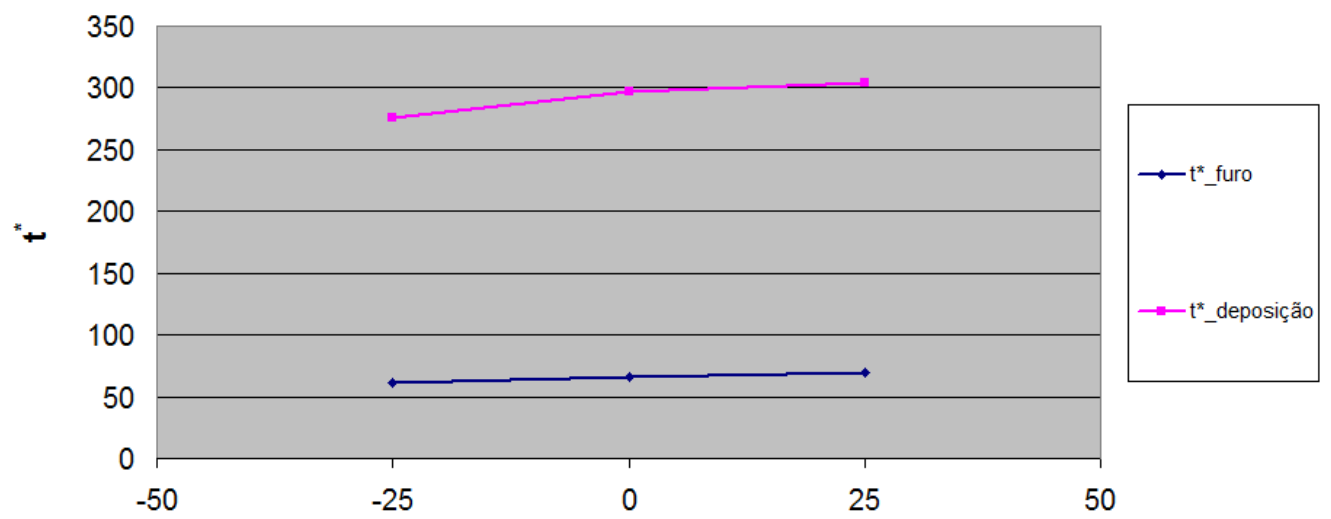

\% Refinamento em relação à $\mathrm{A} 1$

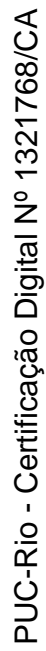

Gráfico 8 - Tempos de Furo e Deposição vs. Refinamento $\left(\mathrm{L}^{*}=20, \rho_{R}=1,61, \eta_{R}=1,00\right)$

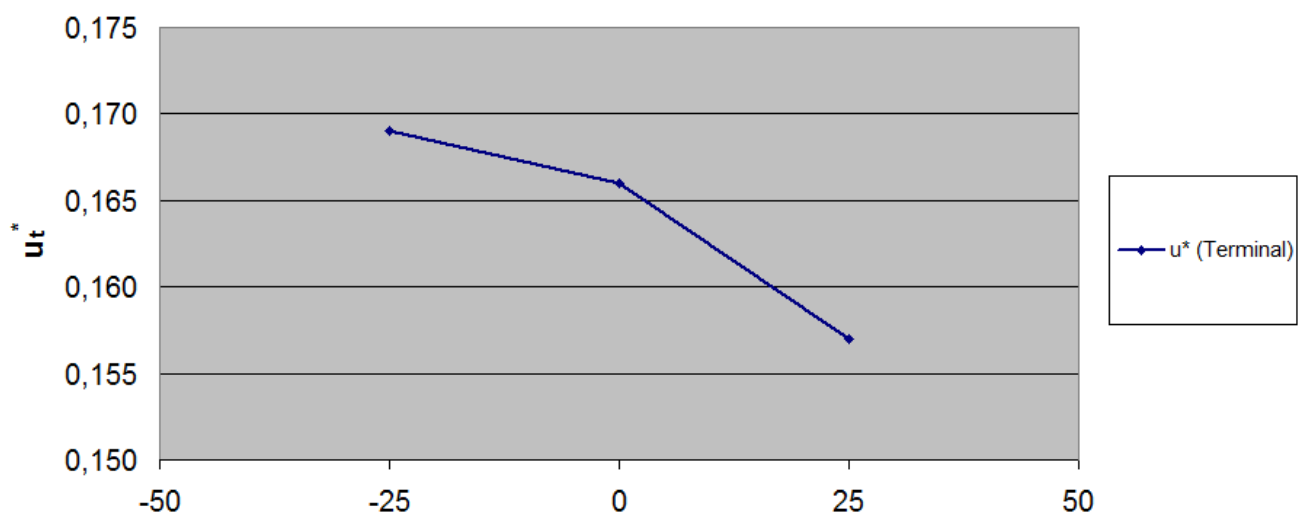

$\%$ Refinamento em relação à $\mathrm{A} 1$

Gráfico 9 - Velocidade Terminal vs. Refinamento $\left(\mathrm{L}^{*}=20, \rho_{R}=1,61, \eta_{R}=1,00\right)$ 


\subsection{Definição da Taxa de Cisalhamento Crítica}

Tendo-se decidido trabalhar com uma malha tridimensional e definido o grau de refinamento da malha, o próximo passo foi determinar a taxa de cisalhamento crítica dos fluidos não-newtonianos de cada caso (o valor da razão de aspecto nesses casos foi igual a 10). A taxa de cisalhamento crítica, $\gamma_{c r}$, é menor ou igual à taxa de cisalhamento característica, sendo $\left(\dot{\gamma}_{c r}\right)_{R}=\frac{\dot{\gamma}_{c r}}{\dot{\gamma}_{c a r}}$.

Vale ressaltar que a facilidade de convergência é maior quanto mais elevada for essa taxa. No entanto, quanto menor for a taxa de cisalhamento crítica, maior será o patamar de viscosidade, aproximando-se mais do modelo HerschelBulkley. Portanto, a taxa de cisalhamento crítica "ótima" seria uma taxa de cisalhamento crítica que se aproximasse bastante do modelo Herschel-Bulkley e, de preferência, também apresentasse facilidade de convergência.

A determinação desta taxa foi realizada da seguinte forma: iniciou-se a simulação numérica para um caso (Caso 1) cuja taxa de cisalhamento crítica fosse recomendada da literatura pelo fato de apresentar rápida convergência e não ser tão alta. Esta taxa é $\dot{\gamma}_{c r}=10^{-3} \dot{\gamma}_{c a r}$. Simultaneamente, foram rodados mais quatro casos com taxas críticas de cisalhamento menores (Caso 2: $\dot{\gamma}_{c r}=10^{-4} \dot{\gamma}_{c a r}$, Caso 3: $\dot{\gamma}_{c r}=10^{-5} \dot{\gamma}_{c a r}$, Caso 4: $\dot{\gamma}_{c r}=10^{-6} \dot{\gamma}_{c a r}$ e Caso 5: $\left.\dot{\gamma}_{c r}=10^{-7} \dot{\gamma}_{c a r}\right)$.

Se todas as discrepâncias dos resultados (tempos de furo) dos quatro primeiros casos em relação aos resultados do último caso (casos 1 e 5; casos 2 e 5; casos 3 e 5; casos 4 e 5) fossem maior ou igual a 5\%, seria simulado mais um caso para o qual a taxa de cisalhamento crítica fosse um décimo da menor taxa cujo caso já tivesse sido rodado, o que não foi necessário. Sabendo-se que $g=9,81 \mathrm{~m} / \mathrm{s}^{2}$ e $\mathrm{D}=1 \mathrm{~m}$, temos que $\mathrm{V}_{\mathrm{car}}=3,13 \mathrm{~m} / \mathrm{s}$ e $\dot{\gamma}_{\text {car }}=3,13 \mathrm{~s}^{-1}$. 
Dos cinco casos analisados, as menores discrepâncias para a velocidade terminal e os tempos de furo e deposição ocorreram para o par de casos 4 e 5 . Os gráficos abaixo ilustram a dependência da velocidade da interface entre os dois fluidos com o tempo além da relação entre a densidade do topo da mistura e o tempo:

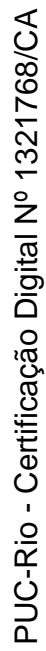

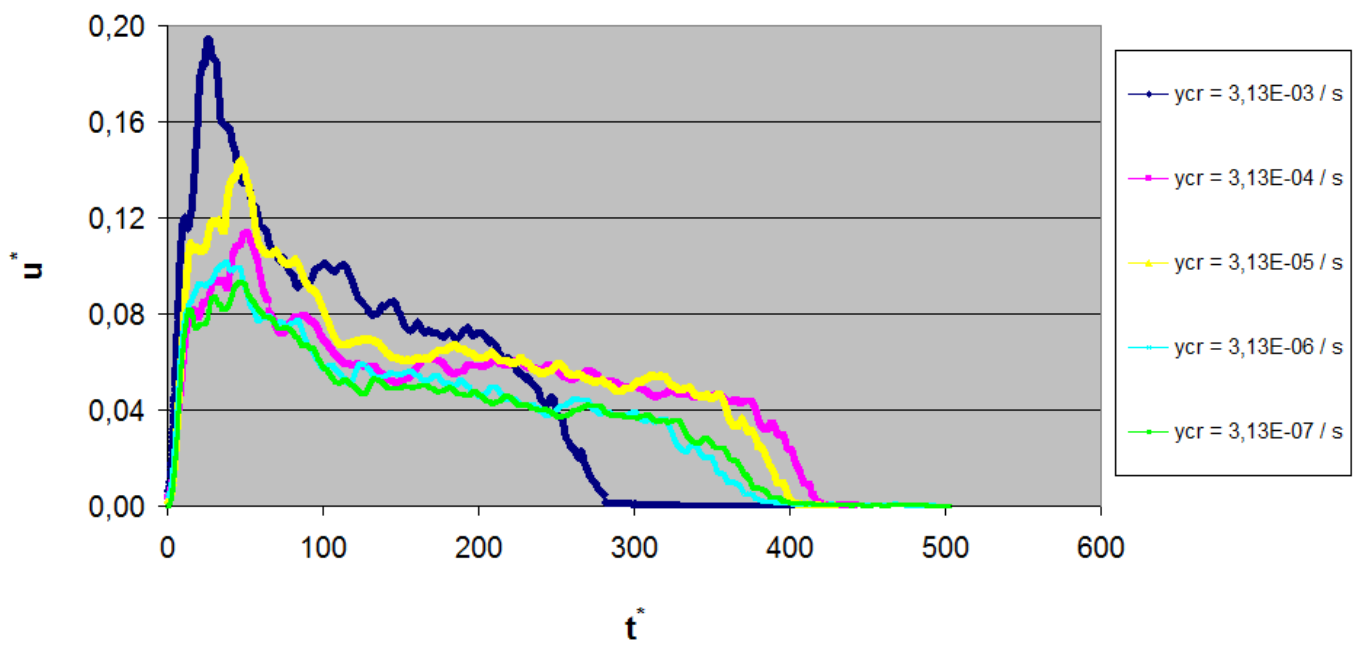

Gráfico 10 - Velocidade Interfacial vs. Tempo $\left(\mathrm{L}^{*}=10, \rho_{R}=1,20\right)$

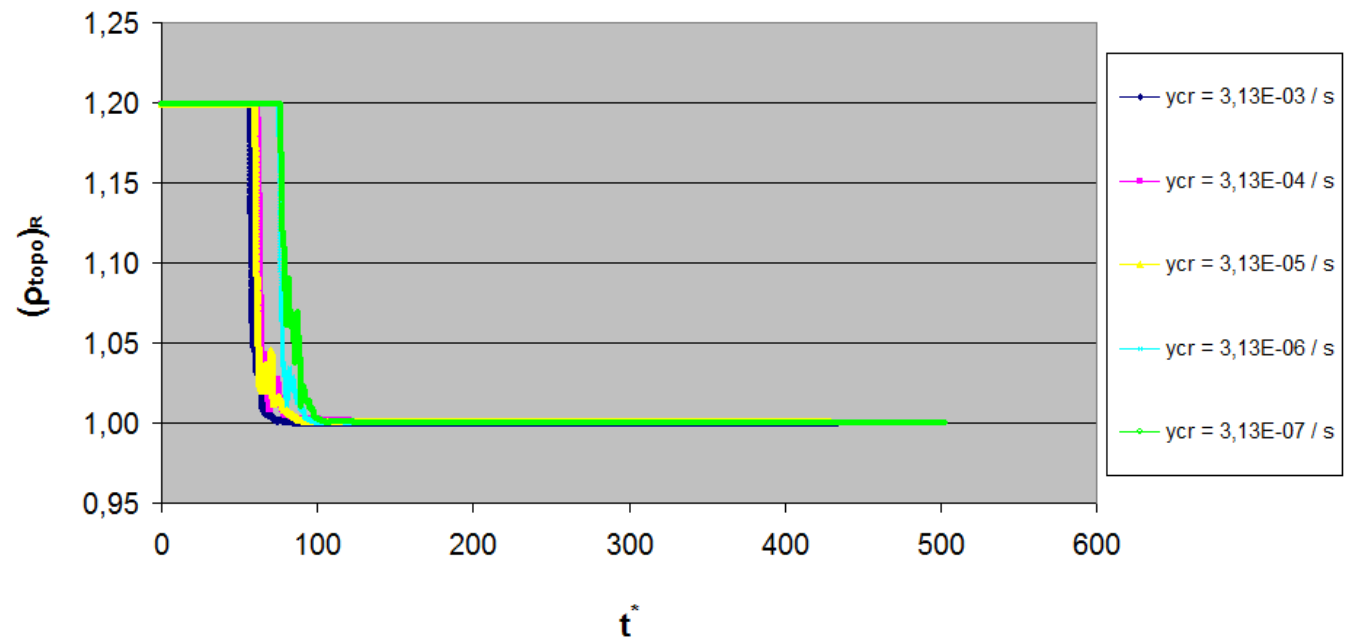

Gráfico 11 - Densidade da mistura no Topo vs. Tempo $\left(\mathrm{L}^{*}=10, \rho_{R}=1,20\right)$ 
As discrepâncias entre os casos 4 e 5 foi nitidamente pequena. Portanto, a taxa de cisalhamento crítica que foi utilizada nos casos em que a investigação paramétrica foi realizada é $\dot{\gamma}_{c r}=10^{-6} \dot{\gamma}_{c a r}=3,13 \cdot 10^{-6} s^{-1}$, o que significa que $\left(\dot{\gamma}_{c r}\right)_{R}=1,00 \cdot 10^{-6}$

Abaixo, é mostrada graficamente e por meio de uma tabela a relação entre os valores das taxas de cisalhamento crítica e os respectivos resultados (velocidade terminal e tempos de furo e deposição) além das discrepâncias entre os resultados:

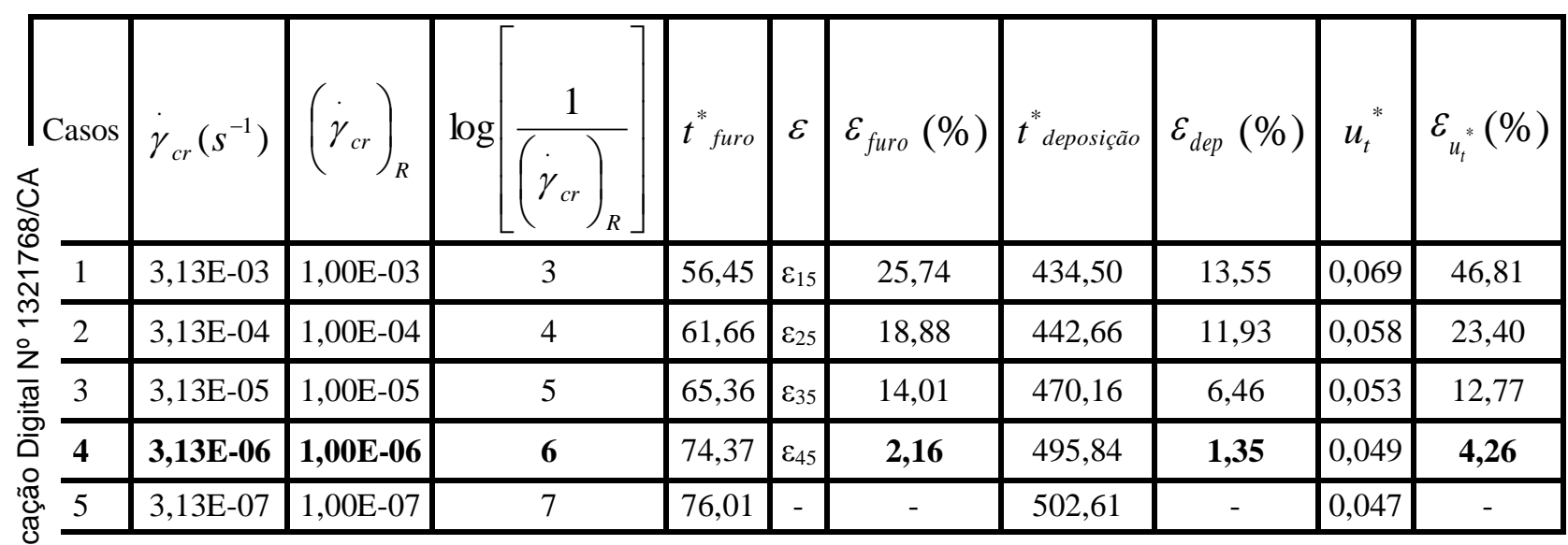

Tabela 5 - Discrepâncias dos resultados em relação ao caso 5 

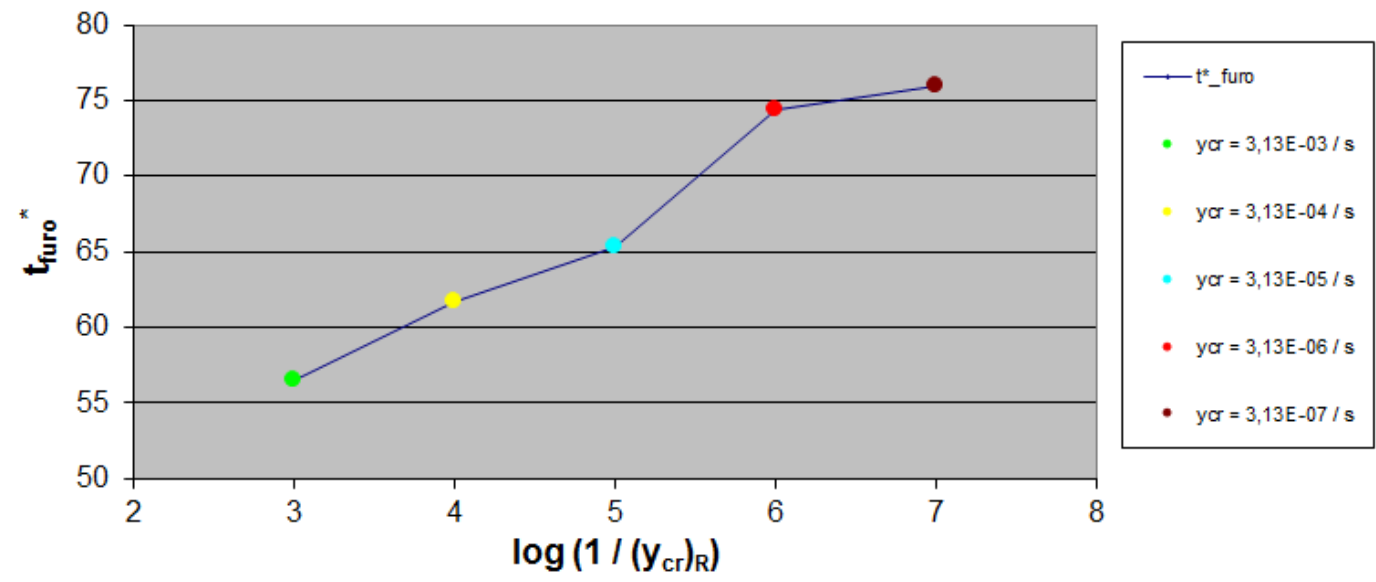

Gráfico 12 - Tempo de Furo vs. $\log \left(\frac{1}{\left(\dot{\gamma}_{c r}\right)_{R}}\right)$

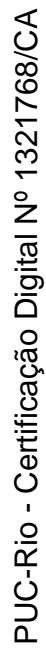

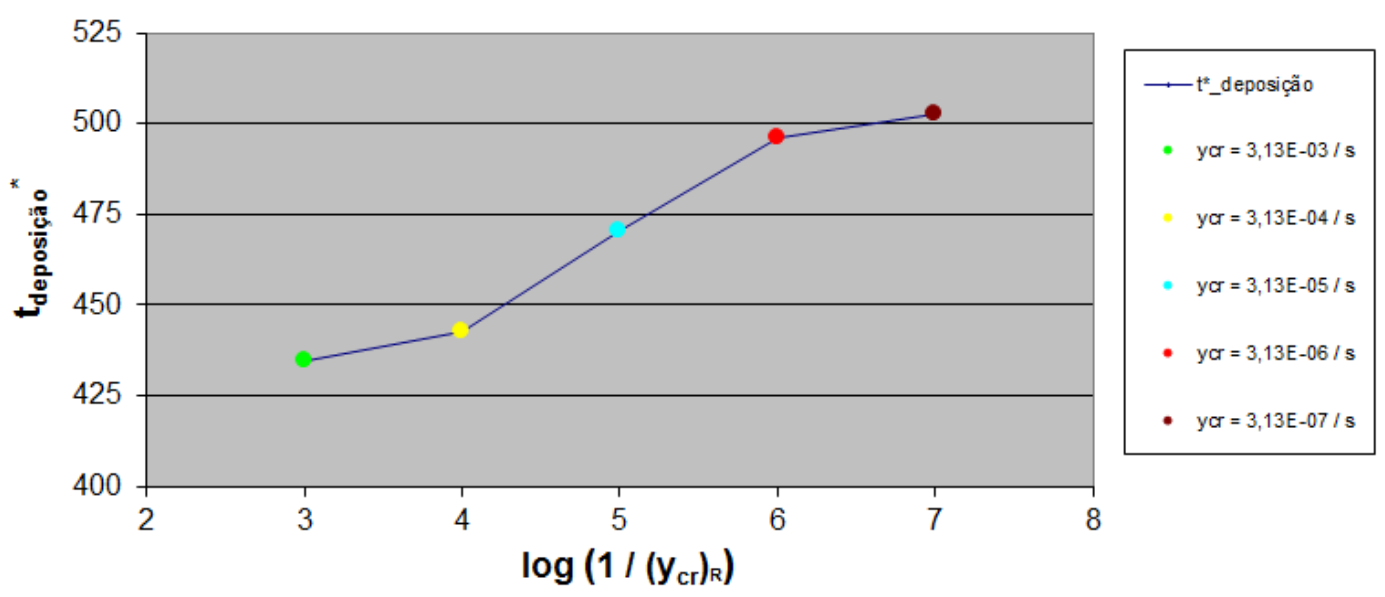

Gráfico 13 - Tempo de Deposição vs. $\log \left(\frac{1}{\left(\dot{\gamma_{c r}}\right)_{R}}\right)$ 


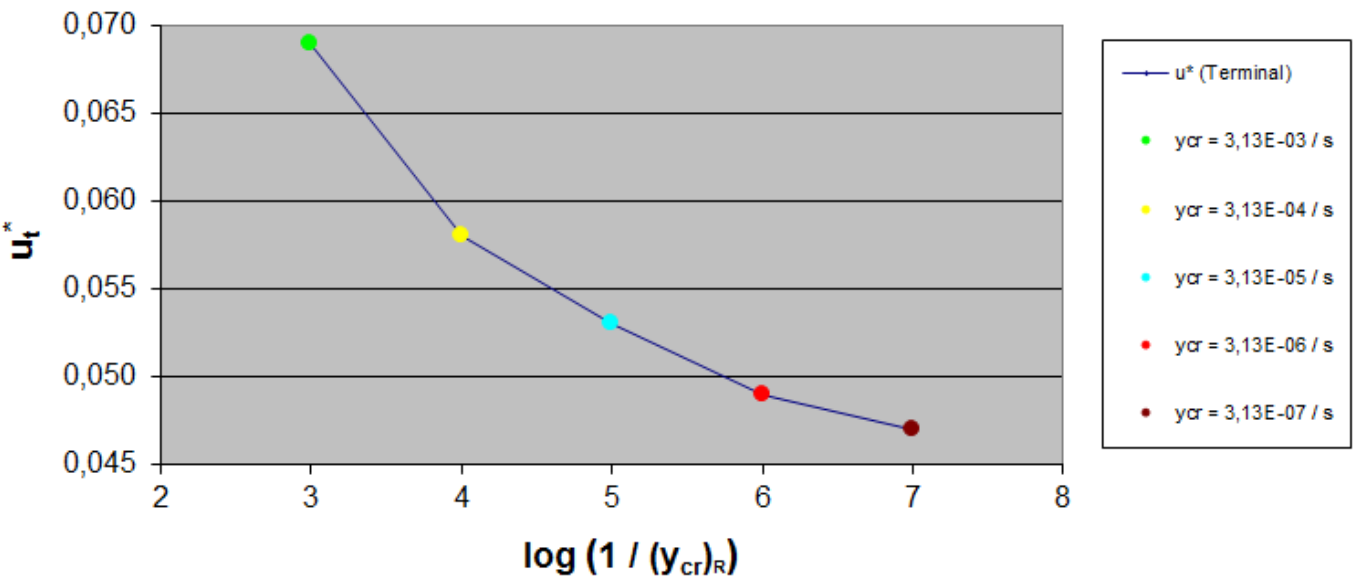

Gráfico 14 - Velocidade Terminal vs. $\log \left(\frac{1}{\left(\dot{\gamma_{c r}}\right)_{R}}\right)$

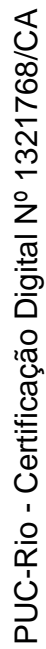




\section{Resultados}

Após a definição da dimensão da malha, do seu refinamento e da taxa de cisalhamento crítica, foi realizada uma investigação paramétrica a fim de verificar-se qual a influência dos parâmetros governantes no processo. Os parâmetros analisados foram a razão de aspecto, a razão entre as densidades dos dois fluidos, a razão entre as viscosidades, a razão entre as tensões-limite de escoamento, a razão entre os índices de potência e a tensão interfacial. Primeiramente, todos os parâmetros foram fixados com exceção da razão de aspecto $\left(\mathrm{L}^{*}\right)$, que foi alterada a fim de verificar-se o seu efeito na simulação. Em seguida, variou-se outro parâmetro mantendo-se constantes todos os demais parâmetros, incluindo a razão de aspecto.

Os resultados gráficos obtidos foram a velocidade da interface entre os fluidos ao longo do tempo, assim como a densidade da mistura no topo do poço com o passar do tempo. Além da velocidade interfacial, os tempos de furo foram usados como comparação entre os casos e, no estudo do efeito da razão de aspecto na operação, os tempos de deposição também foram usados. O tempo de furo é definido como sendo o tempo para o fluido 1 atingir o topo do fluido 2, e o tempo de deposição é o tempo necessário para todo o fluido 2 se depositar no fundo do poço.

\subsection{Influência da Razão de Aspecto}

Primeiramente, foi analisado o efeito da alteração da razão de aspecto na operação: 


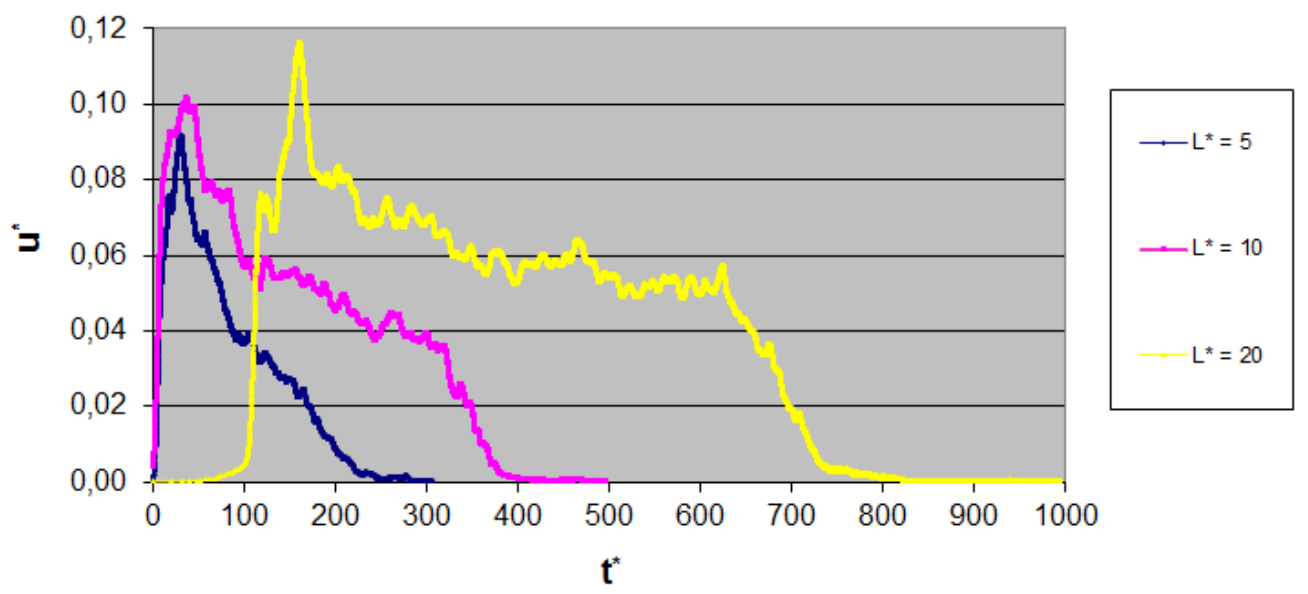

Gráfico 15 - Velocidade Interfacial vs. Tempo $\left(\rho_{R}=1,20, \eta_{R}=1,00\right)$

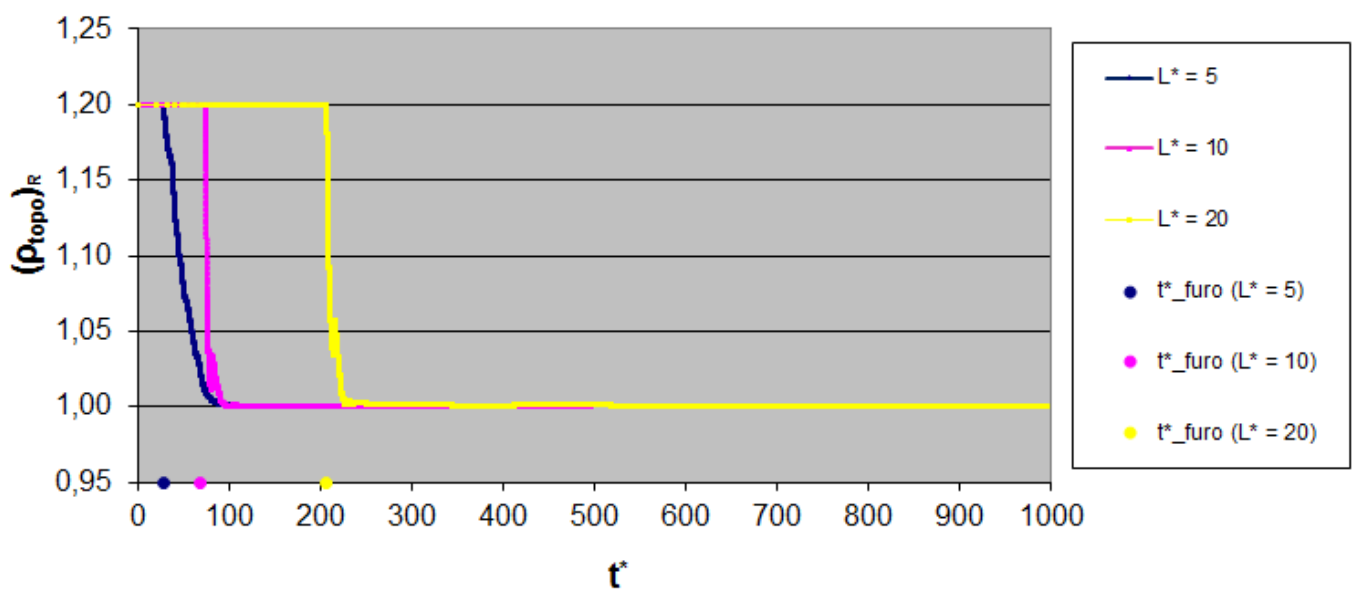

Gráfico 16 - Densidade da mistura no topo vs. Tempo $\left(\rho_{R}=1,20, \eta_{R}=1,00\right)$

Com base nos gráficos mostrados acima, pode-se afirmar que quanto maior é a razão de aspecto, maior é a faixa de estabilidade da velocidade interfacial e terminal assim como os tempos de furo e deposição. Além disso, tanto $\mathrm{L}^{*}=10$ como $\mathrm{L}^{*}=20$ apresentam uma faixa nítida de estabilidade da velocidade interfacial, enquanto que para $\mathrm{L}^{*}=5$ não existe um regime quase permanente.

Na tabela e no gráfico que são mostrados a seguir, podemos visualizar o efeito da razão de aspecto tanto nos tempos de furo como nos tempos de deposição do tampão para cada um dos três casos. Também são apresentados os 
valores das respectivas velocidades terminais (velocidades nas quais o regime é quase permanente):

\begin{tabular}{|c|c|c|c|c|c|c|}
\hline$\rho_{R}$ & $\eta_{R}$ & $L^{*}$ & $t^{*}{ }_{\text {furo }}$ & $t^{*}{ }_{\text {deposição }}$ & $u_{t}{ }^{*}$ & $\varepsilon_{u_{t}{ }^{*}}(\%)$ \\
\hline \multirow{3}{*}{1,20} & \multirow{2}{*}{1,00} & 5 & 28,02 & 352,68 & - & - \\
\cline { 3 - 7 } & & 10 & 68,58 & 496,07 & 0,051 & 7,27 \\
\cline { 3 - 7 } & & 20 & 206,59 & 973,55 & 0,055 & - \\
\hline
\end{tabular}

Tabela 6 - Resultados para diferentes razões de aspecto

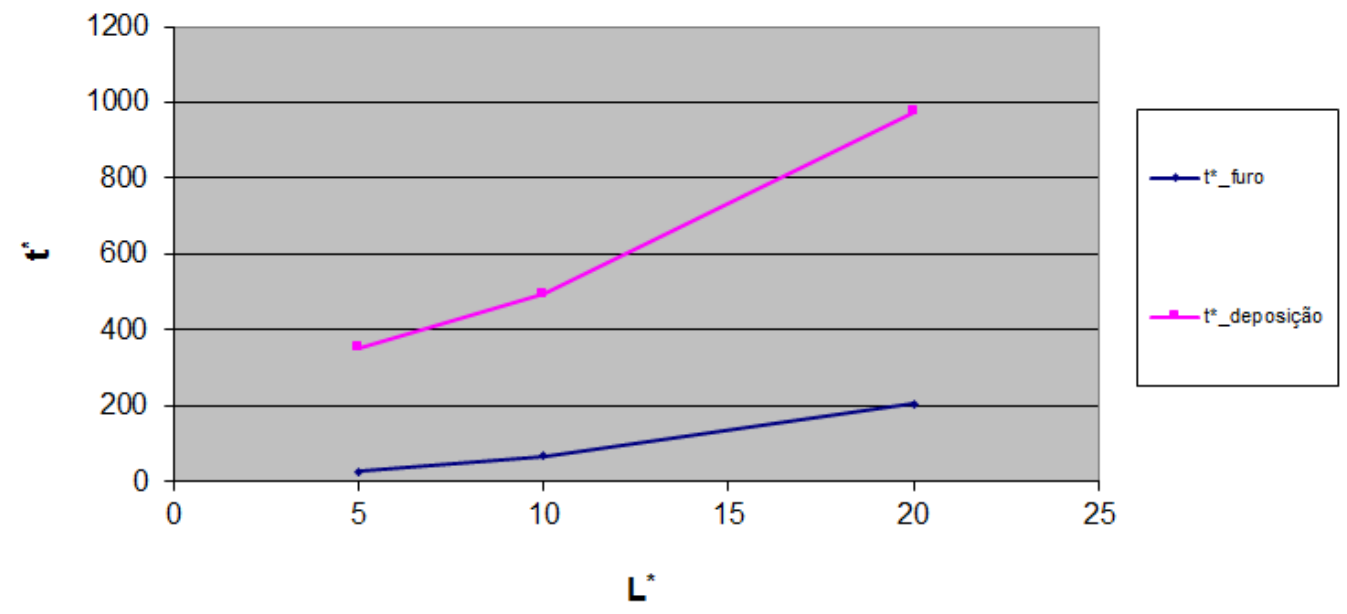

Gráfico 17 - Tempos de Furo e Deposição vs. Razão de Aspecto $\left(\rho_{R}=1,20, \eta_{R}=1,00\right)$

A seguir, é mostrado o gráfico da velocidade terminal das razões de aspecto que apresentam um regime quase permanente $\left(\mathrm{L}^{*}=10\right.$ e $\left.\mathrm{L}^{*}=20\right)$ versus a razão de aspecto: 


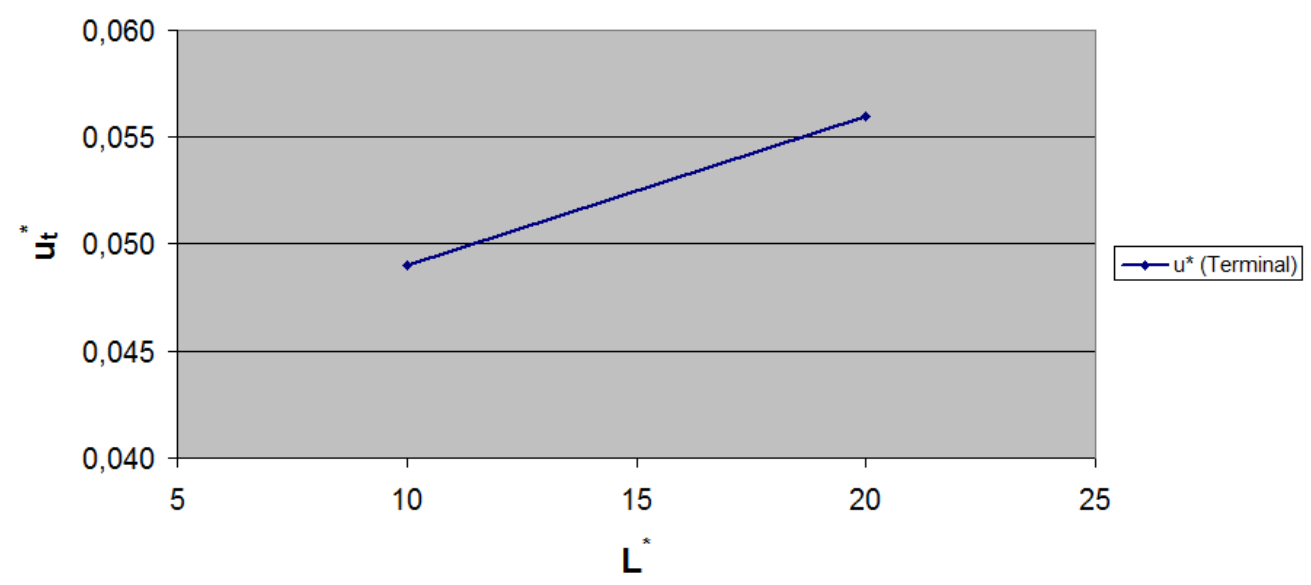

Gráfico 18 - Velocidade Terminal vs. Razão entre Densidades $\left(\mathrm{L}^{*}=10, \eta_{R}=1,00\right)$

De acordo com os gráficos e com a tabela, tanto os tempos de furo e deposição quanto a diferença entre os respectivos tempos de deposição e furo são diretamente proporcionais à razão de aspecto, já que quanto maior é o comprimento que o fluido de perfuração percorre, maior é o tempo que ele leva para furar o topo do poço. De forma semelhante, quanto maior é o comprimento que o tampão leva para se depositar no fundo do poço, maior é o tempo de deposição. Além disso, a velocidade terminal aumenta conforme a razão de aspecto também aumenta. Pode-se notar que as velocidades terminais relativas às razões de aspecto $\mathrm{L}^{*}=10 \mathrm{e} \mathrm{L}^{*}=20$ são muito próximas, indicando que a velocidade terminal não varia de forma considerável a partir de $\mathrm{L}^{*}=10$, podendose extrapolar os resultados do caso em que $\mathrm{L}^{*}=10$ para um caso real $\left(\mathrm{L}^{*} \sim 500\right)$.

\subsection{Influência da Razão Entre Densidades}

Em seguida, foram investigadas as consequiências da alteração da razão entre densidades no processo de tamponamento. Abaixo, iniciou-se essa análise paramétrica com $L^{*}=5$ : 


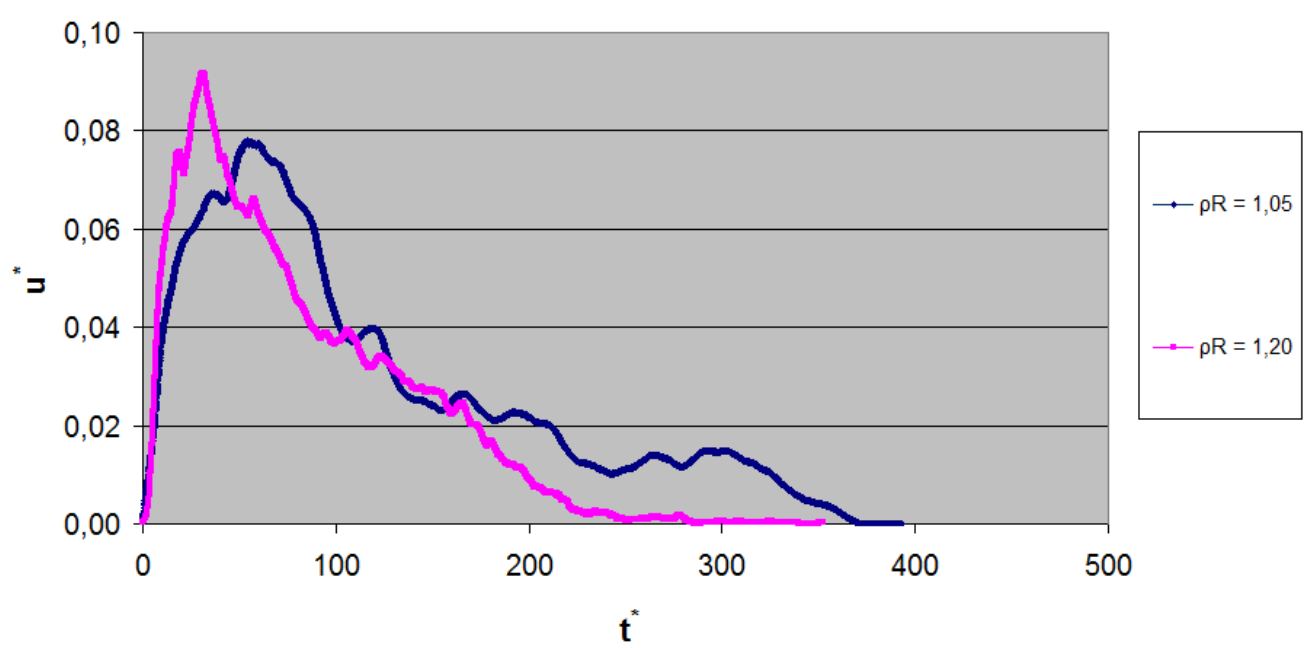

Gráfico 19 - Velocidade Interfacial vs. Tempo $\left(\mathrm{L}^{*}=5, \eta_{R}=1,00\right)$

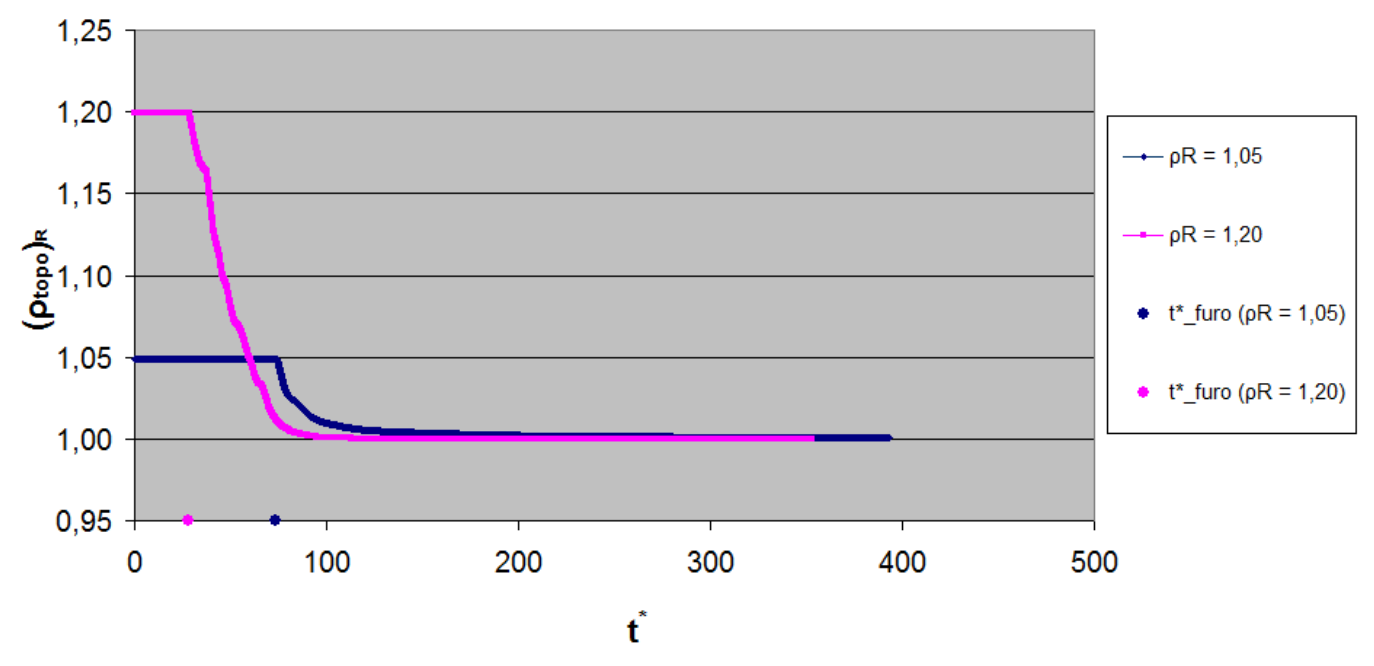

Gráfico 20 - Densidade da mistura no topo vs. Tempo $\left(L^{*}=5, \eta_{R}=1,00\right)$

Baseando-se nos resultados gráficos mostrados correspondentes a $\mathrm{L}^{*}=5$, pudemos concluir que a maior velocidade atingida na interface entre os fluidos é superior conforme a razão entre densidades aumenta da mesma forma que os tempos de furo e deposição são inversamente proporcionais à razão entre densidades visto que, quanto mais pesado é o tampão, mais rápido é o escoamento, levando menos tempo para o tampão se depositar e para o fluido de perfuração furar o topo do poço. Também foi notado que não existe um regime próximo ao regime permanente para esta razão de aspecto. 
A seguir, pode-se observar mais nitidamente nos dois gráficos e na tabela a influência que a razão entre densidades exerce na velocidade terminal e nos tempos de furo e deposição:

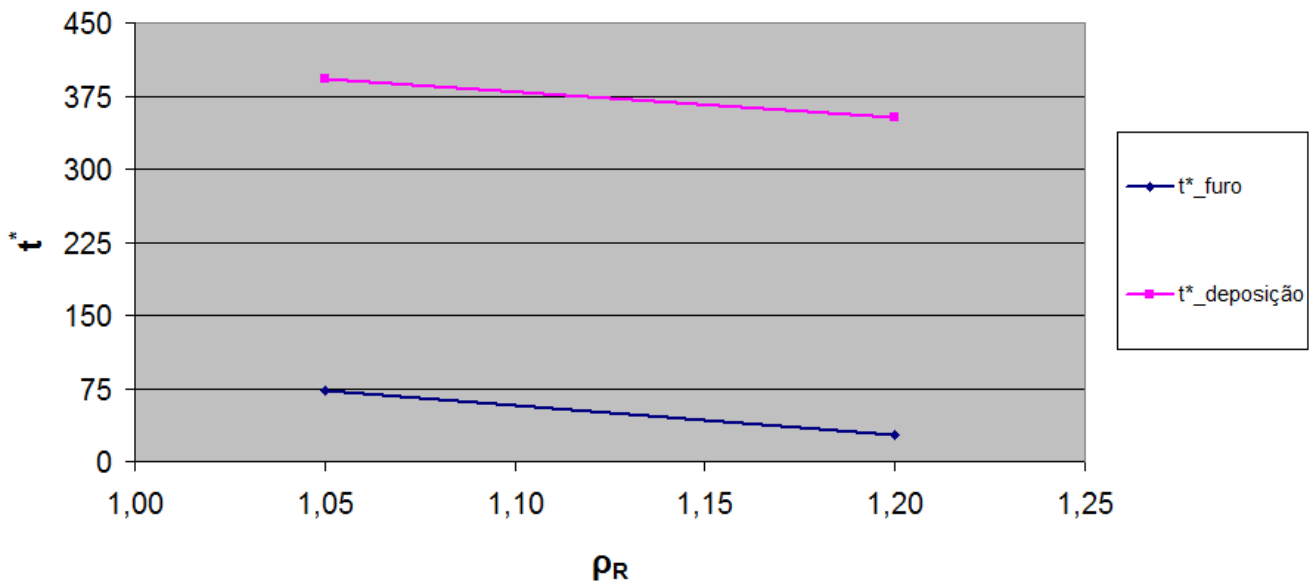

Gráfico 21 - Tempos de furo e deposição vs. Razão entre Densidades para $L^{*}=5$

\begin{tabular}{|c|c|c|c|c|}
\hline$L^{*}$ & $\eta_{R}$ & $\rho_{R}$ & $t^{*}{ }_{\text {furo }}$ & $t^{{ }^{*}}{ }_{\text {deposição }}$ \\
\hline \multirow{2}{*}{5} & \multirow{2}{*}{1,00} & 1,05 & 73,32 & 393,15 \\
\cline { 2 - 5 } & & 1,20 & 28,02 & 352,68 \\
\hline
\end{tabular}

Tabela 7 - Tempos de furo e deposição para $L^{*}=5$

Em seguida, a razão de aspecto foi alterada para $L^{*}=10$ e as razões entre densidades foram variadas (para uma mesma razão entre viscosidades). Para essa razão de aspecto, iniciou-se com $\eta_{R}=0,50$ : 


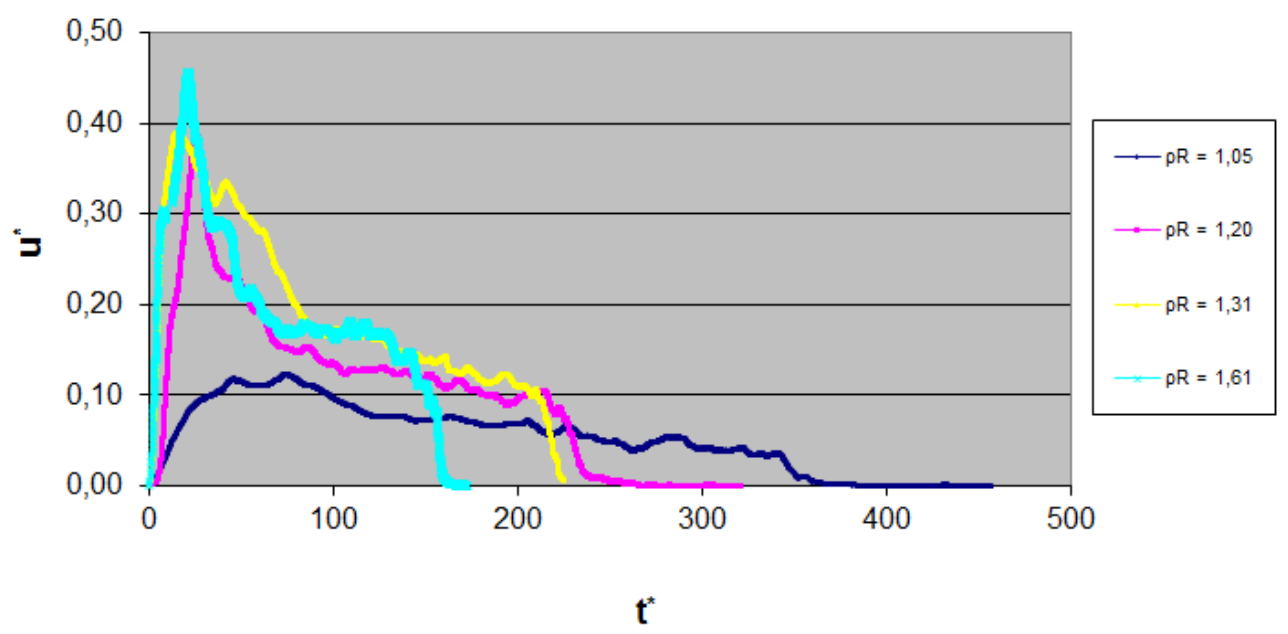

Gráfico 22 - Velocidade Interfacial vs. Tempo $\left(\mathrm{L}^{*}=10, \eta_{R}=0,50\right)$

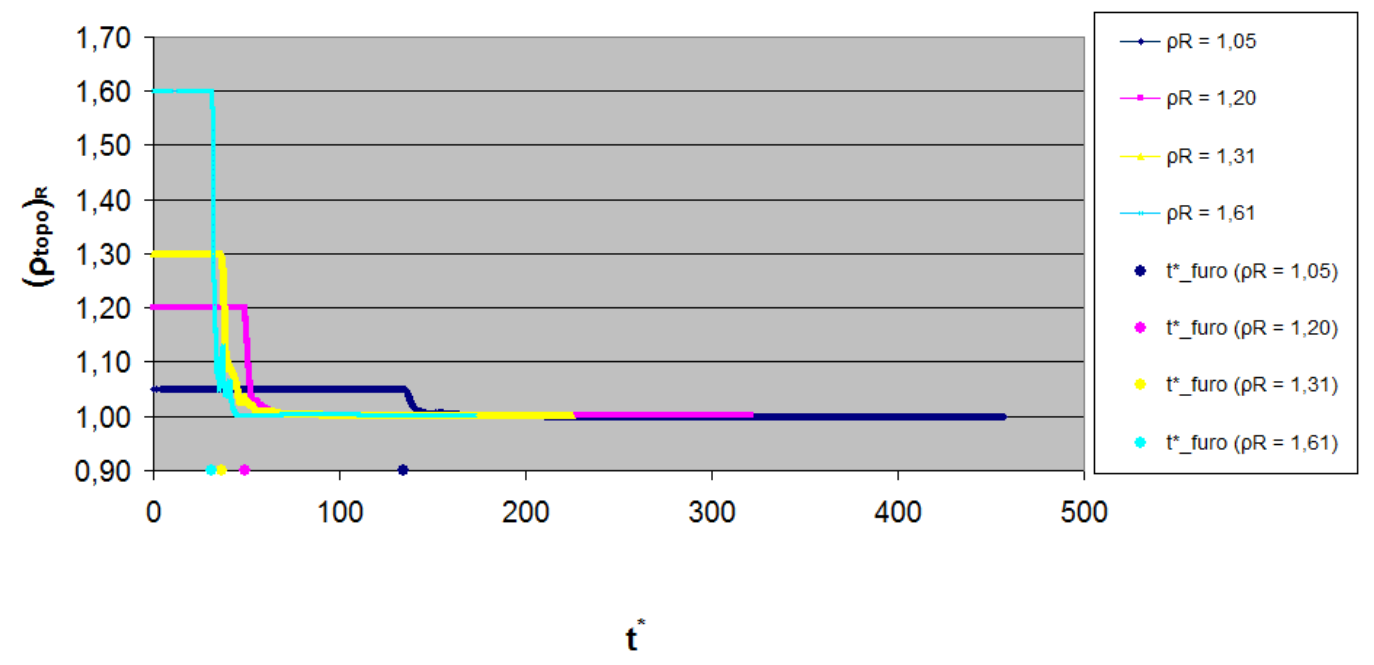

Gráfico 23 - Densidade da mistura no topo vs. Tempo $\left(\mathrm{L}^{*}=10, \eta_{R}=0,50\right)$

Da mesma forma que no caso anterior, quanto maiores são as razões entre densidades, maiores são as velocidades terminais e interfaciais alcançadas. Além disso, foi observado que os tempos de furo e deposição aumentam à medida que essas razões decrescem. Abaixo, pode-se visualizar de forma mais clara nos dois gráficos e na tabela o efeito que a razão entre densidades exerce sobre a velocidade terminal e os tempos de furo e deposição: 


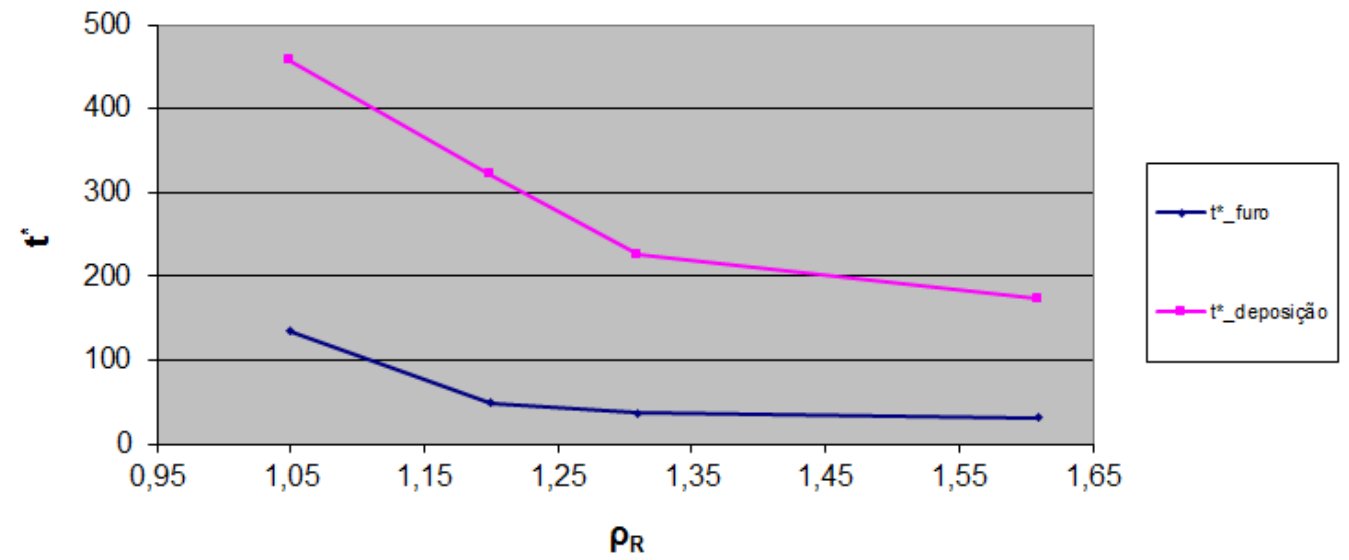

Gráfico 24 - Tempos de furo e deposição vs. Razão entre Densidades $\left(L^{*}=10, \eta_{R}=0,50\right)$

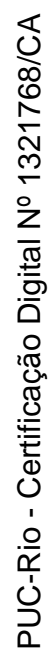

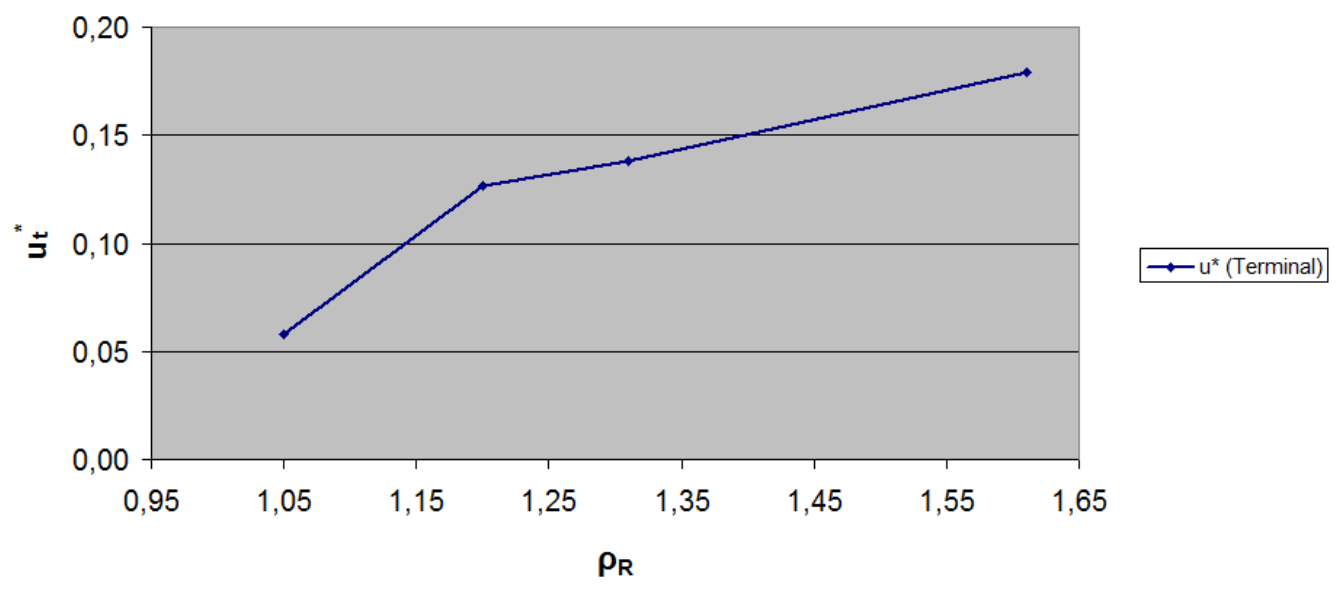

Gráfico 25 - Velocidade terminal vs. Razão entre Densidades $\left(\mathrm{L}^{*}=10, \eta_{R}=0,50\right)$

\begin{tabular}{|c|c|c|c|c|c|}
\hline$L^{*}$ & $\eta_{R}$ & $\rho_{R}$ & $t^{*}{ }_{\text {furo }}$ & $t^{*}{ }_{\text {deposição }}$ & $u_{t}{ }^{*}$ \\
\hline \multirow{3}{*}{10} & \multirow{3}{*}{0,50} & 1,05 & 134,68 & 456,67 & 0,06 \\
\cline { 3 - 6 } & & 1,20 & 48,97 & 321,27 & 0,13 \\
\cline { 3 - 6 } & & 1,31 & 36,55 & 225,07 & 0,14 \\
\cline { 3 - 6 } & & 1,61 & 31,46 & 172,65 & 0,18 \\
\hline
\end{tabular}

Tabela 8 - Velocidade Terminal e Tempos de furo e deposição $\left(\mathrm{L}^{*}=10, \eta_{R}=0,50\right)$ 
A figura seguinte ilustra de forma mais nítida o escoamento para duas diferentes densidades para $\eta_{R}=0,50$ :

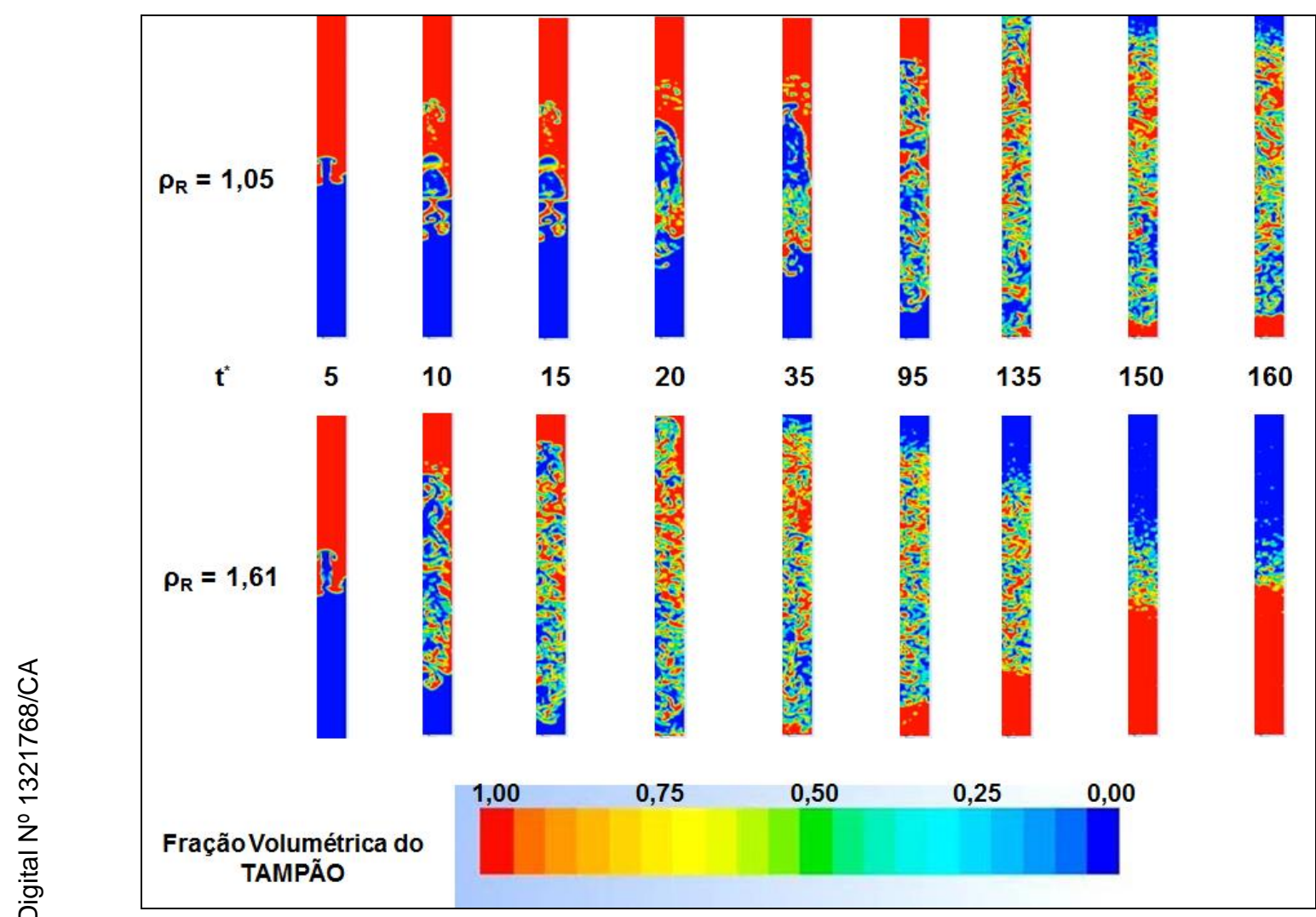

Figura 4 - Perfil do escoamento para $\rho_{R}=1,05$ e $\rho_{R}=1,61$ para $\eta_{R}=0,50$

Abaixo, o mesmo estudo é realizado, mas com uma razão maior entre viscosidades $\left(\eta_{R}=0,75\right)$ :

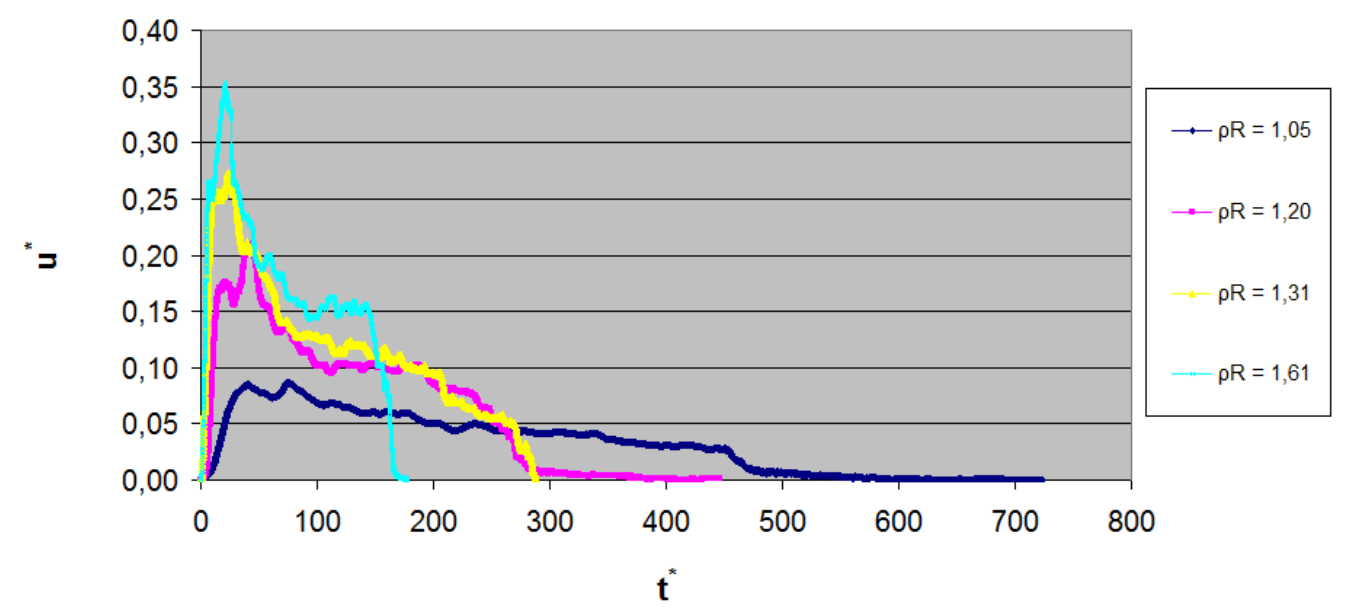

Gráfico 26 - Velocidade Interfacial vs. Tempo $\left(\mathrm{L}^{*}=10, \eta_{R}=0,75\right)$ 


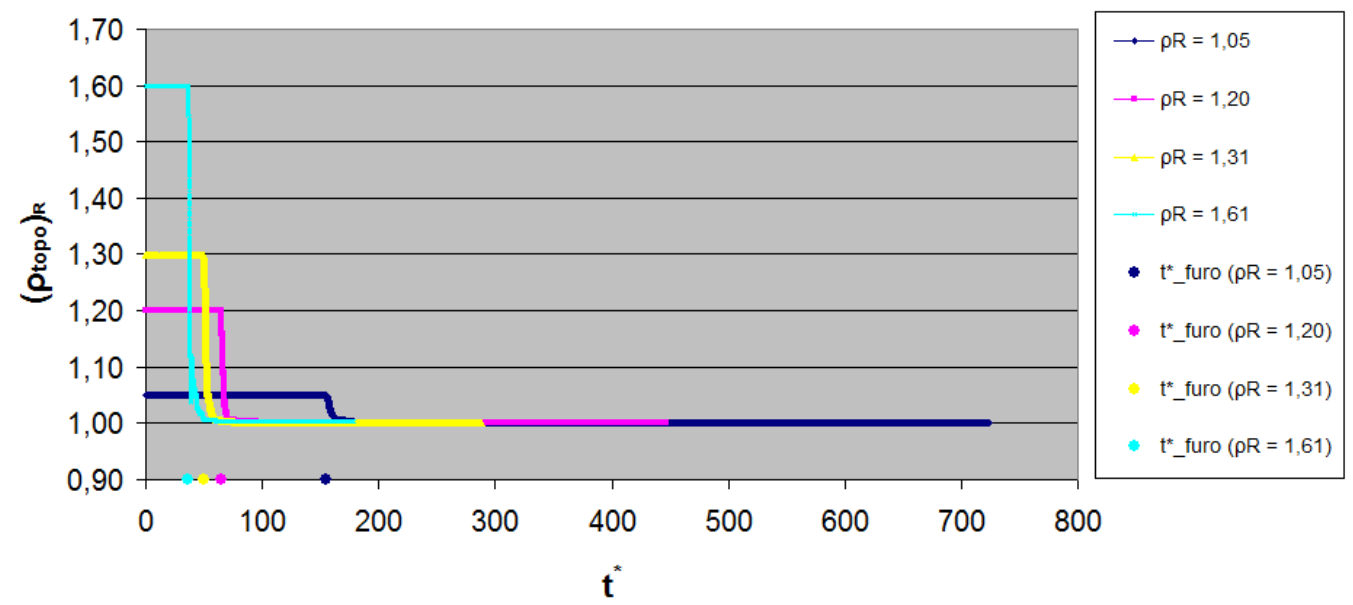

Gráfico 27 - Densidade da mistura no topo vs. Tempo $\left(\mathrm{L}^{*}=10, \eta_{R}=0,75\right)$

Aumentando-se a razão entre viscosidades $\left(\eta_{R}=0,75\right)$, notou-se que os tempos de furos não só continuam sendo inversamente proporcionais à razão entre densidades como também razões baixas entre densidades $\left(\rho_{R}=1,05\right)$ exercem uma influência maior no tempo de furo do que para uma razão mais baixa entre viscosidades. Para complementar, também foi notado que o comprimento do intervalo de tempo no qual o regime é praticamente permanente é inversamente proporcional à razão entre densidades. Além disso, a velocidade terminal e a velocidade na interface são diretamente proporcionais à razão entre densidades. A deposição do tampão é diretamente inversamente proporcional à razão entre densidades.

A seguir, a influência exercida pela razão entre densidades sobre a velocidade terminal e os tempos de furo e deposição é mostrada através de dois gráficos e uma tabela: 


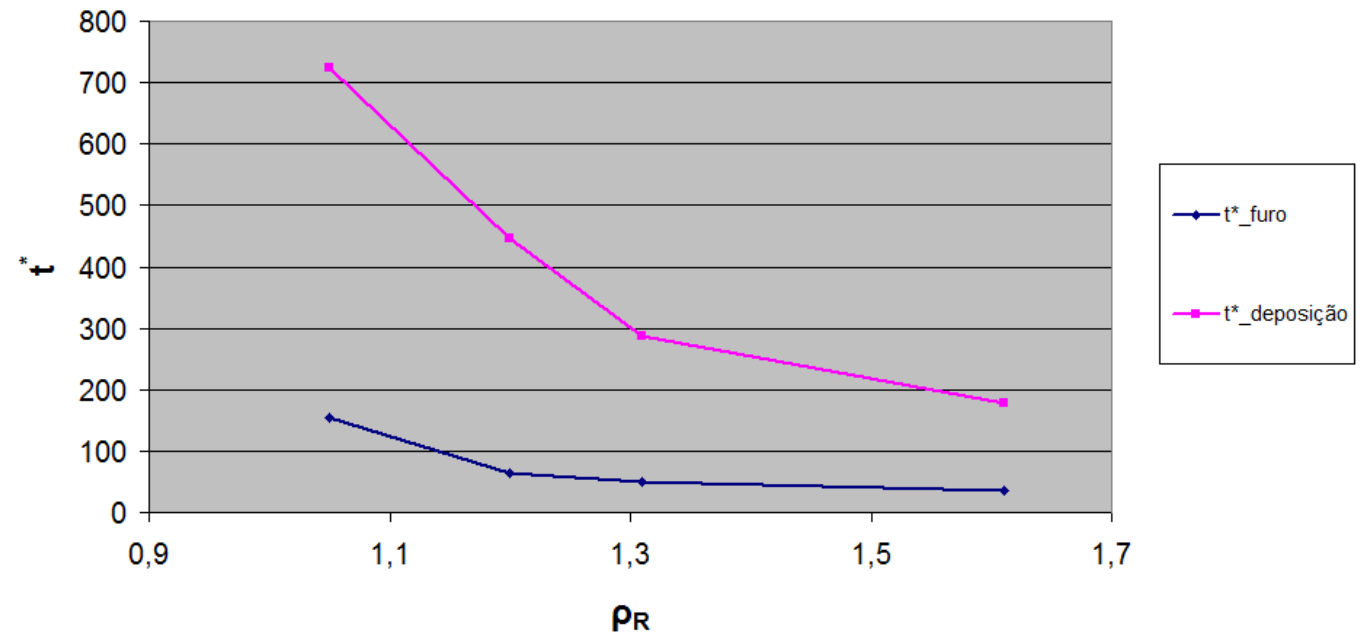

Gráfico 28 - Tempos de furo e deposição vs. Razão entre Densidades $\left(\mathrm{L}^{*}=10, \eta_{R}=0,75\right)$

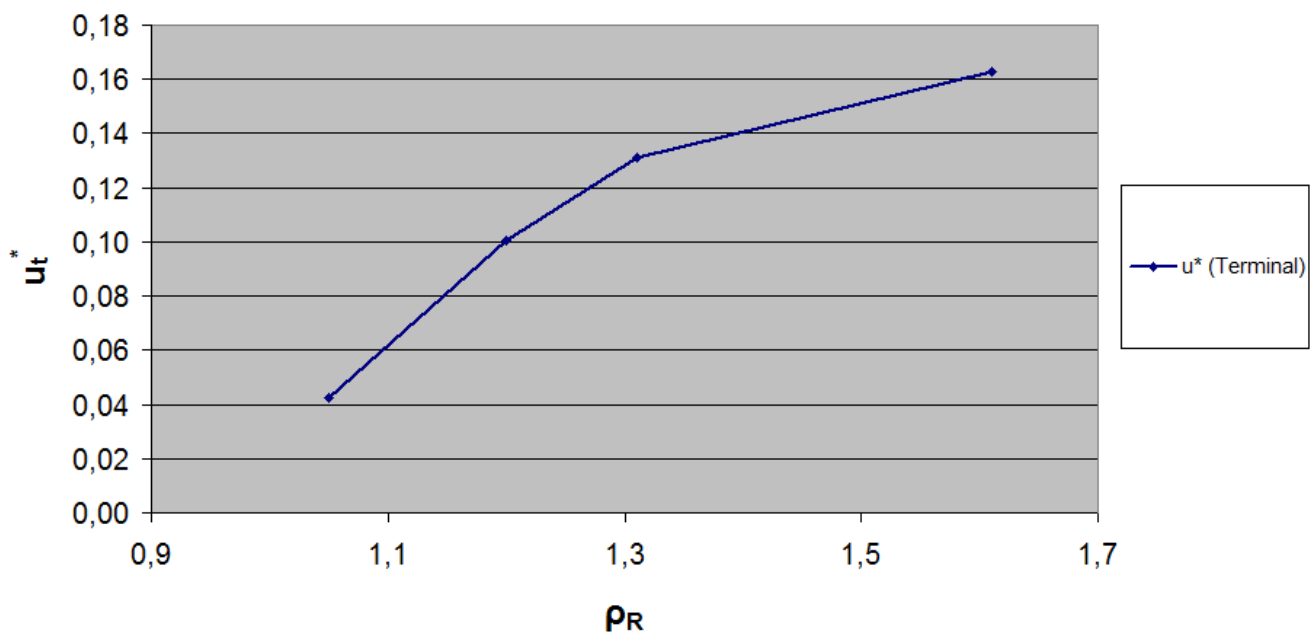

Gráfico 29 - Velocidade Terminal vs. Razão entre Densidades $\left(\mathrm{L}^{*}=10, \eta_{R}=0,75\right)$

\begin{tabular}{|c|c|c|c|c|c|}
\hline$L^{*}$ & $\eta_{R}$ & $\rho_{R}$ & $t^{*}{ }_{\text {furo }}$ & $t^{*}{ }_{\text {deposição }}$ & $u_{t}{ }^{*}$ \\
\hline \multirow{3}{*}{10} & \multirow{3}{*}{0,75} & 1,05 & 155,09 & 724,01 & 0,043 \\
\cline { 3 - 6 } & & 1,20 & 64,48 & 446,19 & 0,101 \\
\cline { 3 - 6 } & & 1,31 & 49,57 & 288,05 & 0,131 \\
\cline { 3 - 6 } & & 1,61 & 36,51 & 178,05 & 0,163 \\
\hline
\end{tabular}

Tabela 9 - Velocidade Terminal e Tempos de furo e deposição $\left(\mathrm{L}^{*}=10, \eta_{R}=0,75\right)$ 
Em seguida, aumenta-se viscosidade do tampão mais uma vez, de forma que a razão entre viscosidades é alterada de $\eta_{R}=0,75$ para $\eta_{R}=1,00$ :

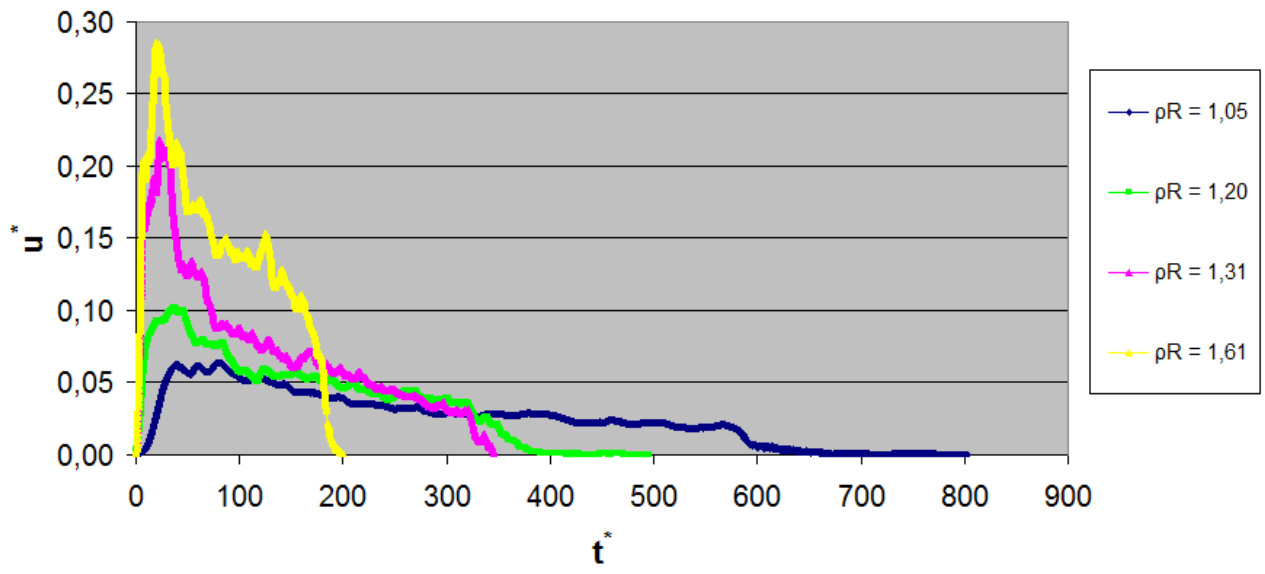

Gráfico 30 - Velocidade Interfacial vs. Tempo $\left(\mathrm{L}^{*}=10, \eta_{R}=1,00\right)$

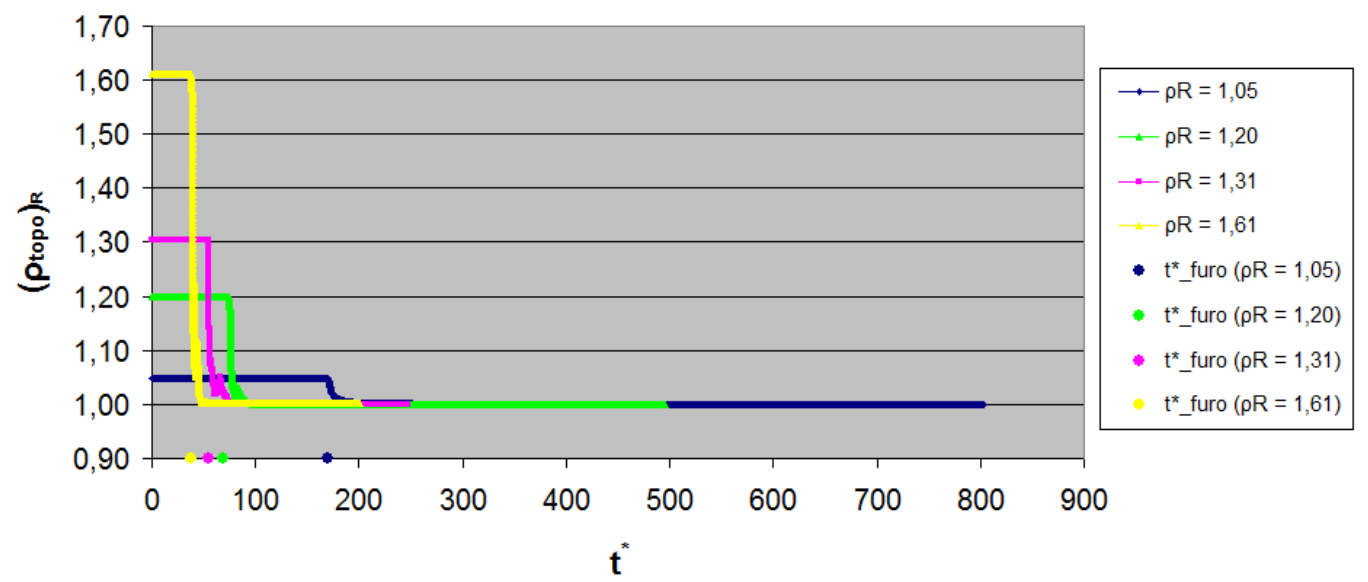

Gráfico 31 - Densidade da mistura no topo vs. Tempo $\left(\mathrm{L}^{*}=10, \eta_{R}=1,00\right)$

Os gráficos acima mostram que, quando as viscosidades do tampão e do fluido de perfuração são iguais, os tempos de furos e deposição aumentam conforme a razão entre densidades diminui. Além disso, é observado que a velocidade terminal e a faixa de velocidades interfaciais são diretamente proporcionais à razão entre densidades. 
A seguir, são apresentados a velocidade terminal e os tempos de furo e deposição graficamente e através de uma tabela, enfatizando o efeito que a razão entre densidades exerce sobre esses parâmetros:

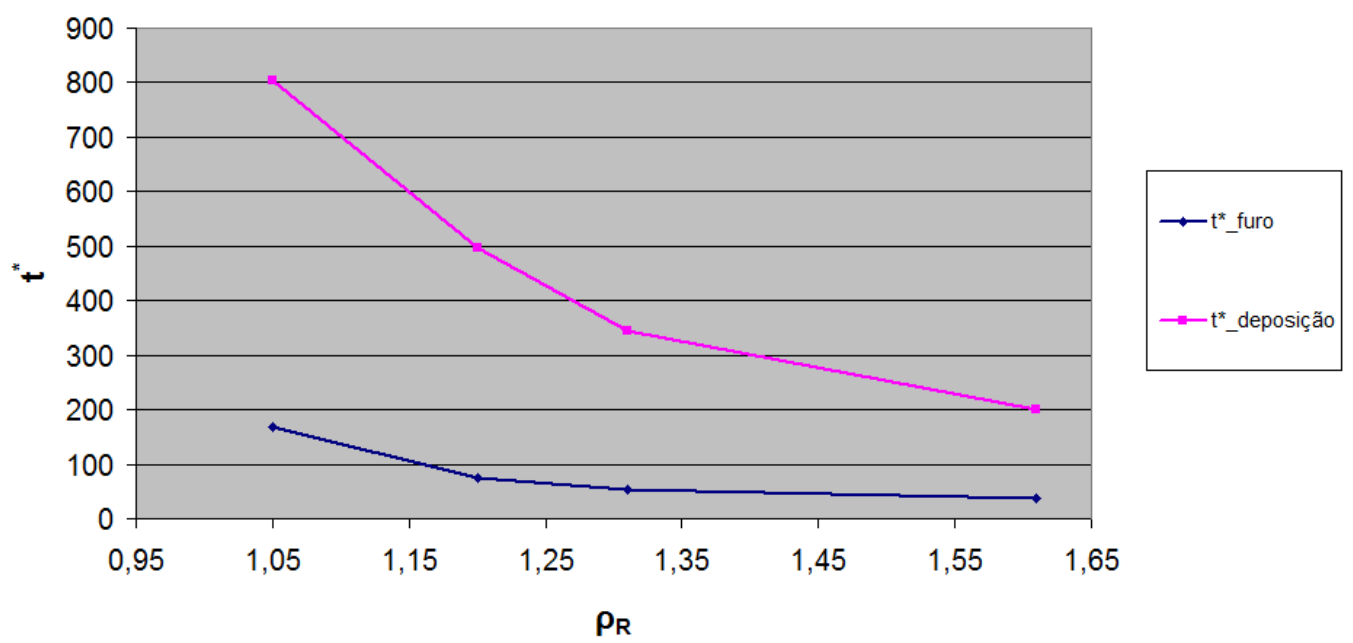

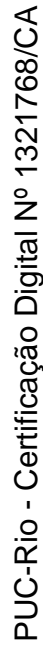

Gráfico 32 - Tempos de furo e deposição vs. Razão entre Densidades $\left(\mathrm{L}^{*}=10, \eta_{R}=1,00\right)$

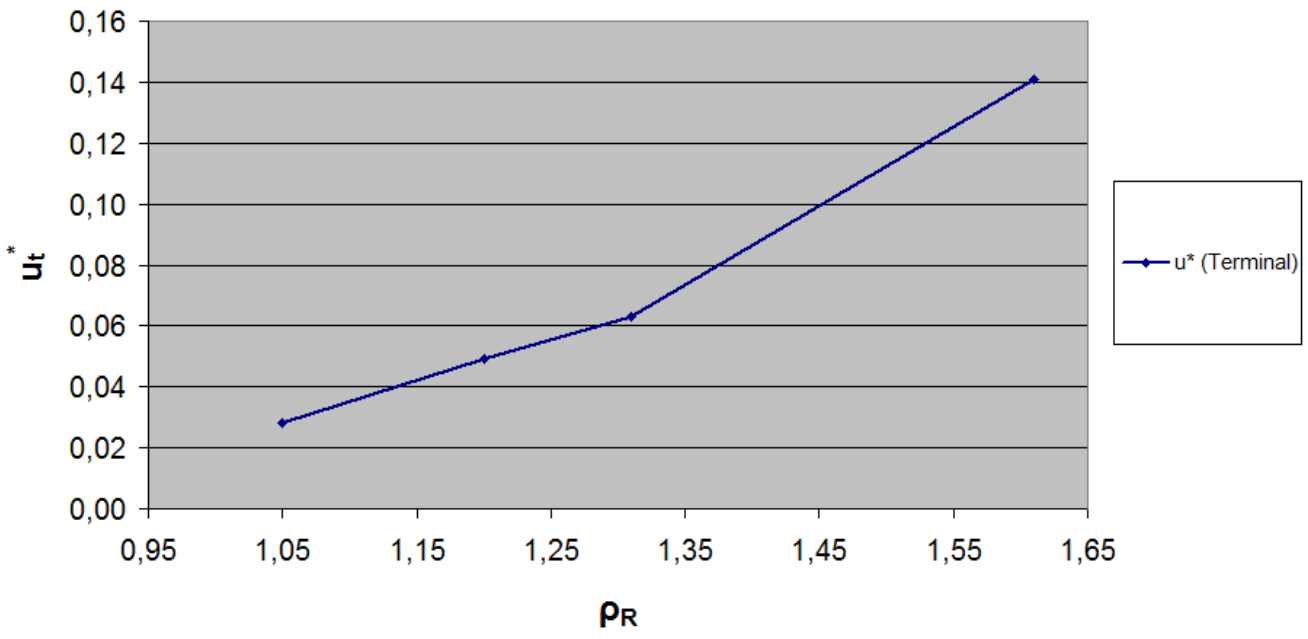

Gráfico 33 - Velocidade Terminal vs. Razão entre Densidades $\left(\mathrm{L}^{*}=10, \eta_{R}=1,00\right)$ 


\begin{tabular}{|c|c|c|c|c|c|}
\hline$L^{*}$ & $\eta_{R}$ & $\rho_{R}$ & $t^{{ }^{*}}{ }_{\text {furo }}$ & $t^{{ }^{*}}{ }_{\text {deposiçã }}$ & $u_{t}{ }^{{ }^{*}}$ \\
\hline \multirow{3}{*}{10} & \multirow{3}{*}{1,00} & 1,05 & 169,33 & 803,67 & 0,028 \\
\cline { 3 - 6 } & & 1,20 & 74,37 & 495,84 & 0,049 \\
\cline { 3 - 6 } & & 1,31 & 54,14 & 345,66 & 0,063 \\
\cline { 3 - 6 } & & 1,61 & 38,39 & 200,24 & 0,141 \\
\hline
\end{tabular}

Tabela 10 - Velocidade Terminal e Tempos de furo e deposição $\left(\mathrm{L}^{*}=10, \eta_{R}=1,00\right)$

A tabela e os gráficos seguintes mostram a influência da razão entre densidades dos dois fluidos nas velocidades terminais e nos tempos de furo e deposição de todos os casos em que o efeito da razão entre viscosidades foi analisado:

\begin{tabular}{|c|c|c|c|c|c|}
\hline$L^{*}$ & $\eta_{R}$ & $\rho_{R}$ & $t_{\text {furo }}^{*}$ & $t^{*}{ }_{\text {deposição }}$ & $u_{t}^{*}$ \\
\hline \multirow{2}{*}{5} & \multirow{2}{*}{1,00} & 1,05 & 73,32 & 393,15 & - \\
\hline & & 1,20 & 28,02 & 352,68 & - \\
\hline \multirow{12}{*}{10} & \multirow{4}{*}{0,50} & 1,05 & 134,68 & 456,67 & 0,058 \\
\hline & & 1,20 & 48,97 & 321,27 & 0,126 \\
\hline & & 1,31 & 36,55 & 225,07 & 0,138 \\
\hline & & 1,61 & 31,46 & 172,65 & 0,179 \\
\hline & \multirow{4}{*}{0,75} & 1,05 & 155,09 & 724,01 & 0,043 \\
\hline & & 1,20 & 64,48 & 446,19 & 0,101 \\
\hline & & 1,31 & 49,57 & 288,05 & 0,131 \\
\hline & & 1,61 & 36,51 & 178,05 & 0,163 \\
\hline & \multirow{4}{*}{1,00} & 1,05 & 169,33 & 803,67 & 0,028 \\
\hline & & 1,20 & 74,37 & 495,84 & 0,049 \\
\hline & & 1,31 & 54,14 & 345,66 & 0,063 \\
\hline & & 1,61 & 38,39 & 200,24 & 0,141 \\
\hline
\end{tabular}

Tabela 11 - Resultados para diferentes razões entre densidades 


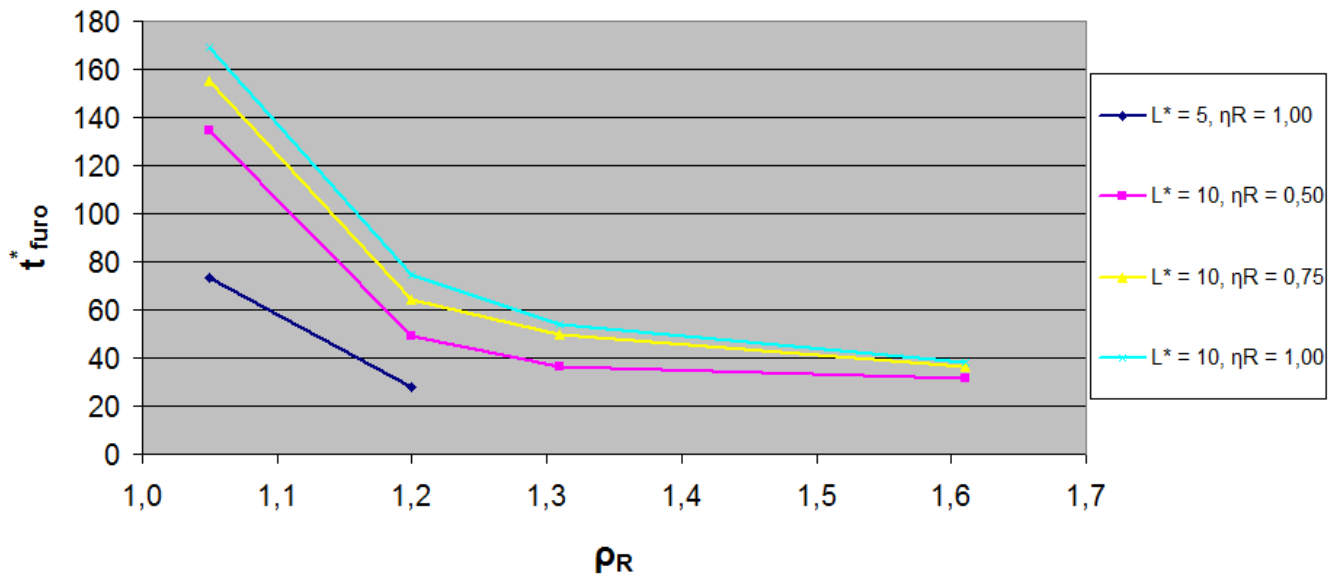

Gráfico 34 - Tempo de Furo vs. Razão entre Densidades

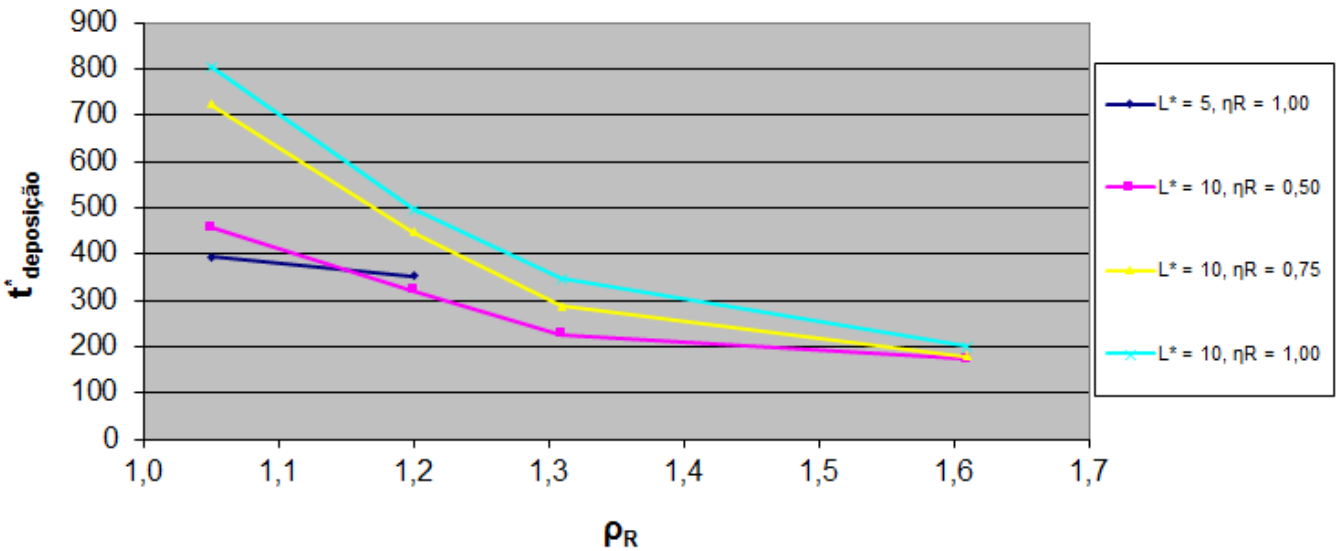

Gráfico 35 - Tempo de Deposição vs. Razão entre Densidades 


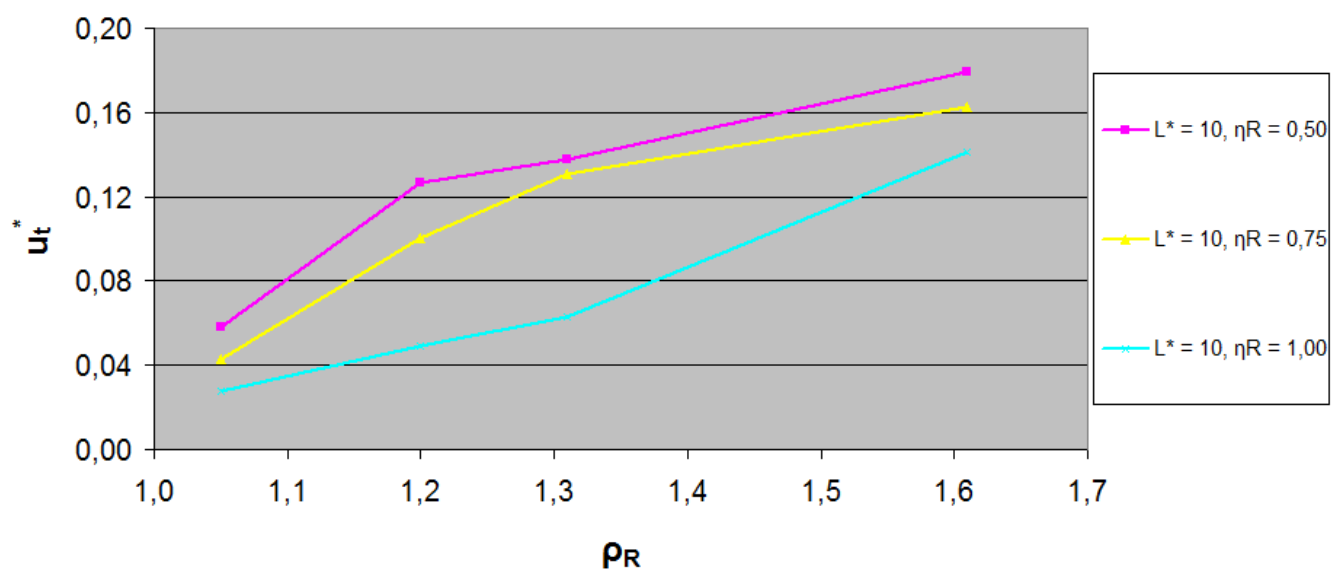

Gráfico 36 - Velocidade Terminal vs. Razão entre Densidades

\subsection{Influência da Razão Entre Viscosidades}

Após a análise do efeito provocado pela modificação da razão entre densidades, prosseguiu-se o estudo com a investigação da influência causada pela razão entre viscosidades (para uma mesma razão entre densidades), iniciando-se a investigação paramétrica para $\rho_{R}=1,05$. A seguir, podemos observar graficamente o efeito que o incremento na razão entre as viscosidades (causado pelo aumento na viscosidade da pasta de cimento) exerce sobre a velocidade da interface entre os fluidos e sobre o tempo de furo:

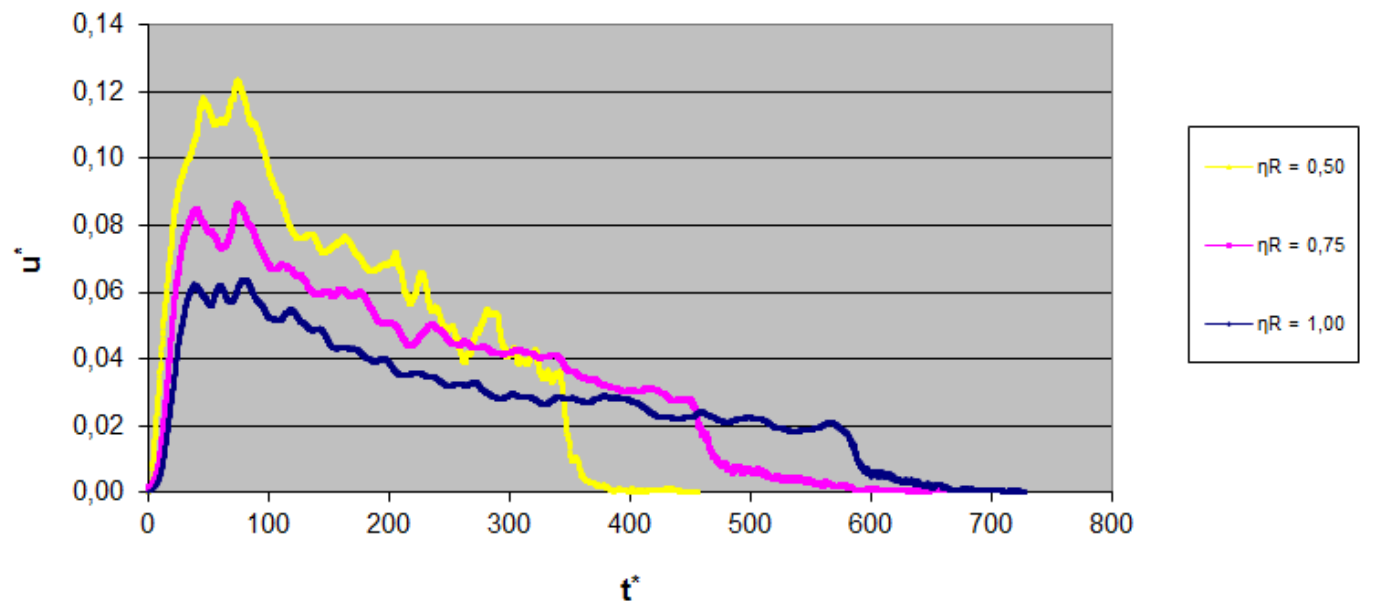

Gráfico 37 - Velocidade Interfacial vs. Tempo $\left(\mathrm{L}^{*}=10, \rho_{R}=1,05\right)$ 


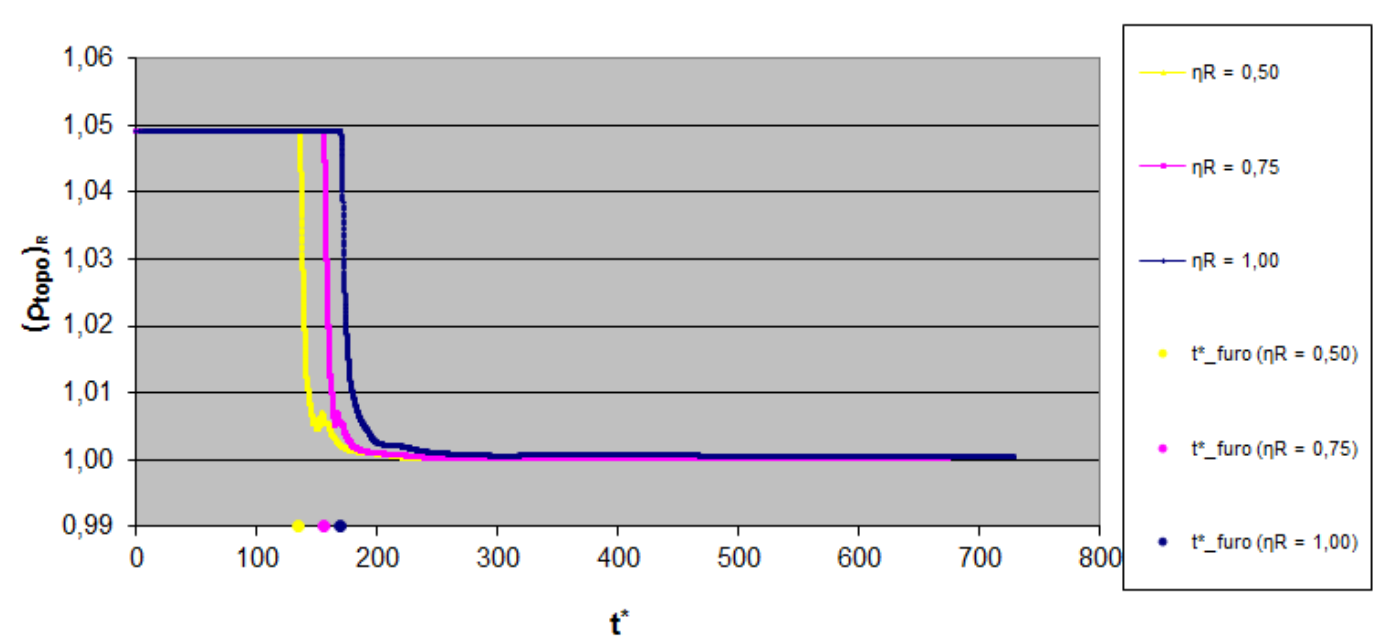

Gráfico 38 - Densidade da mistura no topo vs. Tempo $\left(\mathrm{L}^{*}=10, \rho_{R}=1,05\right)$

Com base nos gráficos acima, pode-se dizer que a velocidade terminal e interfacial aumentam conforme a razão entre viscosidades diminui sendo, portanto, grandezas inversamente proporcionais. Além disso, observa-se que os tempos de furo e deposição aumentam quanto maior for esta razão, o que significa que essas grandezas são diretamente proporcionais. Estas duas relações podem ser explicadas pelo fato de quanto maior a razão entre viscosidades, maior é a resistência ao escoamento e, conseqüentemente, a interface entre os fluidos se move de forma mais lenta e a deposição do cimento é mais demorada da mesma forma que a contaminação.

O efeito da razão entre viscosidades nos tempos de furo e deposição e na velocidade terminal é melhor observado por meio dos dois gráficos a seguir: 


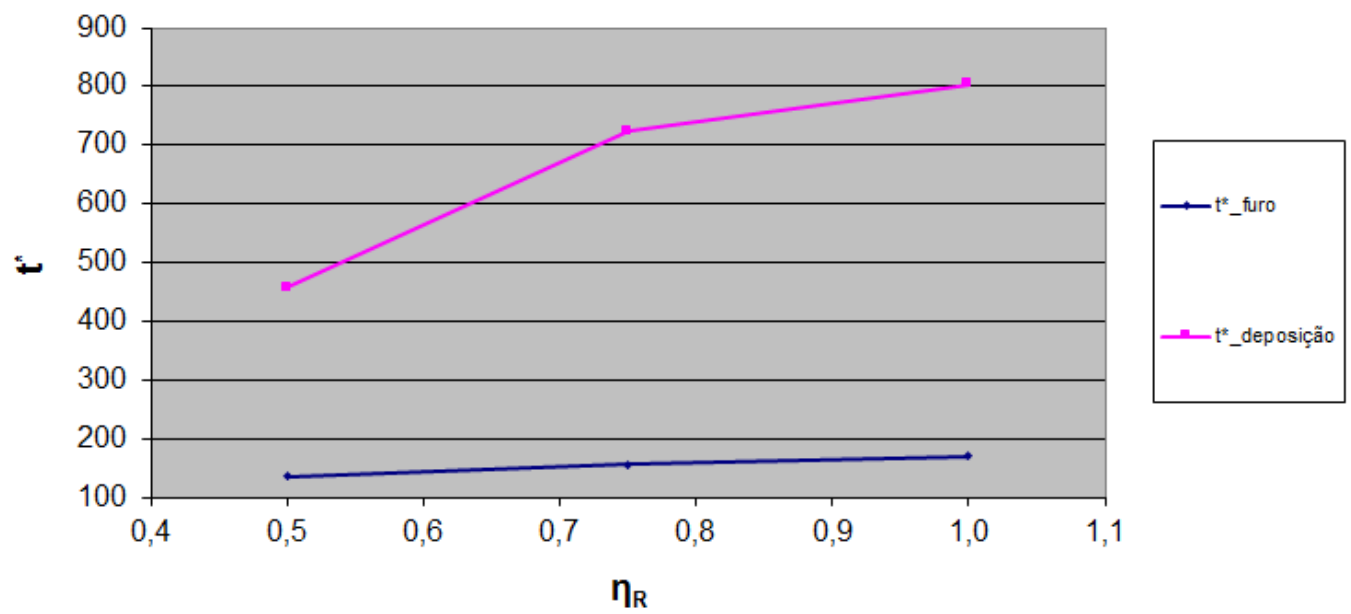

Gráfico 39 - Tempos de furo e deposição vs. Razão entre Viscosidades $\left(\mathrm{L}^{*}=10, \rho_{R}=1,05\right)$

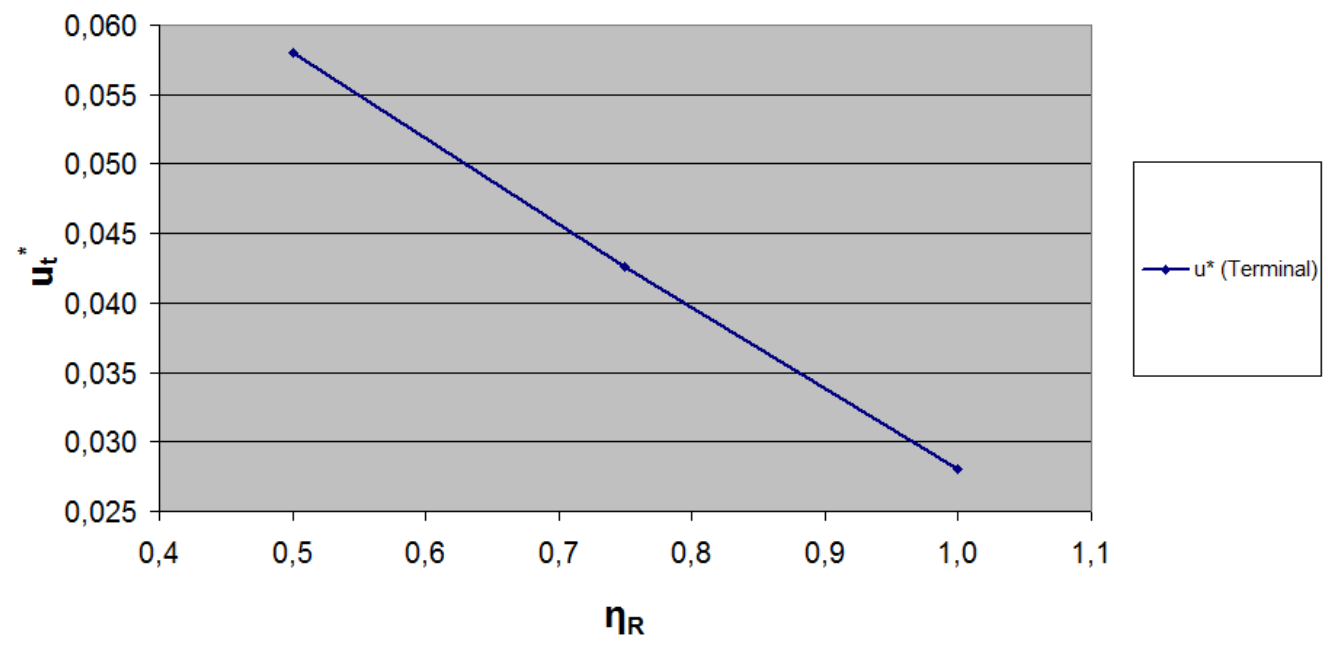

Gráfico 40 - Velocidade Terminal vs. Razão entre Viscosidades $\left(\mathrm{L}^{*}=10, \rho_{R}=1,05\right)$

A tabela a seguir contém os valores da velocidade terminal e dos tempos de furo e deposição de cada caso em que variou-se a razão entre viscosidades, mantendo-se a razão entre densidades igual a 1,05:

\begin{tabular}{|c|c|c|c|c|c|}
\hline$L^{*}$ & $\rho_{R}$ & $\eta_{R}$ & $t^{*}{ }_{\text {furo }}$ & $t^{*}{ }_{\text {deposição }}$ & $u_{t}{ }^{*}$ \\
\hline \multirow{3}{*}{10} & \multirow{3}{*}{1,05} & 0,50 & 134,68 & 456,67 & 0,058 \\
\cline { 3 - 6 } & & 0,75 & 155,09 & 724,01 & 0,043 \\
\cline { 3 - 6 } & & 1,00 & 169,33 & 803,67 & 0,028 \\
\hline
\end{tabular}

Tabela 12 - Velocidade Terminal e Tempos de furo e deposição $\left(\mathrm{L}^{*}=10, \rho_{R}=1,05\right)$ 
A seguir, é apresentada uma figura que mostra de modo mais nítido o efeito do aumento da razão entre viscosidades no processo de tamponamento para $\rho_{R}=1,05:$

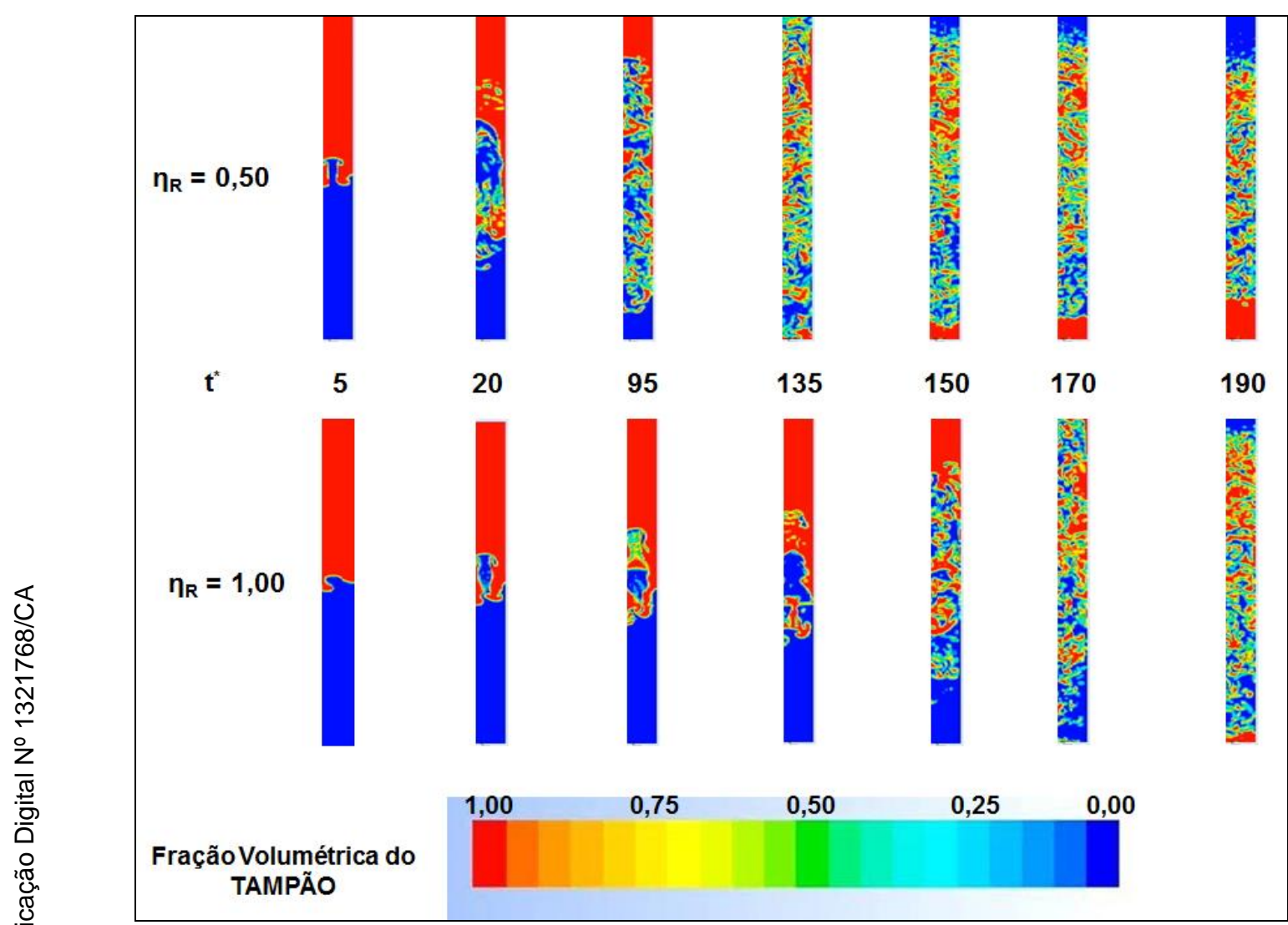

Figura 5 - Perfil do escoamento para $\eta_{R}=0,50$ e $\eta_{R}=1,00$ para $\rho_{R}=1,05$

Abaixo, são apresentados os gráficos para uma razão entre densidades maior $\left(\rho_{R}=1,20\right)$ : 


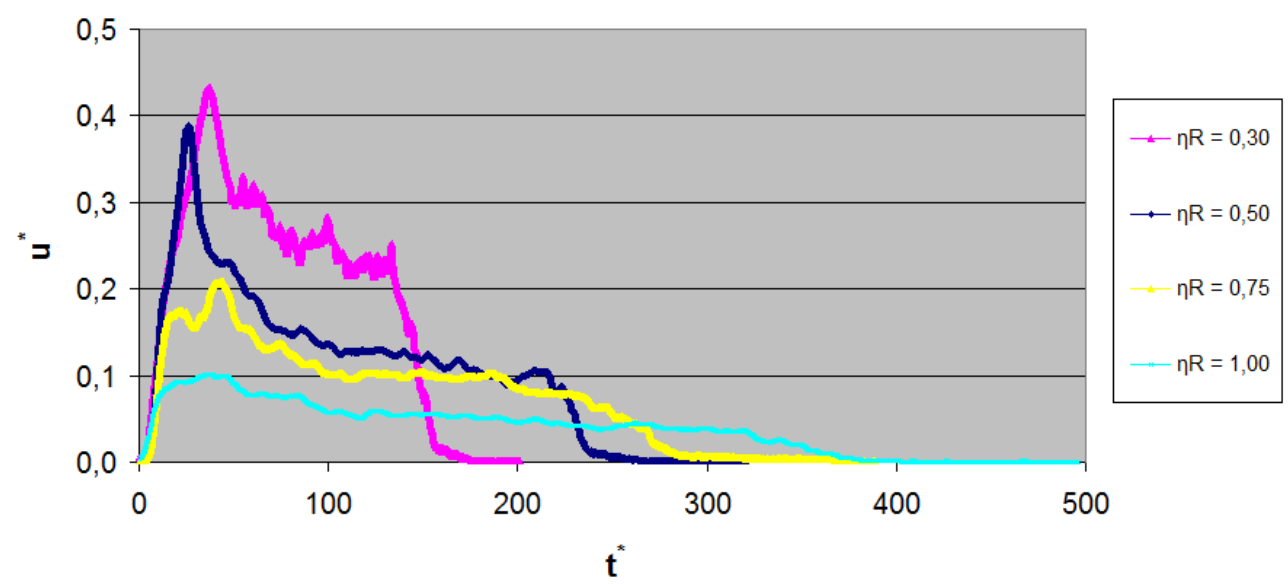

Gráfico 41 - Velocidade Interfacial vs. Tempo $\left(\mathrm{L}^{*}=10, \rho_{R}=1,20\right)$

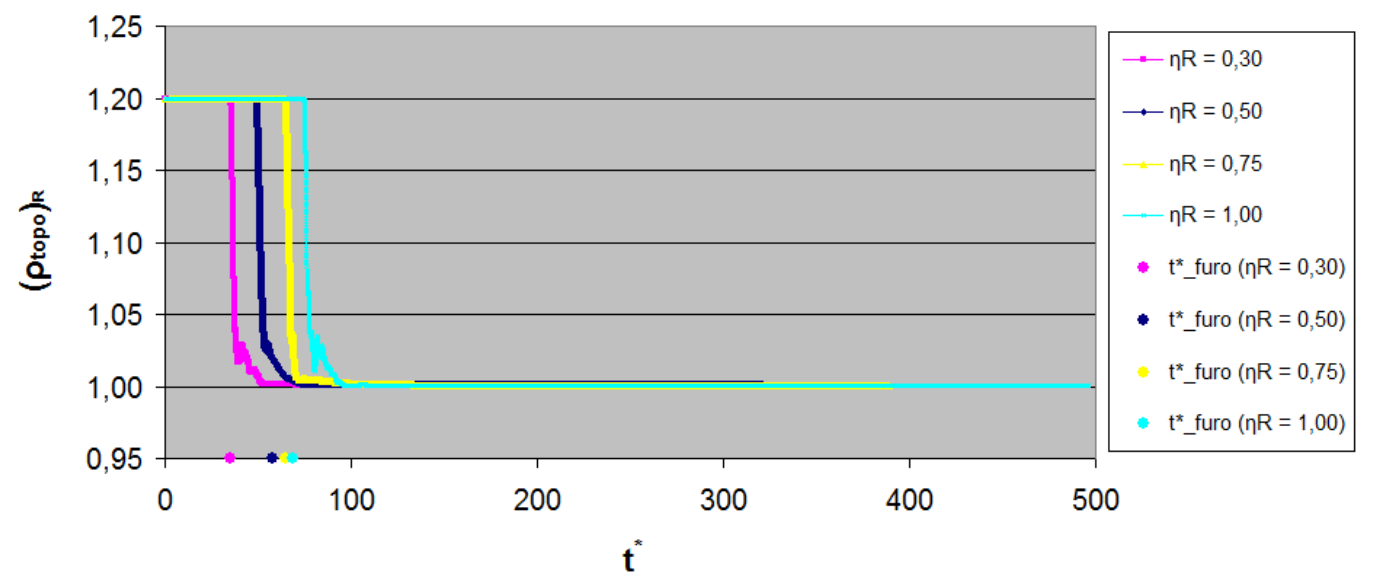

Gráfico 42 - Densidade da mistura no topo vs. Tempo $\left(\mathrm{L}^{*}=10, \rho_{R}=1,20\right)$

Os gráficos acima mostram que, para $\rho_{R}=1,20$, os tempo de furo e deposição aumentam conforme a razão entre viscosidades também aumenta. Para esta mesma razão entre densidades, razões elevadas entre viscosidades $\left(\eta_{R} \geq 0,75\right)$ passam a influenciar cada vez menos o furo e a deposição. Quanto às velocidades interfacial e terminal, é observado que, apesar de o perfil de velocidades ser similar, as faixas de velocidades interfaciais são mais amplas da mesma forma que as velocidades terminais aumentam para razões menores entre viscosidades, configurando uma relação de proporcionalidade inversa. 
A seguir, são apresentados dois gráficos e uma tabela que demonstram o efeito da razão entre viscosidades na velocidade terminal e nos tempos de furo e deposição:

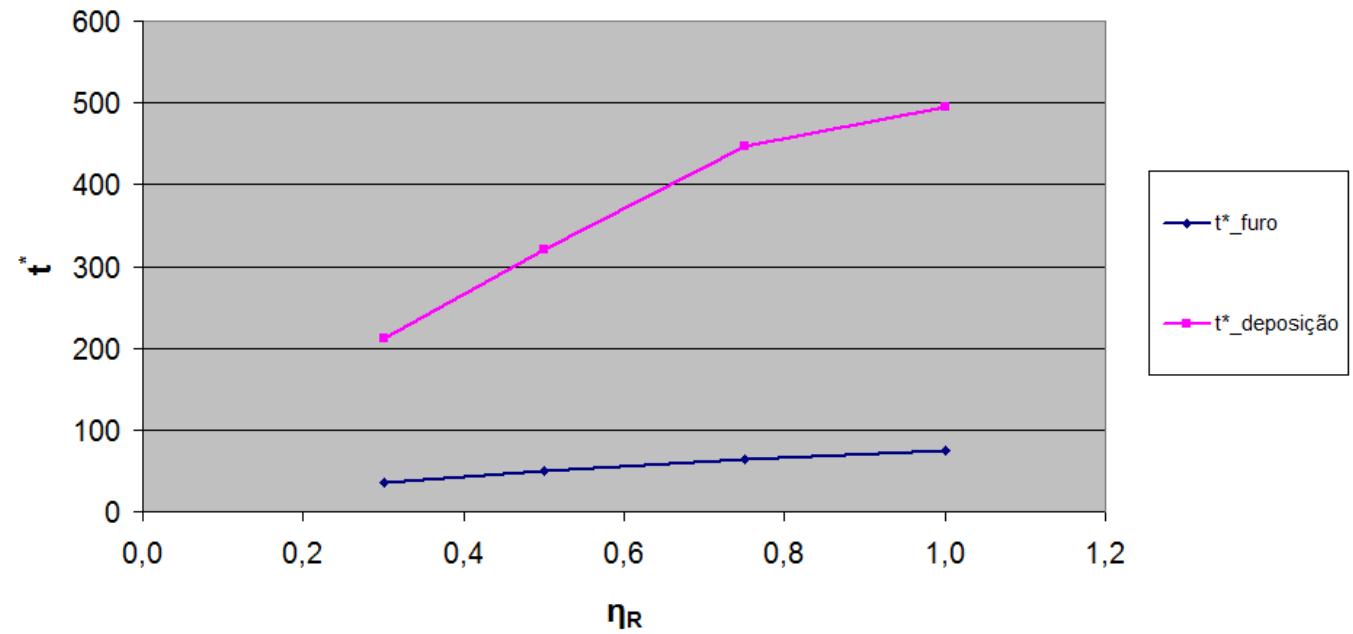

Gráfico 43 - Tempos de furo e deposição vs. Razão entre Viscosidades $\left(L^{*}=10, \rho_{R}=1,20\right)$

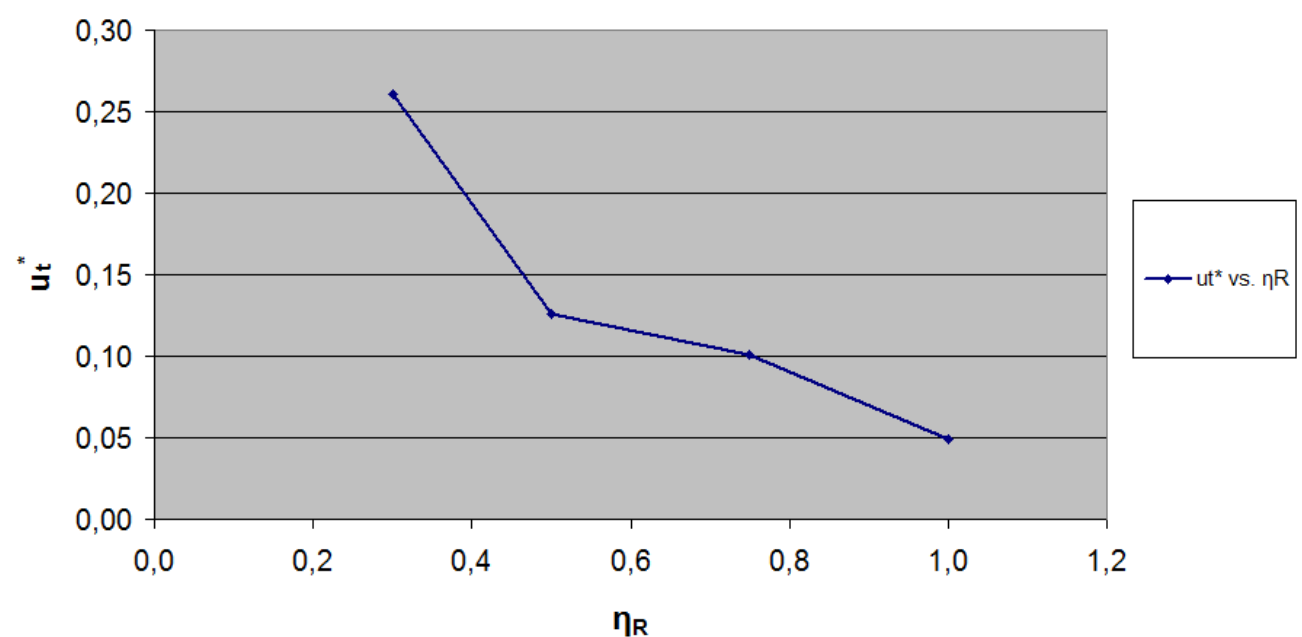

Gráfico 44 - Velocidade Terminal vs. Razão entre Viscosidades $\left(L^{*}=10, \rho_{R}=1,20\right)$ 


\begin{tabular}{|c|c|c|c|c|c|}
\hline$L^{*}$ & $\rho_{R}$ & $\eta_{R}$ & $t^{*}{ }_{\text {furo }}$ & $t^{*}{ }_{\text {deposição }}$ & $u_{t}{ }^{*}$ \\
\hline \multirow{3}{*}{10} & \multirow{3}{*}{1,20} & 0,30 & 35,35 & 212,15 & 0,26 \\
\cline { 3 - 6 } & & 0,50 & 48,97 & 321,27 & 0,13 \\
\cline { 3 - 6 } & & 0,75 & 64,48 & 446,19 & 0,10 \\
\cline { 3 - 6 } & & 1,00 & 74,37 & 495,84 & 0,05 \\
\hline
\end{tabular}

Tabela 13 - Velocidade Terminal e Tempos de furo e deposição $\left(\mathrm{L}^{*}=10, \rho_{R}=1,20\right)$

A seguir, são apresentados os gráficos para uma razão entre densidades superior $\left(\rho_{R}=1,31\right)$ :

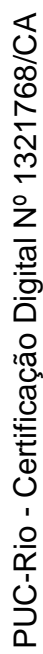

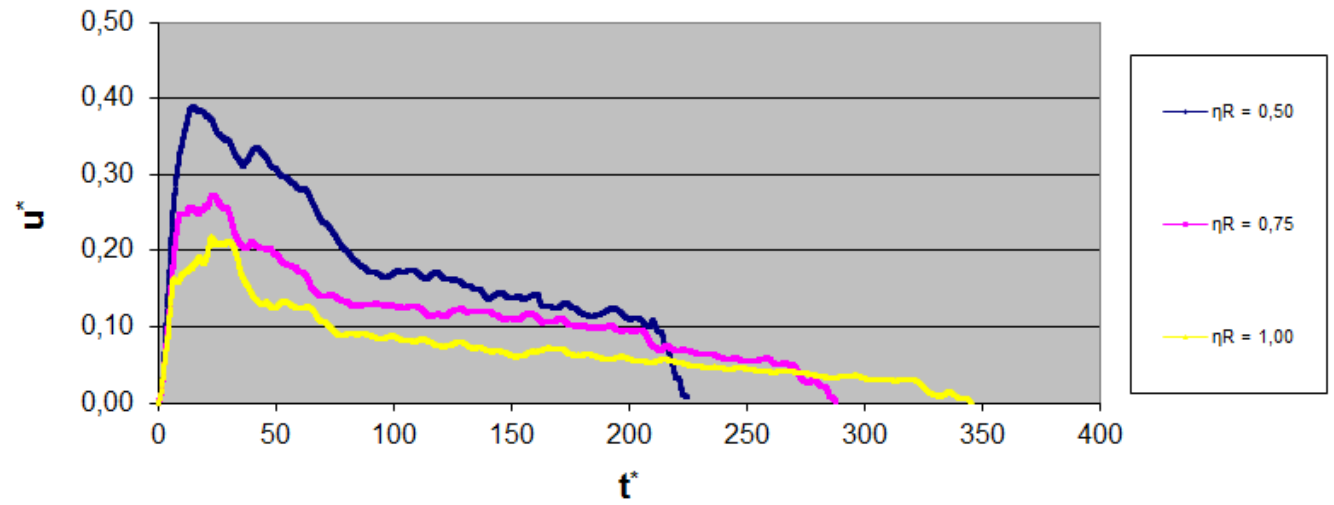

Gráfico 45 - Velocidade Interfacial vs. Tempo $\left(\mathrm{L}^{*}=10, \rho_{R}=1,31\right)$

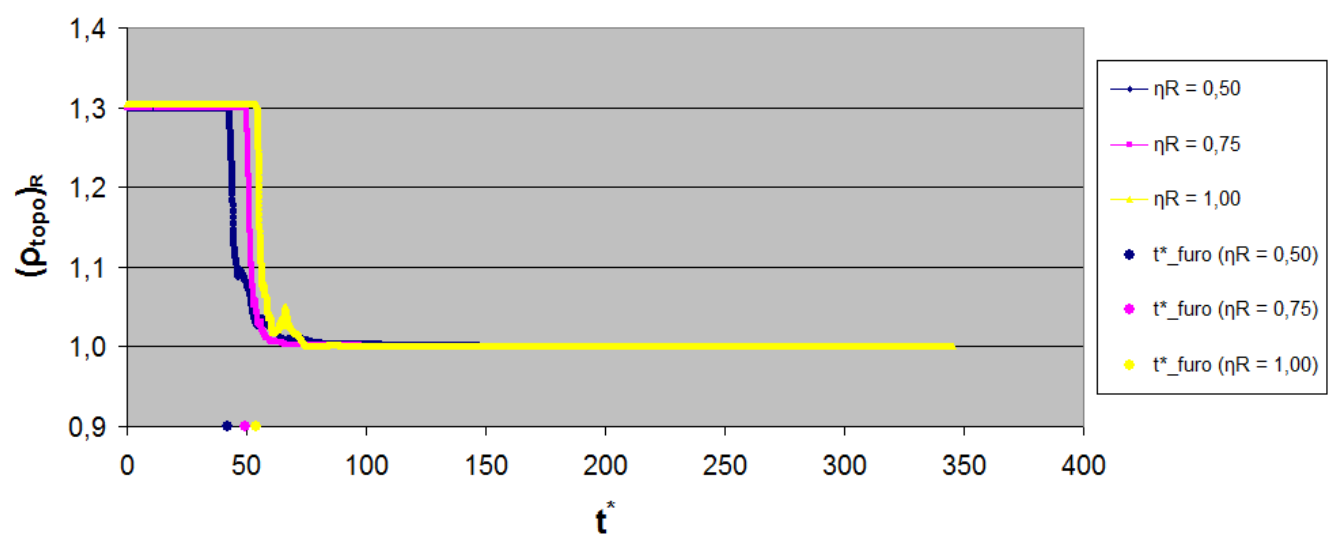

Gráfico 46 - Densidade da mistura no topo vs. Tempo $\left(\mathrm{L}^{*}=10, \rho_{R}=1,31\right)$ 
Os gráficos acima mostram que os tempos de furo e deposição são diretamente proporcionais à razão entre viscosidades. As velocidades terminais $\mathrm{e}$ interfaciais são inversamente proporcionais a esta razão.

A seguir, são mostrados dois gráficos e uma tabela que mostram a variação da velocidade terminal e dos tempos de furo e deposição com a razão entre viscosidades:

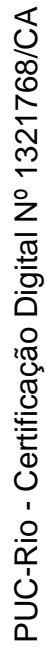

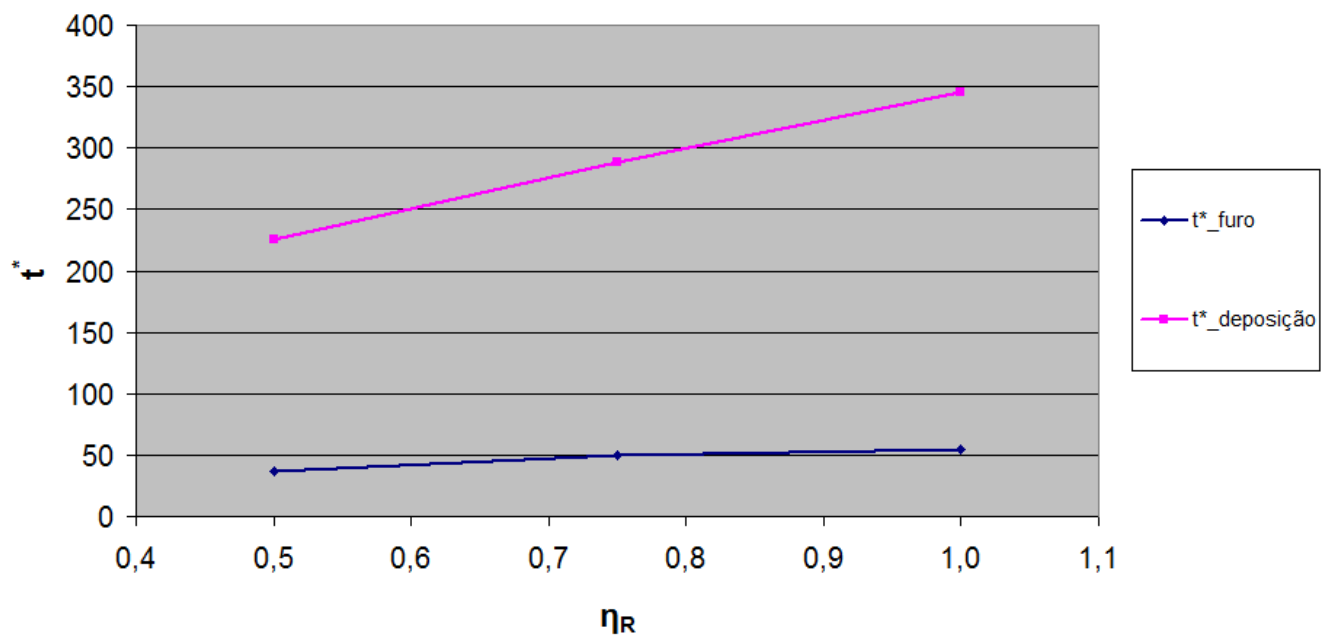

Gráfico 47 - Tempos de furo e deposição vs. Razão entre Viscosidades $\left(\mathrm{L}^{*}=10, \rho_{R}=1,31\right)$

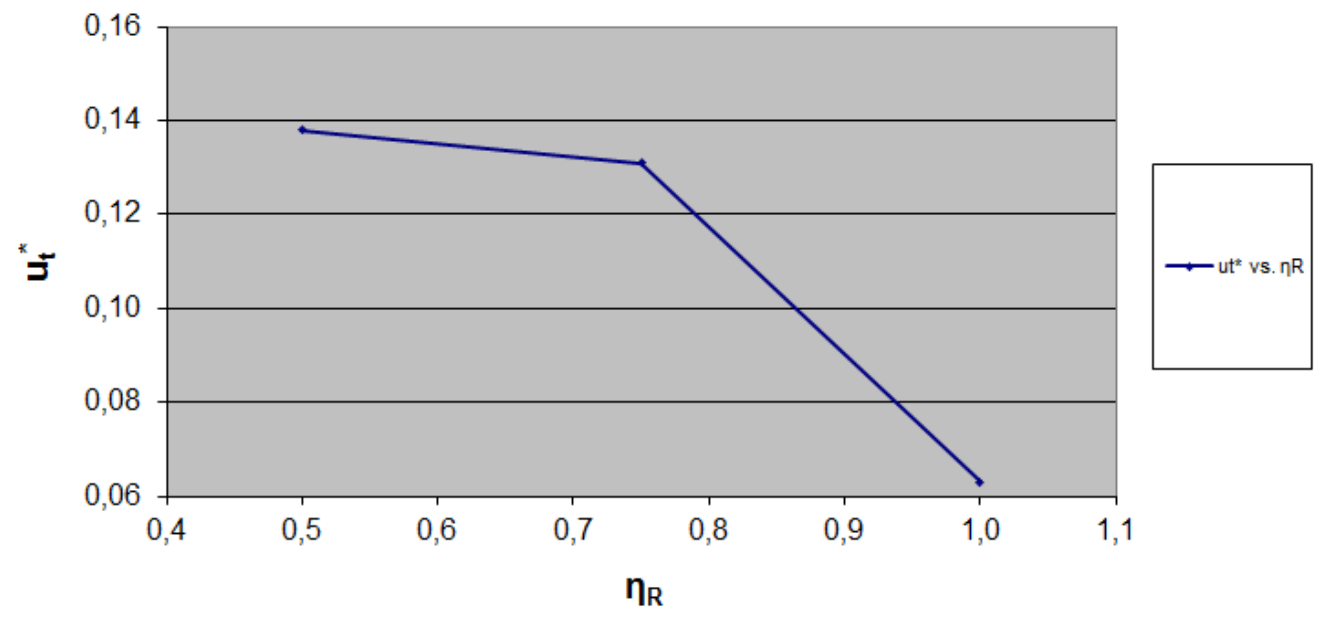

Gráfico 48 - Velocidade Terminal vs. Razão entre Viscosidades $\left(L^{*}=10, \rho_{R}=1,31\right)$ 


\begin{tabular}{|c|c|c|c|c|c|}
\hline \multirow{2}{*}{$L^{*}$} & $\rho_{R}$ & $\eta_{R}$ & $t^{*}{ }_{\text {furo }}$ & $t^{*}{ }^{*}{ }_{\text {deposição }}$ & $u_{t}{ }^{*}$ \\
\hline \multirow{3}{*}{10} & \multirow{3}{*}{1,31} & 0,50 & 36,55 & 225,07 & 0,138 \\
\cline { 3 - 6 } & & 0,75 & 49,57 & 288,05 & 0,131 \\
\cline { 3 - 6 } & & 1,00 & 54,14 & 345,66 & 0,063 \\
\hline
\end{tabular}

Tabela 14 - Velocidade Terminal e Tempos de furo e deposição $\left(\mathrm{L}^{*}=10, \rho_{R}=1,31\right)$

Em seguida, aumentou-se a razão entre densidades para 1,61. Os gráficos são exibidos abaixo:

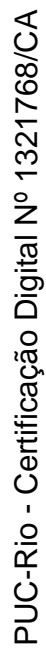

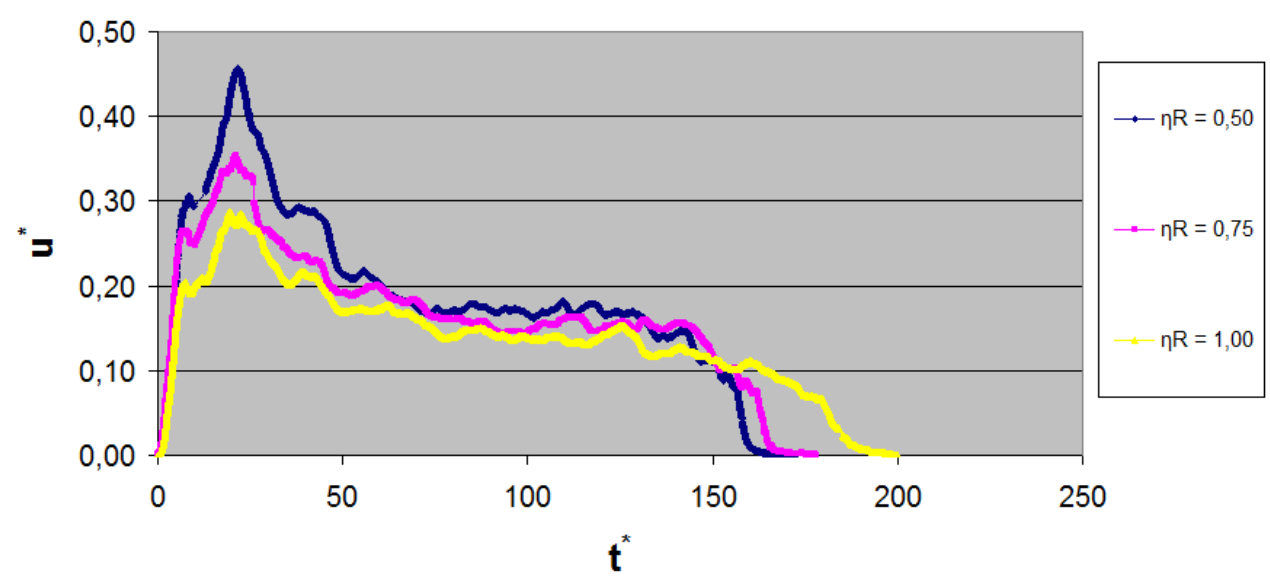

Gráfico 49 - Velocidade Interfacial vs. Tempo $\left(\mathrm{L}^{*}=10, \rho_{R}=1,61\right)$

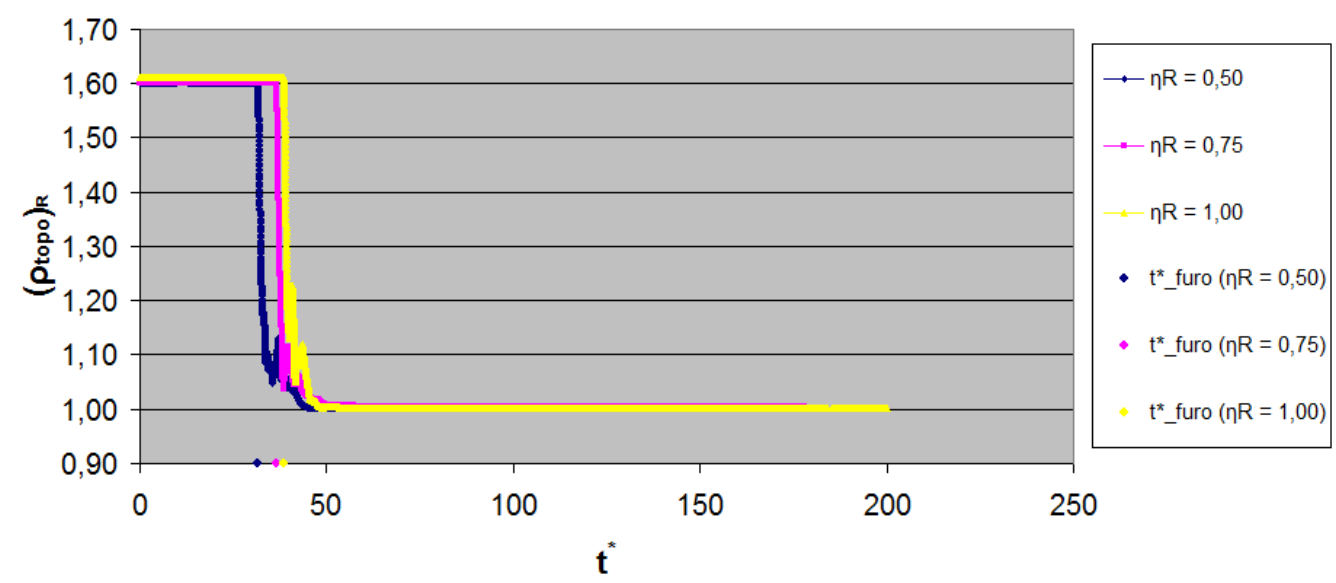

Gráfico 50 - Densidade da mistura no topo vs. Tempo $\left(\mathrm{L}^{*}=10, \rho_{R}=1,61\right)$ 
De acordo com os gráficos acima, é observado que a velocidade interfacial e terminal são inversamente proporcionais à razão entre viscosidades. Entretanto, os tempos de furo e deposição continuam sendo diretamente proporcionais a esta razão. A seguir, é apresentada uma tabela com os valores dos tempos de furo e deposição além dos valores da velocidade terminal:

\begin{tabular}{|c|c|c|c|c|c|}
\hline$L^{*}$ & $\rho_{R}$ & $\eta_{R}$ & $t^{*}{ }_{\text {furo }}$ & $t^{*}{ }_{\text {deposição }}$ & $u_{t}{ }^{*}$ \\
\hline \multirow{3}{*}{10} & \multirow{3}{*}{1,61} & 0,50 & 31,46 & 172,65 & 0,179 \\
\cline { 3 - 6 } & & 0,75 & 36,51 & 178,05 & 0,163 \\
\cline { 3 - 6 } & & 1,00 & 38,39 & 200,24 & 0,141 \\
\hline
\end{tabular}

Tabela 15 - Velocidade Terminal e Tempos de furo e deposição $\left(L^{*}=10, \rho_{R}=1,61\right)$

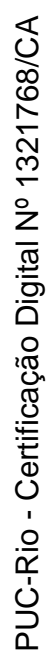

Abaixo, são mostrados dois gráficos que reforçam a relação entre a velocidade terminal e os tempos de furo e deposição com a razão entre viscosidades:

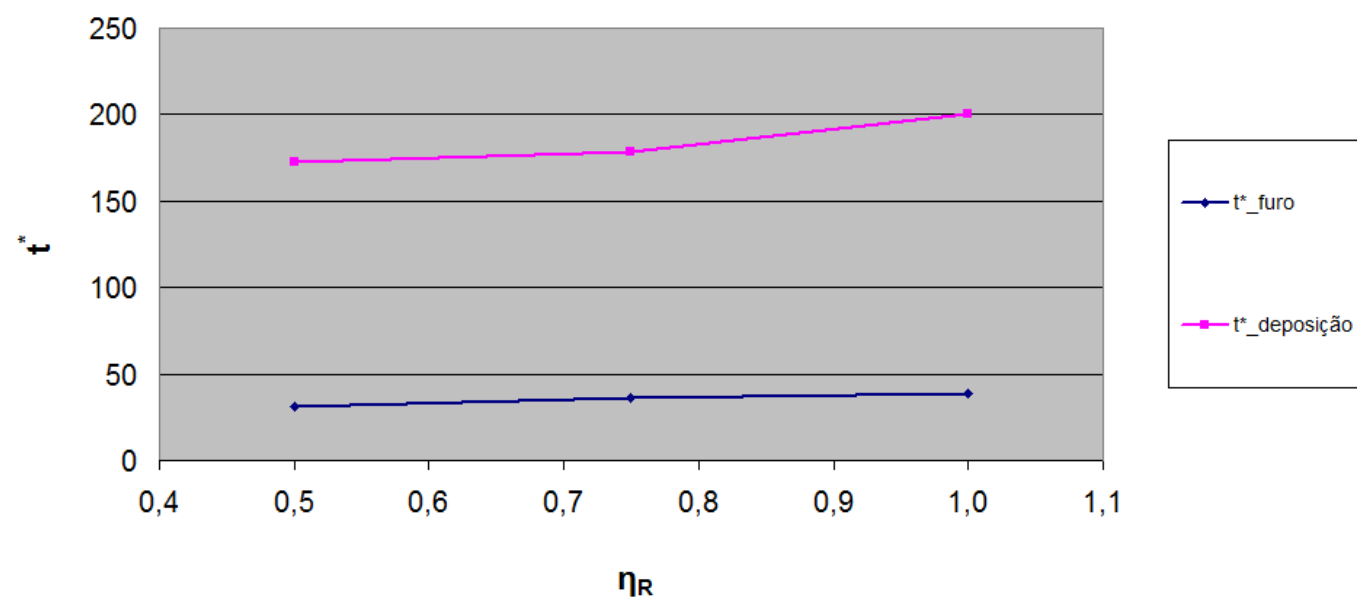

Gráfico 51 - Tempos de furo e deposição vs. Razão entre Viscosidades $\left(\mathrm{L}^{*}=10, \rho_{R}=1,61\right)$ 


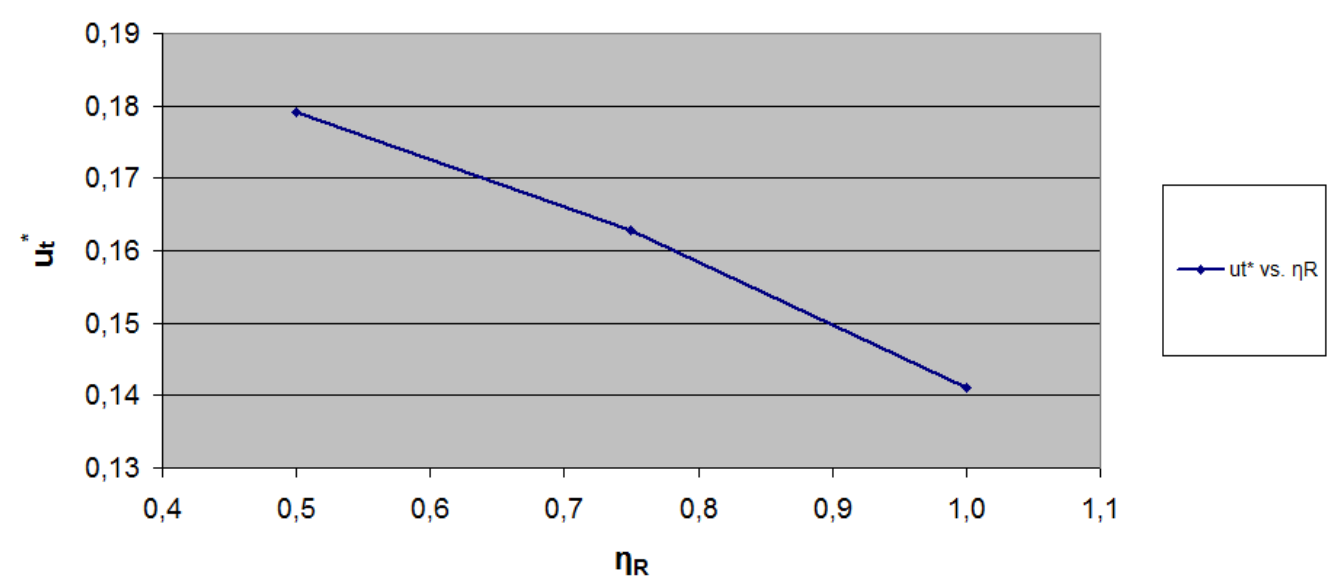

Gráfico 52 - Velocidade Terminal vs. Razão entre Viscosidades $\left(L^{*}=10, \rho_{R}=1,61\right)$

A seguir, é apresentada uma tabela com as velocidades terminais e os tempos de furo e deposição para cada razão entre viscosidades além de três gráficos que reforçam a dependência da velocidade terminal e dos tempos de furo e deposição em relação à razão entre viscosidades:

\begin{tabular}{|c|c|c|c|c|c|}
\hline$L^{*}$ & $\rho_{R}$ & $\eta_{R}$ & $t^{*}{ }_{\text {furo }}$ & $t^{*}{ }_{\text {deposição }}$ & $u_{t}{ }^{*}$ \\
\hline \multirow{4}{*}{1,05} & 0,50 & 134,68 & 456,67 & 0,058 \\
\cline { 3 - 6 } & & 0,75 & 155,09 & 724,01 & 0,043 \\
\cline { 3 - 6 } & & 1,00 & 169,33 & 803,67 & 0,028 \\
\cline { 3 - 6 } & \multirow{4}{*}{1,20} & 0,30 & 35,35 & 212,15 & 0,261 \\
\cline { 3 - 6 } & & 0,50 & 48,97 & 321,27 & 0,126 \\
\cline { 3 - 6 } & & 0,75 & 64,48 & 446,19 & 0,101 \\
\cline { 3 - 6 } & \multirow{3}{*}{1,31} & 1,00 & 74,37 & 495,84 & 0,049 \\
\cline { 3 - 6 } & & 0,50 & 36,55 & 225,07 & 0,138 \\
\cline { 3 - 6 } & & 0,75 & 49,57 & 288,05 & 0,131 \\
\cline { 3 - 6 } & \multirow{3}{*}{1,61} & 1,00 & 54,14 & 345,66 & 0,063 \\
\cline { 3 - 6 } & & 0,50 & 31,46 & 172,65 & 0,179 \\
\cline { 3 - 6 } & & 0,75 & 36,51 & 178,05 & 0,163 \\
\cline { 3 - 6 } & & 1,00 & 38,39 & 200,24 & 0,141 \\
\hline
\end{tabular}

Tabela 16 - Resultados para diferentes razões entre viscosidades

A seguir, são exibidos os gráficos que mostram de forma clara a influência da razão entre viscosidades na velocidade terminal e nos tempos de furo e deposição para todos os casos nos quais o efeito desta razão foi investigado: 


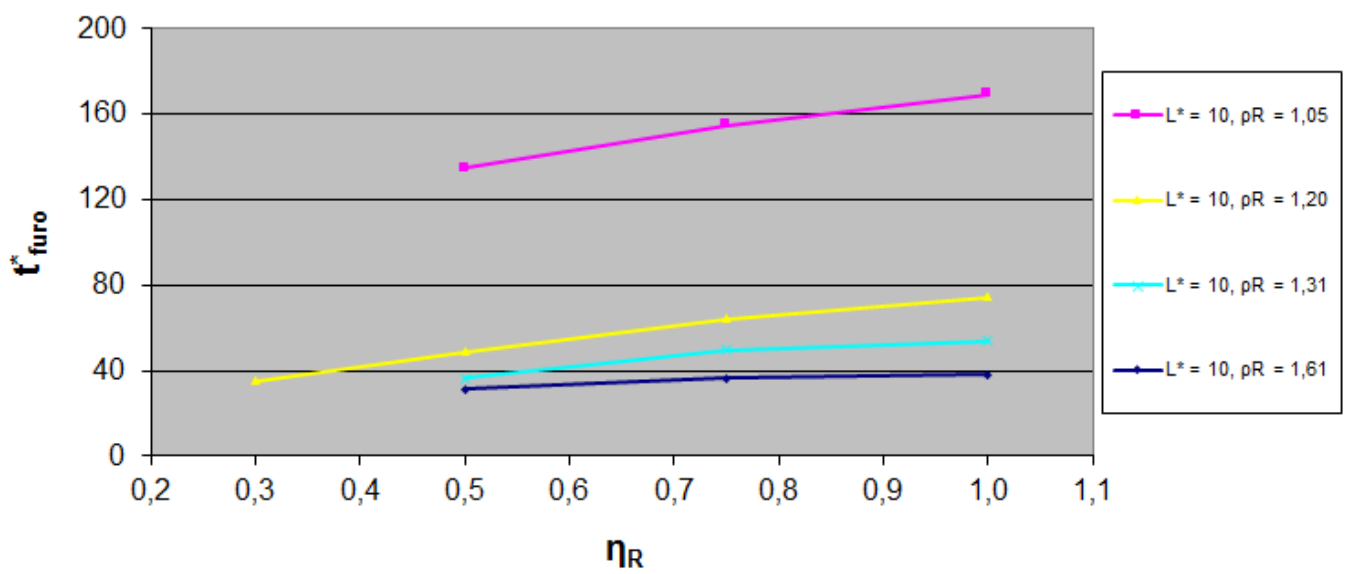

Gráfico 53 - Tempo de Furo vs. Razão entre Viscosidades

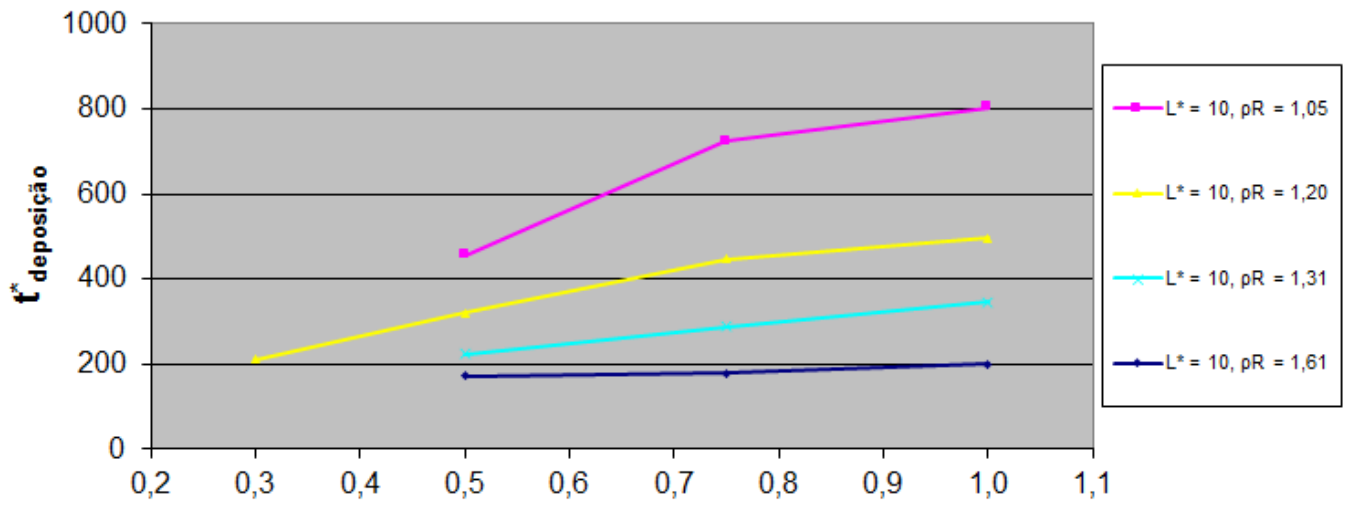

$\eta_{R}$

Gráfico 54 - Tempo de Deposição vs. Razão entre Viscosidades 


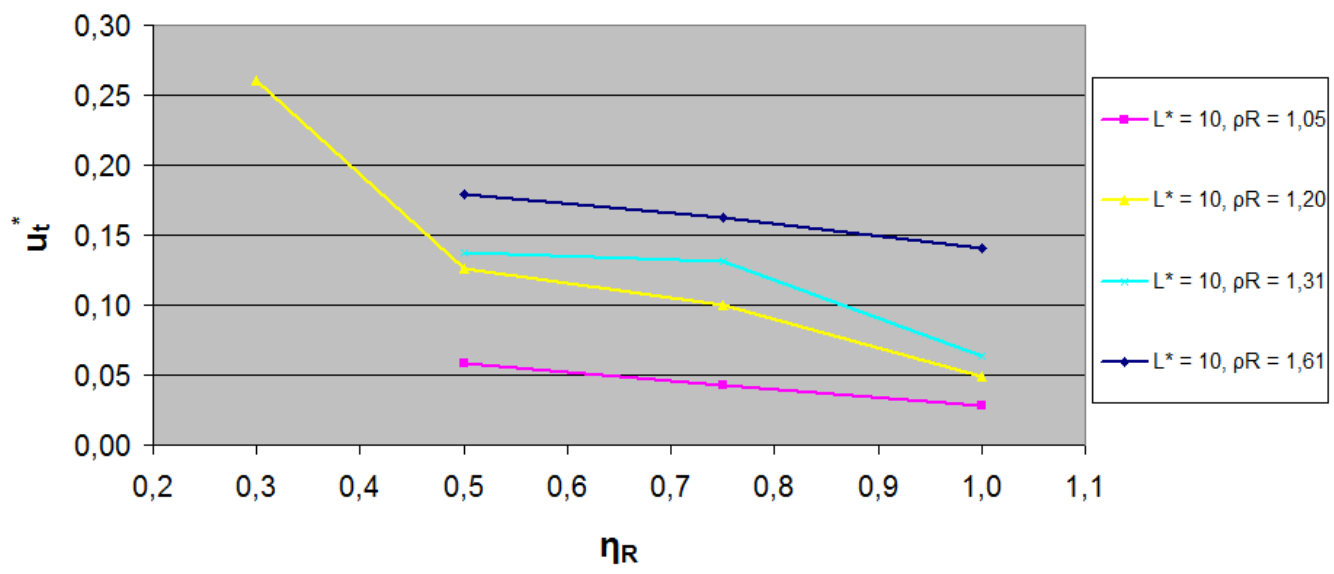

Gráfico 55 - Velocidade Terminal vs. Razão entre Viscosidades

\subsection{Influência da Razão Entre Tensões Limite de Escoamento}

Tendo-se analisado o efeito que a alteração da razão entre densidades e viscosidades provoca na operação de tamponamento de poços, a próxima meta foi o estudo da influência exercida pelo aumento da razão entre tensões limite de escoamento para um mesmo par de razões entre densidades e viscosidades iguais a, respectivamente, 1,20 e 1,00:

A seguir, pode-se visualizar graficamente a influência que o aumento da razão entre as tensões limite de escoamento (causado pelo aumento da tensão limite de escoamento do cimento) exerce sobre a velocidade interfacial e sobre o tempo de furo: 


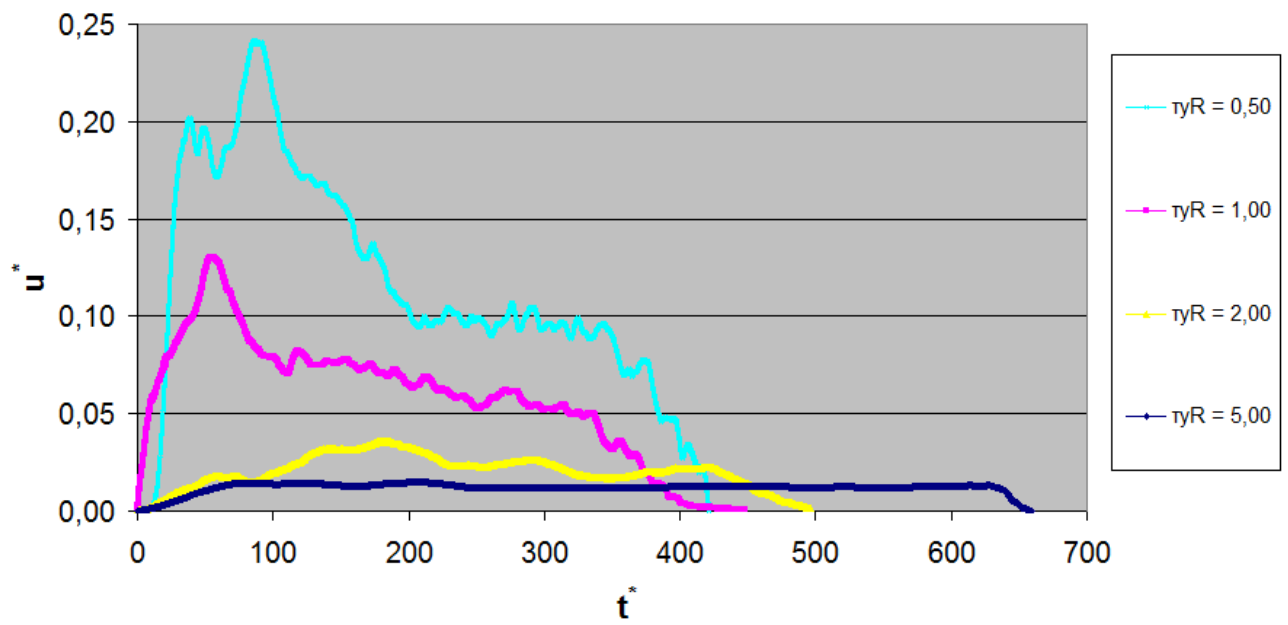

Gráfico 56 - Velocidade Interfacial vs. Tempo $\left(\mathrm{L}^{*}=10, \rho_{R}=1,20, \eta_{R}=1,00\right)$

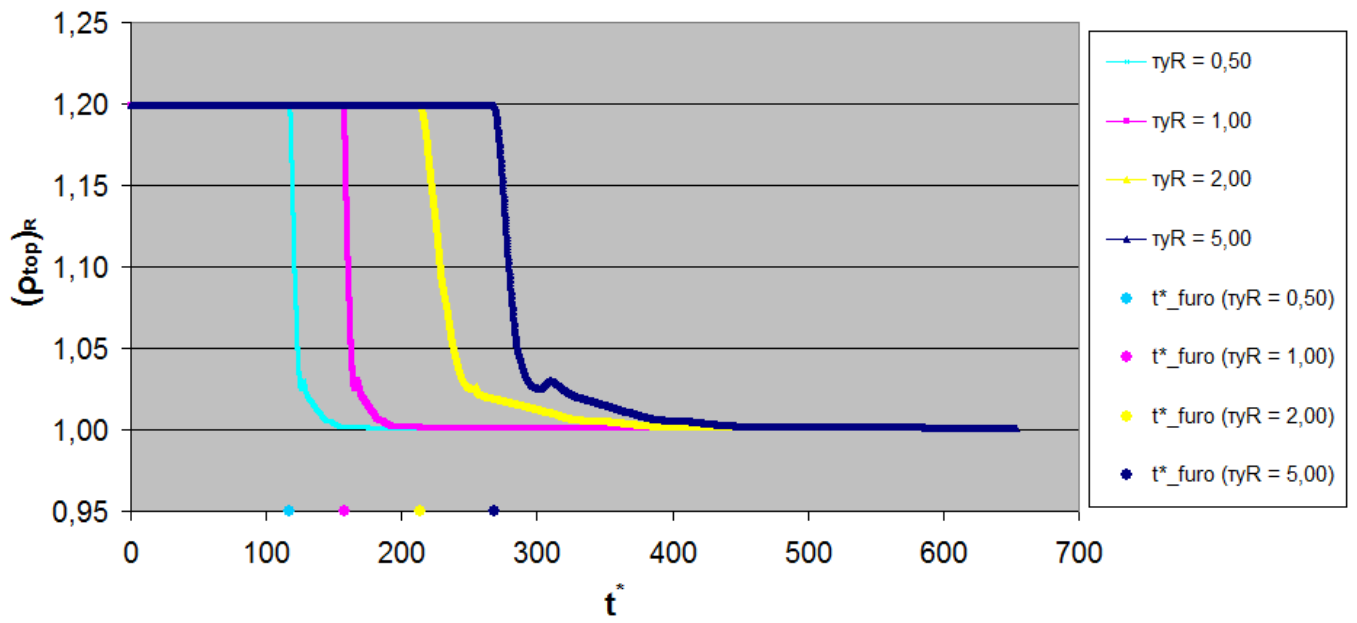

Gráfico 57 - Densidade da mistura no topo vs. Tempo $\left(\mathrm{L}^{*}=10, \rho_{R}=1,20, \eta_{R}=1,00\right)$

Com base nos gráficos observados, pode-se afirmar que a faixa de velocidade da interface e a velocidade terminal diminuem conforme a razão entre as tensões-limite de escoamento aumenta, o que significa que a relação entre a velocidade e a razão entre tensões é inversamente proporcional. Além disso, notase que os tempos de furo e deposição são diretamente proporcionais à razão entre as tensões limite de escoamento, já que quanto maior é esta razão, mais 
significativa é a resistência ao escoamento, levando um tempo maior para o fluido de perfuração "furar" o topo do poço e para o tampão se depositar no fundo do poço. A tabela abaixo mostra os valores das velocidades terminais, tempos de furo e deposição para cada razão entre as tensões limite de escoamento, enquanto que os dois gráficos seguintes ilustram a dependência entre a velocidade terminal, tempos de furo e deposição em relação às razões das tensões limite:

\begin{tabular}{|c|c|c|c|c|c|c|c|}
\hline$L^{*}$ & $\rho_{R}$ & $\eta_{R}$ & $n_{R}$ & $\tau_{y_{R}}$ & $t^{*}{ }_{\text {furo }}$ & $t^{*}{ }_{\text {deposição }}$ & $u_{t}{ }^{*}$ \\
\hline \multirow{3}{*}{10} & \multirow{3}{*}{1,20} & \multirow{3}{*}{1,00} & \multirow{3}{*}{0,56} & 0,50 & 117,09 & 421,33 & 0,095 \\
\cline { 4 - 8 } & & & & 1,00 & 157,36 & 448,09 & 0,062 \\
\cline { 4 - 8 } & & & 2,00 & 213,98 & 496,56 & 0,032 \\
\cline { 4 - 8 } & & & 5,00 & 268,15 & 659,16 & 0,019 \\
\hline
\end{tabular}

Tabela 17 - Resultados (Razão entre Tensões Limite de Escoamento)
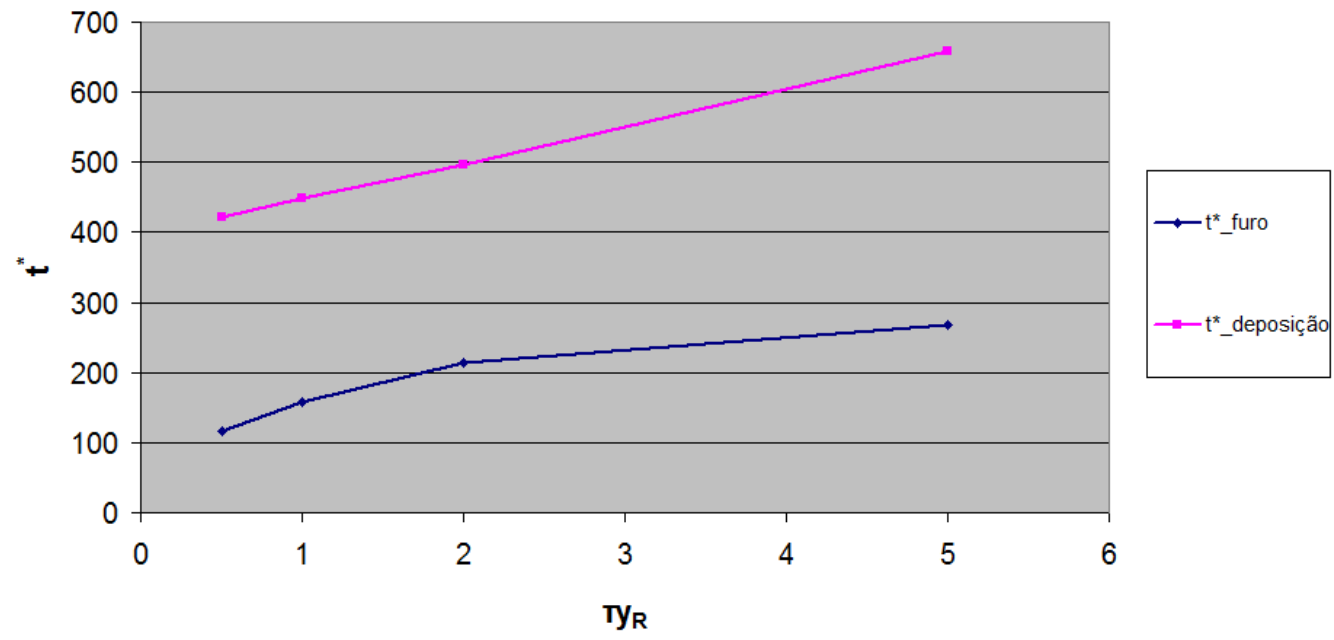

Gráfico 58 - Tempo de Furo e Deposição vs. Razão entre Tensões Limite 


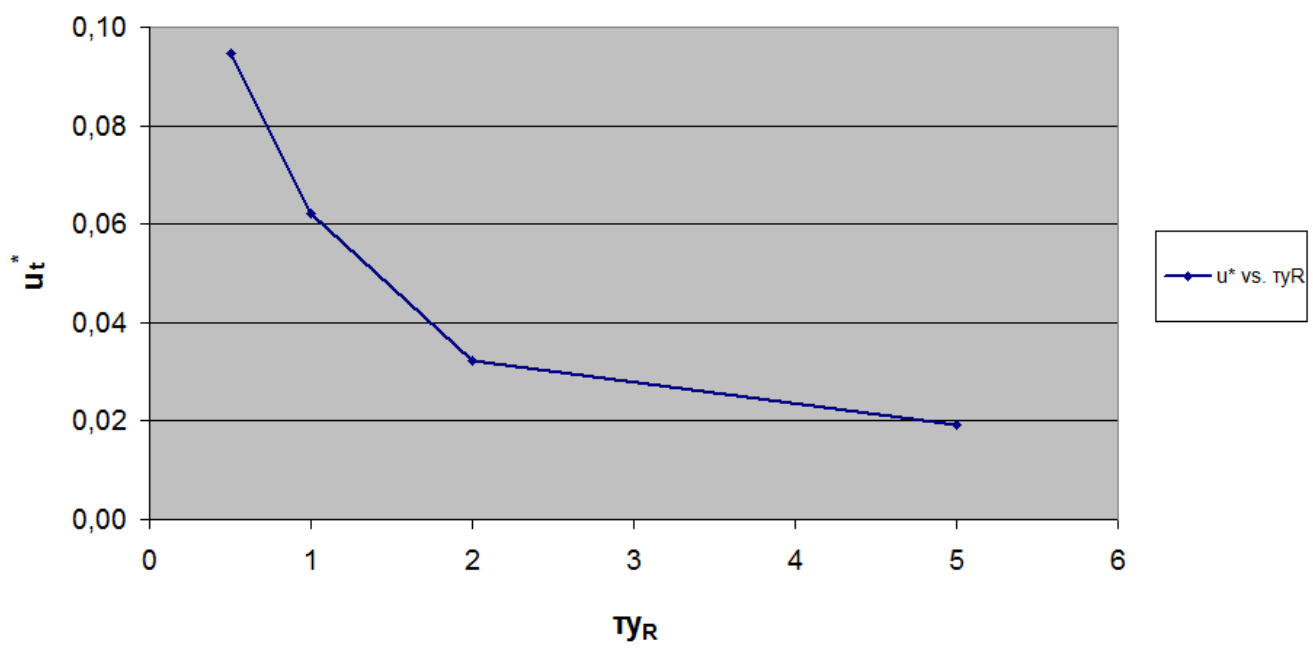

Gráfico 59 - Velocidade Terminal vs. Razão entre Tensões Limite

A figura seguinte mostra a influência que a razão entre as tensões limite de escoamento exerce na operação ao comparar-se o escoamento para dois valores:

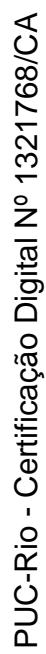

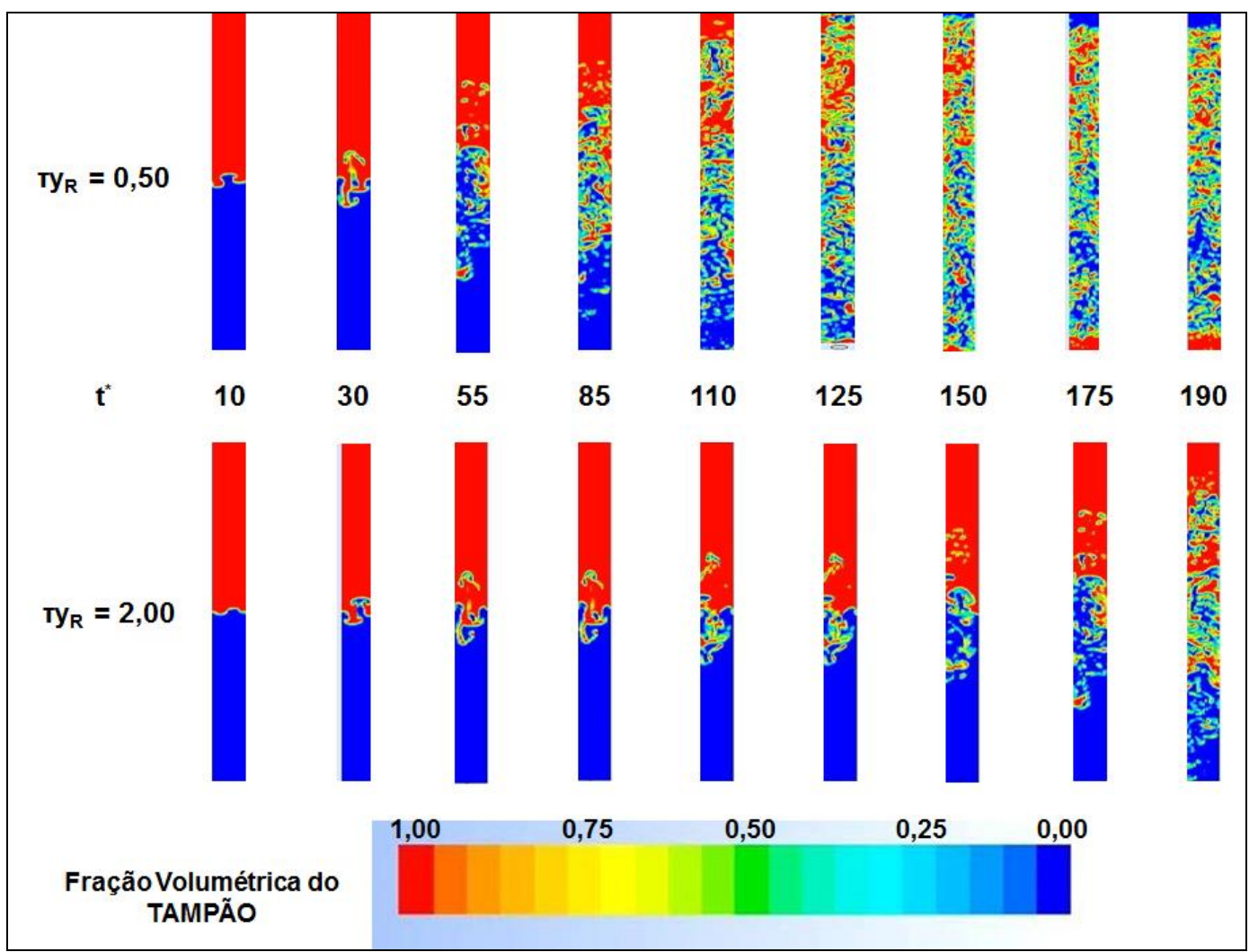

Figura 6 - Perfil do escoamento para $\tau_{y_{R}}=0,50$ e $\tau_{y_{R}}=2,00$ 


\subsection{Influência da Razão Entre Índices de Comportamento}

Depois da análise dos efeitos causados pela razão entre as razões de tensão limite de escoamento dos fluidos, prosseguiu-se com o estudo dos efeitos causados pelo aumento da razão entre os índices de comportamento (ou índices de potência) dos fluidos (aumentou-se o índice de comportamento do tampão, enquanto que o índice de comportamento do fluido de perfuração permaneceu inalterado). Nos gráficos seguintes, podemos observar a relação entre a velocidade interfacial e o tempo assim como a dependência da densidade da mistura no topo do poço com o tempo:

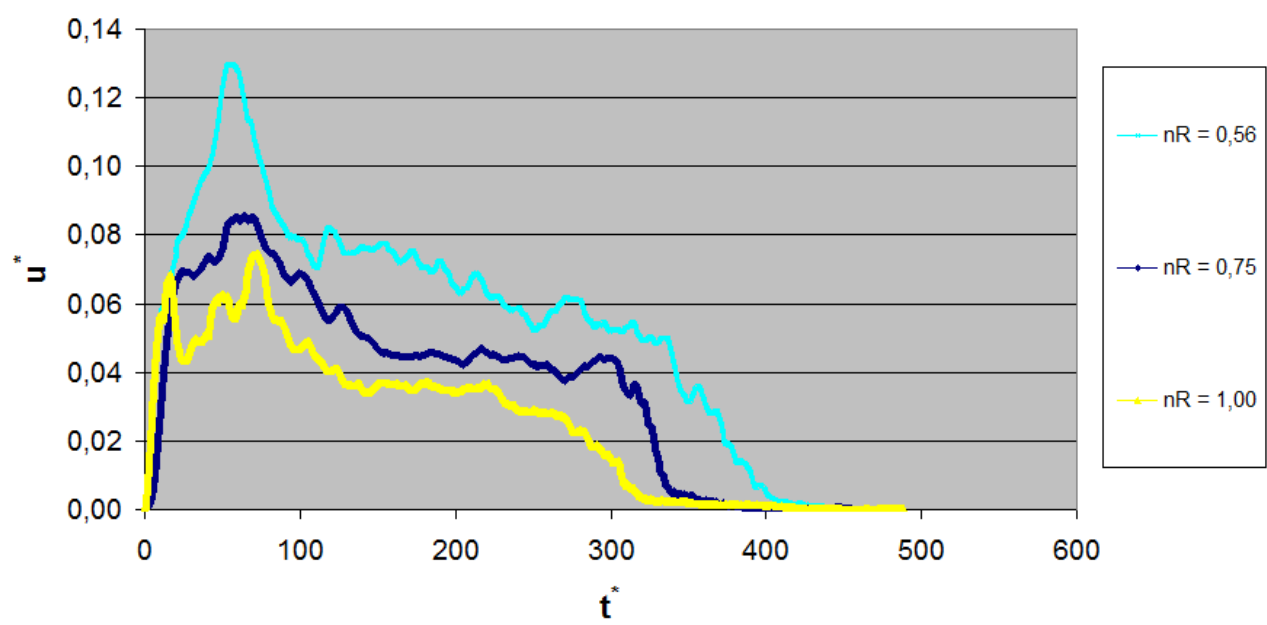

Gráfico 60 - Velocidade Interfacial vs. Tempo $\left(\mathrm{L}^{*}=10, \rho_{R}=1,20, \eta_{R}=1,00, \tau_{y_{R}}=1,00\right)$ 


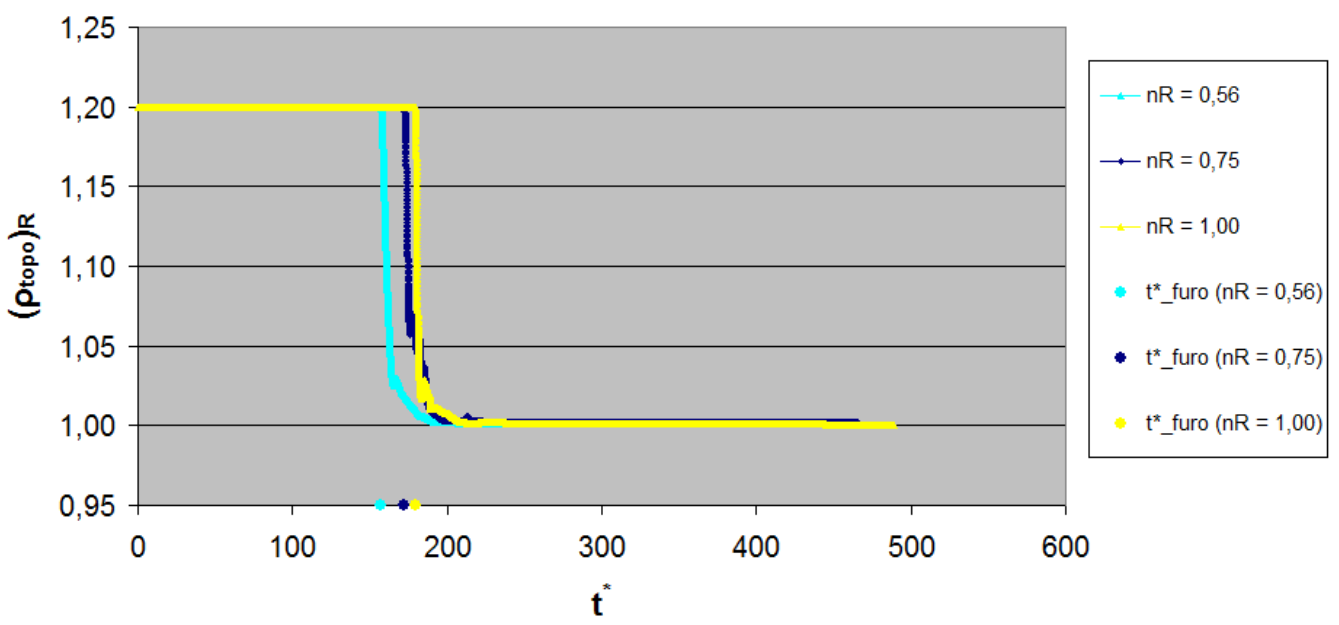

Gráfico 61 - Densidade da mistura no topo vs. Tempo $\left(\mathrm{L}^{*}=10, \rho_{R}=1,20, \eta_{R}=1,00, \tau_{y_{R}}=\right.$ $1,00)$

Com base nos gráficos acima, é válido afirmar que a velocidade terminal diminui à medida que a razão entre os índices de potência aumenta da mesma forma que o tempo de furo se torna mais elevado conforme esta mesma razão aumenta.

Este comportamento pode ser explicado pois, com o aumento do índice de potência do tampão, maior é a razão entre os índices de potência e, conseqüentemente, maior é a razão entre viscosidades, dificultando o escoamento e, como resultado, gerando menores velocidades terminais e maiores tempos de furo e deposição. Na tabela seguinte, são apresentados os valores numéricos dos resultados:

\begin{tabular}{|c|c|c|c|c|c|c|c|}
\hline$L^{*}$ & $\rho_{R}$ & $\eta_{R}$ & $\tau_{y_{R}}$ & $n_{R}$ & $t^{*}{ }_{\text {furo }}$ & $t^{*}{ }_{\text {deposição }}$ & $u_{t}{ }^{*}$ \\
\hline \multirow{2}{*}{10} & \multirow{3}{*}{1,20} & \multirow{3}{*}{1,00} & \multirow{2}{*}{1,00} & 0,56 & 157,36 & 448,09 & 0,062 \\
\cline { 4 - 8 } & & & & 0,75 & 172,23 & 472,96 & 0,044 \\
\cline { 4 - 8 } & & & 1,00 & 179,48 & 488,84 & 0,035 \\
\hline
\end{tabular}

Tabela 18 - Resultados (Razão entre Índices de Comportamento) 
Os gráficos a seguir ilustram o comportamento dos tempos de furo e deposição e da velocidade terminal conforme a razão entre os índices de comportamento de cada fluido é aumentada:

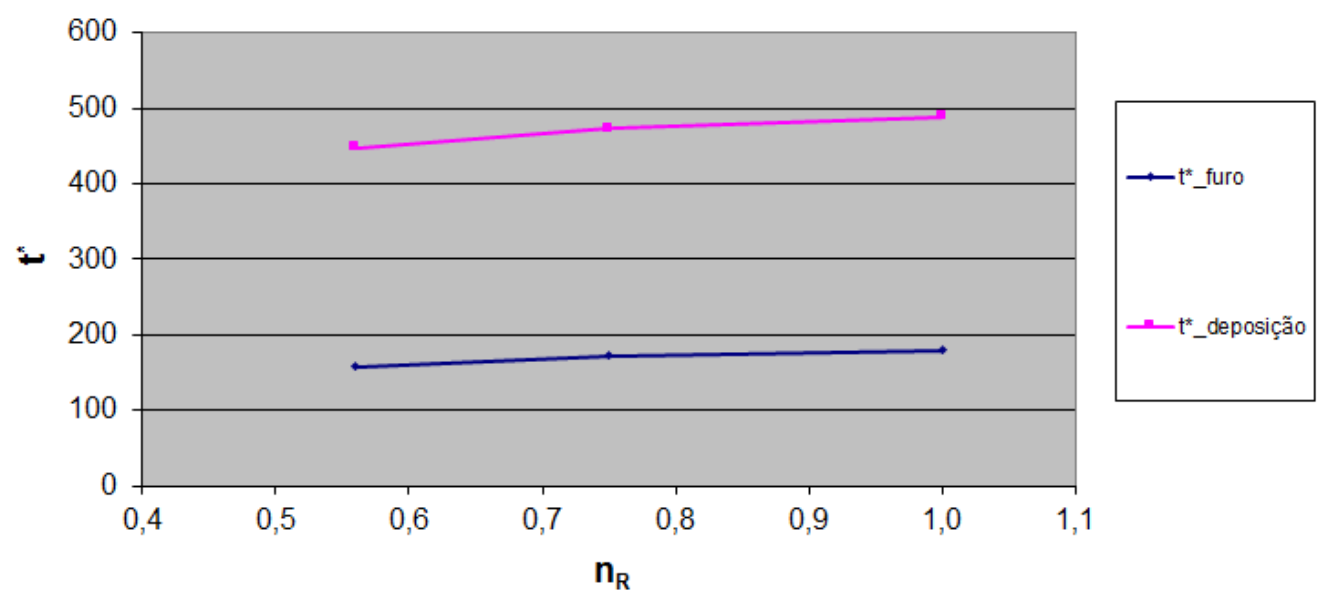

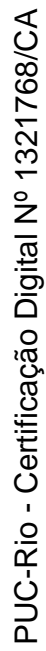

Gráfico 62 - Tempo de Furo e Deposição vs. Razão entre Índices de Comportamento

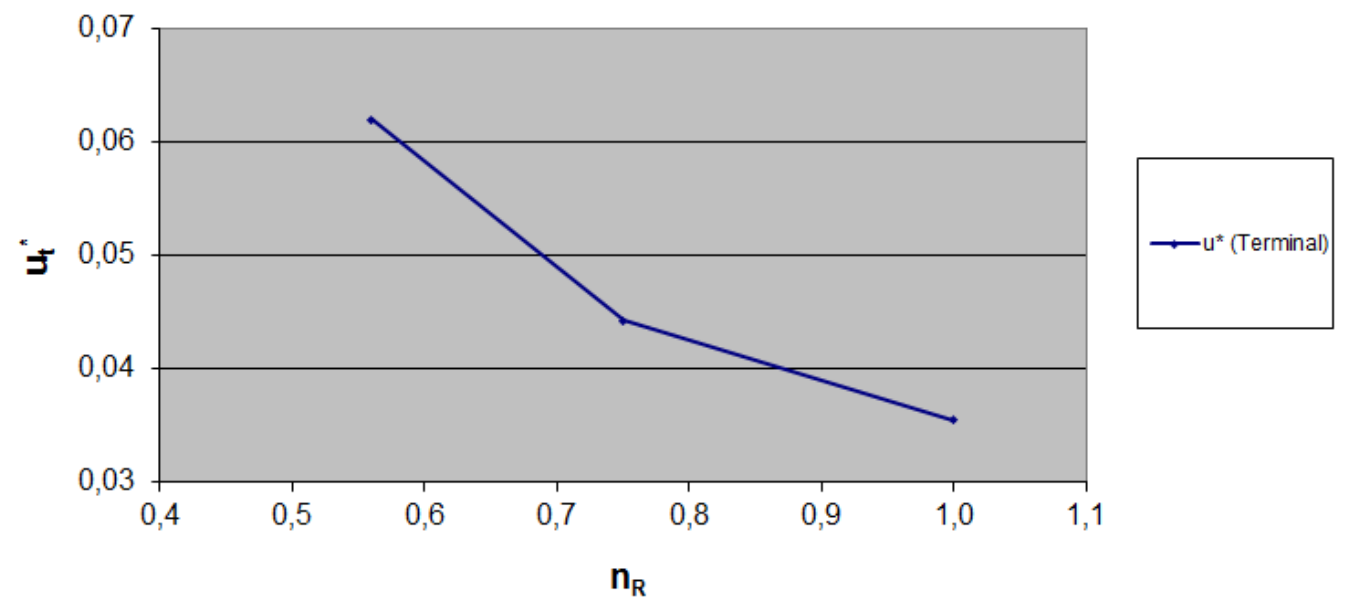

Gráfico 63 - Velocidade Terminal vs. Razão entre Índices de Comportamento

A figura seguinte mostra as etapas do escoamento multifásico para $n_{R}=0,56$ e para $n_{R}=1,00$ : 


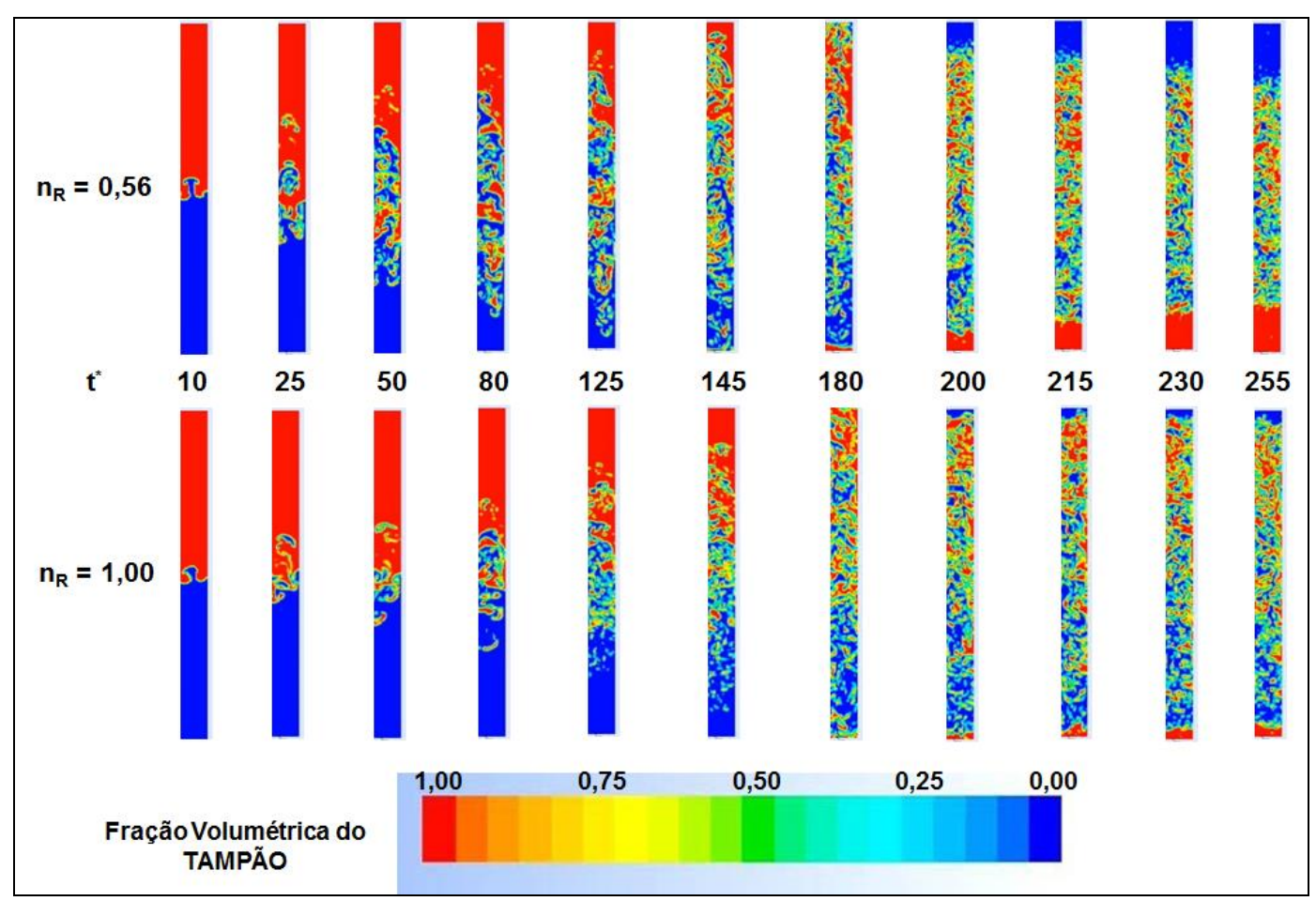

Figura 7 - Perfil do escoamento para $n_{R}=0,56$ e $n_{R}=1,00$

\subsection{Influência da Tensão Interfacial}

Após o estudo da influência exercida pela razão entre os índices de potência dos dois fluidos, iniciou-se o estudo dos efeitos causados pela presença de uma tensão na interface entre os fluidos. Um caso no qual não há tensão na interface foi comparado com outro caso em que a tensão interfacial é $\sigma=0,07 N \cdot m^{-1}$.

Antes de realizar a simulação, foi efetuado um cálculo com base nos parâmetros apresentados anteriormente ( $B o$ e $C a$ ) com o objetivo de provar-se que em todos os casos apresentados anteriormente, a tensão interfacial realmente poderia ser desprezada, ou seja, se as forças gravitacionais e viscosas atuantes no fluido de perfuração fossem muito maiores do que as forças decorrentes da tensão interfacial, ela poderia, portanto, ser negligenciada. Vale lembrar que as propriedades do fluido de perfuração (densidade e viscosidade) utilizadas no cálculo desses parâmetros foram a menor diferença entre densidades (o menor $\Delta \rho$ utilizado nos casos é $\left.\Delta \rho=\rho_{2}-\rho_{1}=810,6\left[\frac{\mathrm{kg}}{\mathrm{m}^{3}}\right]-772\left[\frac{\mathrm{kg}}{\mathrm{m}^{3}}\right]=38,6\left[\frac{\mathrm{kg}}{\mathrm{m}^{3}}\right]\right)$ e a 
menor viscosidade do fluido de perfuração (a menor viscosidade do fluido de perfuração usada nos casos é $\eta_{1}=3,690 P$ ) de todos os casos mostrados anteriormente visto que, se para esses valores mínimos de $\Delta \rho$ e $\eta_{1}$, as forças gravitacionais e as forças viscosas fossem muito superiores às forças de tensão interfacial, as forças gravitacionais e viscosas superariam mais ainda as forças interfaciais para $\Delta \rho$ e $\eta_{1}$ maiores. Considerando $\sigma=0,07 N . \mathrm{m}^{-1}$, temos que:

$$
\begin{aligned}
& B o=5409 \cong 5,41 \times 10^{3} \\
& C a=165=1,65 \times 10^{2}
\end{aligned}
$$

Como Bo é muito grande, a força gravitacional é muito maior do que a força gerada pela tensão superficial. Da mesma forma, como $\mathrm{Ca}$ é grande, as forças viscosas superam consideravelmente as forças geradas pela tensão na interface. Portanto, as forças gravitacionais e viscosas são muito maiores do que as forças interfaciais, sugerindo que as forças na interface possam ser negligenciadas nos demais casos de análise paramétrica. Para verificar isso, os dois casos foram comparados, sendo mostrados adiante.

Nos gráficos seguintes, pode-se visualizar a dependência da velocidade interfacial e da densidade da mistura no topo do poço com o tempo para um caso em que a tensão na interface é nula e para outro caso no qual o valor da tensão interfacial é $\sigma=0,07 N \cdot m^{-1}$ : 


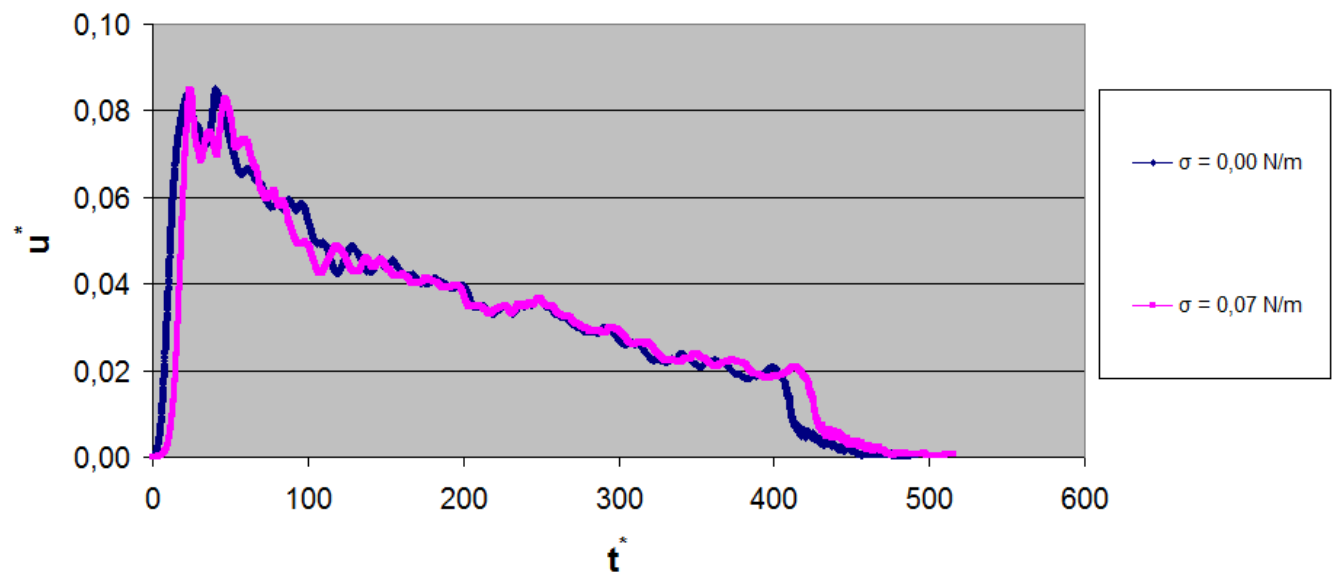

Gráfico 64 - Velocidade Interfacial vs. Tempo $\left(\mathrm{L}^{*}=10, \rho_{R}=1,05, \eta_{R}=0,50\right)$

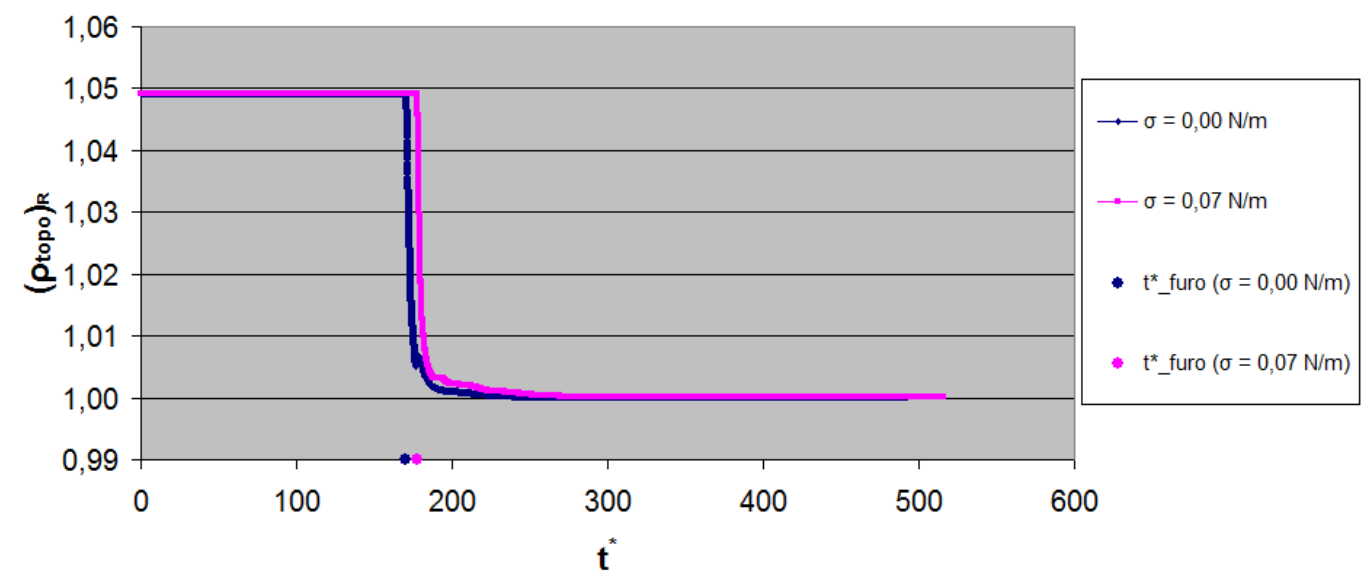

Gráfico 65 - Densidade da mistura no topo vs. Tempo $\left(\mathrm{L}^{*}=10, \rho_{R}=1,05, \eta_{R}=0,50\right)$

Com base nos gráficos mostrados, é válido afirmar que a tensão na interface não influencia consideravelmente a operação de tamponamento de poços (velocidades interfacial e terminal próximas assim como tempos de furo e deposição similares).

A seguir, é apresentada uma tabela contendo os resultados numéricos dos dois casos investigados assim como as discrepâncias do caso em que há uma tensão na interface em relação ao caso no qual a tensão interfacial é nula: 


\begin{tabular}{|c|c|c|c|c|c|c|c|c|c|c|}
\hline$L^{*}$ & $\rho_{R}$ & $\eta_{R}$ & $\tau_{y_{R}}$ & $\sigma\left(N \cdot m^{-1}\right)$ & $t^{*}$ furo & $t^{*}$ deposição & $u_{t}^{*}$ & $\varepsilon_{\text {furo }}(\%)$ & $\varepsilon_{\text {dep }}(\%)$ & $\varepsilon_{u_{t}}{ }^{*}(\%)$ \\
\hline \multirow[b]{2}{*}{10} & \multirow{2}{*}{1,05} & \multirow{2}{*}{0,50} & \multirow{2}{*}{1,00} & 0,00 & 170,07 & 492,68 & 0,038 & - & - & - \\
\hline & & & & 0,07 & 177,43 & 515,84 & 0,037 & 4,32 & 4,70 & 3,55 \\
\hline
\end{tabular}

Tabela 19 - Influência da tensão interfacial no tempo de furo

Considerando as baixas discrepâncias mostradas na tabela em relação ao caso no qual a tensão na interface é ausente, pode-se justificar o desprezo da tensão interfacial nos demais casos analisados. Vale lembrar que as baixas discrepâncias se devem ao fato de as forças interfaciais serem muito menores do que as forças gravitacionais e viscosas. 


\section{Conclusão}

Com base nos resultados obtidos numericamente, pode-se afirmar que a menor razão de aspecto para a qual não haverá a contaminação do cimento antes do seu tempo de cura como também não ocorrerá um desperdício considerável de tampão é $L^{*}=10$ visto que essa baixa razão de aspecto apresenta uma estabilidade nítida da velocidade da interface entre os fluidos para uma faixa considerável de tempo, além de a velocidade terminal relativa a essa razão de aspecto ser muito próxima à velocidade terminal relativa à razão de aspecto $L^{*}=20$, indicando que a velocidade terminal é praticamente constante com o aumento da razão de aspecto (a partir de $L^{*}=10$ ) . Com isso, pode-se fazer uma extrapolação de dados desta razão de aspecto para um caso real $\left(L^{*} \approx 200\right.$ ), no qual certamente ocorre um gasto significativo de tampão a fim de garantir-se um processo de tamponamento livre de contaminação.

Quanto à investigação paramétrica realizada, pode-se afirmar que a velocidade permanece estável em $L^{*}=10$ e $L^{*}=20$, não se estabilizando em $L^{*}=5$. É observado que o intervalo de tempo em que o regime é quase permanente aumenta conforme a razão de aspecto também aumenta. Além disso, tanto os tempos de furo e deposição do tampão quanto à diferença entre os respectivos tempos de deposição e furo são diretamente proporcionais à razão de aspecto, o que é esperado, já que os fluidos percorrem um comprimento maior durante o escoamento conforme se aumenta a razão de aspecto, gerando altos tempos de furo e deposição. As velocidades interfacial e terminal mostraram-se diretamente proporcionais à razão de aspecto.

A respeito da razão entre densidades, é válido ressaltar que a razão entre densidades do tampão e do fluido de perfuração exercem influência notável nos tempos de furo e deposição e na velocidade terminal entre os dois fluidos. De modo geral, a velocidade interfacial e terminal são diretamente proporcionais à razão entre densidades, ao passo que os tempos de furo e deposição apresentam uma relação inversa, decrescendo conforme a razão entre densidades aumenta 
visto que, quanto mais pesado é o tampão, mais instável tende a ser o processo de tamponamento e, conseqüentemente, mais rápida é a operação, o que é sinônimo de altas velocidades e baixos tempos de furo e deposição.

Em relação à razão entre viscosidades, pode-se dizer que as velocidades interfaciais e terminais são inversamente proporcionais a esta razão visto que, à medida que a viscosidade do tampão aumenta (para uma mesma viscosidade do fluido de perfuração), maior é a dificuldade que a pasta de cimento tem de se locomover (conservação de massa) e, conseqüentemente, maior é a resistência ao escoamento do fluido de perfuração, resultando em velocidades menores. Pelo mesmo motivo, o fluido de perfuração leva um tempo maior para "furar" o topo do poço de petróleo assim como o tampão se deposita mais lentamente conforme a razão entre viscosidades aumenta, o que significa que os tempos de furo e deposição são diretamente proporcionais a esta razão.

Considerando-se os resultados obtidos nos casos em que as razões entre tensões limite de escoamento foram alteradas (modificando-se a tensão limite do tampão e mantendo-se a tensão limite do fluido de perfuração inalterada), podemos ressaltar que as velocidades interfacial e terminal são inversamente proporcionais à razão entre tensões limite de escoamento assim como os tempos de furo e deposição são diretamente proporcionais a essa mesma razão, o que pode ser explicado pela idéia de que quanto maior é a tensão limite de escoamento do tampão em relação à tensão limite do fluido de perfuração, maior é a resistência ao escoamento inicial, visto que a força resultante da tensão limite do tampão precisa ser superada para ocorrer o movimento tanto do tampão como do fluido de perfuração (fluido de perfuração também não consegue se mover por causa da conservação de massa). Conseqüentemente, maior é a tendência de estabilidade durante o processo, o que significa que a faixa de velocidade da interface assim como a velocidade terminal entre os fluidos tendem a ser menores conforme essa razão aumenta assim como o "furo" do fluido de perfuração no topo do poço e a deposição do tampão no fundo do poço demoram mais para ocorrer. 
Com base no estudo paramétrico efetuado para a razão entre os índices de potência, é válido afirmar que as velocidades interfacial e terminal são inversamente proporcionais à razão entre os índices de potência ao passo que os tempos de furo e deposição são diretamente proporcionais a esta razão visto que, quanto mais elevado é o índice de potência do tampão em relação ao índice de potência do fluido de perfuração, maior é a razão entre as viscosidades dos fluidos, isto é, mais viscoso é o tampão em comparação com o fluido de perfuração. Por este motivo, quanto maior é esta razão, o deslocamento dos fluidos encontra uma resistência mais alta, levando mais tempo para o fluido de perfuração "furar" o topo do poço e para o tampão se depositar no fundo do poço assim como o escoamento tende a ser mais lento, resultando em menores velocidade interfacial e terminal.

Com base nos casos relacionados à análise paramétrica da tensão interfacial, pode-se dizer que a presença da tensão na interface não interfere nitidamente no processo de tamponamento, o que justifica o desprezo da tensão interfacial no restante dos casos estudados. A negligência da tensão interfacial se deve ao fato de as forças gravitacionais e viscosas serem muito superiores às forças geradas pela tensão interfacial.

\subsection{Proposta para trabalhos futuros}

Para os próximos estudos, é recomendado explorar mais os efeitos reológicos, ampliando a faixa de valores analisada, principalmente para a razão entre os índices de comportamento (os tempos de furo e deposição não sofreram uma influência tão nítida pela faixa de valores empregada para a razão entre estes índices quanto nos casos das razões de densidades e viscosidades, por exemplo).

Propõe-se a análise da variação de parâmetros que não foram estudados nesta tese como a temperatura (todos os casos foram considerados isotérmicos), a pressão (apesar de exercer influência na operação, a pressão não foi analisada) e o diâmetro (o diâmetro foi considerado igual em todos os casos). Também 
recomenda-se simular mais casos com ênfase na tensão interfacial. Além disso, é sugerida a verificação da existência de uma razão de aspecto maior do que 5 e menor do que 10 para a qual não ocorra a contaminação do cimento antes do seu tempo de cura e também não ocorra o desperdício de tampão.

Para finalizar, a recomendação mais importante é a variação dos parâmetros relativos ao fluido de perfuração (densidade, viscosidade, tensão limite de escoamento e índice de comportamento), visto que o efeito de cada razão foi estudado apenas com base na modificação das propriedades da pasta de cimento. Por exemplo, seria um equívoco afirmar que a operação seria a mesma se, em vez de trabalhássemos com tensões limite de escoamento do tampão e fluido de perfuração iguais a $2 \mathrm{~Pa}$ e $1 \mathrm{~Pa}$, respectivamente, estudássemos tensões iguais a 20 $\mathrm{Pa}$ e $10 \mathrm{~Pa}$, visto que a razão nesses dois casos é exatamente a mesma. Em outras palavras, não só a razão entre os parâmetros $\left(\frac{\tau_{y_{2}}}{\tau_{y_{1}}}\right.$, por exemplo) é importante como também a soma de cada parâmetro $\left(\frac{\tau_{y_{1}}}{\tau_{y_{1}}+\tau_{y_{2}}}\right.$, por exemplo $)$ deve ser considerada.

\subsection{Observações}

É valido lembrar que o comprimento de cimento utilizado nos casos relativos à análise paramétrica é 10 metros (para um diâmetro igual a 1 metro) e que o valor exigido pela legislação é igual a 60 metros (para um diâmetro próximo a 0,28 metros). A finalidade do estudo numérico foi justamente mostrar que este comprimento, $60 \mathrm{~m}$ (e diâmetro próximo a $0,28 \mathrm{~m}$ ), não é necessário para garantir que não ocorra a contaminação do cimento antes do seu tempo de cura, visto que a contaminação também não ocorrerá para um comprimento igual a 10 metros (e diâmetro igual a $1 \mathrm{~m})$. 
Considerando que o tempo de cura do cimento ocorre em uma faixa de 4 a 7 horas, pode-se ressaltar que, quanto maior é lenta é a cura, maior deve ser o tempo de contaminação a fim de evitar a contaminação da pasta de cimento visto que o aumento brusco de viscosidade ocorreria em um tempo maior.

Um outro fato importante a ser levado em consideração é que o tempo de contaminação definido e calculado na análise numérica é rigorosamente o tempo em que o fluido de perfuração encosta no topo do poço. Isso significa que um comprimento mínimo foi desprezado, sendo esse comprimento uma pequena distância em relação ao topo do poço (o tempo de contaminação poderia ser definido como o tempo em que o fluido de perfuração quase encosta no topo, ou seja, o tempo em que este fluido atinge uma coordenada espacial pré-determinada e próxima ao topo). 


\section{Referências bibliográficas}

1 PINTO, E. N. M. G. et al. Adição de Plastificantes em pastas de cimento para poços de petróleo: Avaliação do comportamento reológico, 2007, 4 PDETRO, Campinas, SP, p. 1-3, 10 p.

2 CHIPALAVELA, A. F. Análise e Discussão das Operações de Perfuração e Completação em Poços Petrolíferos, 2013, p. 42-43, 103 p.

3 ABDU, A.; NACCACHE, M. F.; MENDES, P. R. S. Effect of Rheology on Well Plugging Process, 2012, IMECE 2012-8614, p. 3-4, 9 p.

4 KERSWELL, R. R. Exchange flow of two immiscible fluids and the principle of maximum flux. Journal of Fluid Mechanics, 2011, vol. 682, p. 132-159.

5 BECKETT, F. M. et al. An experimental study of low-Reynoldsnumber exchange flow of two Newtonian fluids in a vertical pipe. Journal of Fluid Mechanics, 2011, vol. 682, p. 652-670.

6 FRIGAARD, I. A.; SCHERZER, O. Uniaxial exchange flows of two Bingham fluids in a cylindrical duct. IMA Journal of Applied Mathematics, 1998, vol. 61, p. 237-266.

7 SWEENEY, H.; KERSWELL, R. R.; MULLIN, T. Rayleigh-Taylor instability in a finite cylinder: linear stability analysis and long-time fingering solutions. Journal of Fluid Mechanics, 2013, vol. 734, p. 338362.

8 CALVERT, D. G.; HEATHMAN, J. F.; GRIFFITH, J. E. Plug Cementing: Horizontal to Vertical Conditions. Society of Petroleum Engineers, 1995, SPE 30514.

9 HARESTAD, K. et al. Optimization of Balanced-Plug Cementing. SPE Drilling \& Completion, 1997, SPE 35084.

10 CRAWSHAW, J. P.; FRIGAARD, I. Cement Plugs: Stability and Failure by Buoyancy-Driven Mechanism. Society of Petroleum Engineers, 1999, SPE 56959.

11 SMITH, R. C.; BEIRUTE, R. M.; HOLMAN, G. B. Improved Method of Setting Successful Cement Plugs. Society of Petroleum Engineers, 1984, SPE 11415.

12 MEIBURG, E. et al. Density-Driven Instabilities of VariableViscosity Miscible Fluids in a Capillary Tube. New York Academy of Sciences, 2004, vol.1027, p. 383-402. 
13 PAPANASTASIOU, T. C. Flow of materials with yield. Journal of Rheology, 1987, vol. 31, p. 385-404.

14 Fluent Users Guide, ANSYS Inc., 2010.

15 Fluent Users Guide, ANSYS Inc., 2010. Disponível em: $<$ http://imechanica.org/files/fluent_13.0_lecture05-solver-settings.pdf> (p. L5-10). Acesso em: 3 ago. 2015.

16 BUSON, D. F. Escoamento Óleo-Gás em Equipamento Submarino: Influência da Fração Volumétrica de gás na separação de fases no módulo de bombeio, 2013, Universidade Federal do Espírito Santo, p. 37-38, $57 \mathrm{p}$.

17 Fluent Users Guide, ANSYS Inc., 2014. Disponível em: $<$ http://www.arc.vt.edu/ansys_help/flu_th/flu_th_sec_uns_solve_pv.html\#fl u_th_uns_sec_simple>. Acesso em: 25 out. 2015.

18 PATANKAR, S. V., 1980, Numerical Heat Transfer and Fluid Flow. Hemisphere, Washington, DC.

19 Fluent Users Guide, ANSYS Inc., 2014. Disponível em: $<$ http://www.arc.vt.edu/ansys_help/flu_th/flu_th_sec_uns_solve_pv.html\#fl u_th_piso>. Acesso em: 19 out. 2015.

20 ISSA, R. I. Solution of the Implicitly Discretized Fluid Flow Equation by Operator Splitting, 1986, Journal of Computational Physics, vol. 62, p. 40-65.

21 Fluent Users Guide, ANSYS Inc., 2014. Disponível em: $<$ http://www.arc.vt.edu/ansys_help/flu_th/flu_th_sec_eval_derivatives.html \#x1-91800019.3.3>. Acesso em: 27 out. 2015.

22 Fluent Users Guide, ANSYS Inc., 2014. Disponível em:

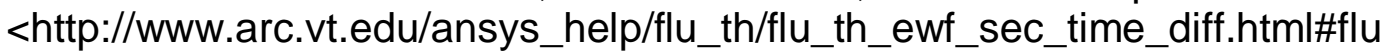
th_ewf_sec_time_diff_first_expl>. Acesso em: 2 ago. 2015.

23 Fluent Users Guide, ANSYS Inc., 2014. Disponível em: $<$ http://www.arc.vt.edu/ansys_help/flu_th/flu_th_ewf_sec_time_diff.html\#flu th_ewf_sec_time_diff_first_impl>. Acesso em: 27 set. 2015.

24 GASPAR, P. D.; PITARMA, R. A. Esquemas de discretização em escoamentos com regime de convecção mista: Estudo de caso, 2004, p. 5, 9 p.

25 Fluent Users Guide, ANSYS Inc., 2014. Disponível em: <http://www.arc.vt.edu/ansys_help/flu_th/flu_th_vof_surf_tens.html>. Acesso em: 10 ago. 2015. 
26 FAVERO, J. L., 2009, Simulação de Escoamentos Viscoelásticos: Desenvolvimento de uma metodologia de análise utilizando o software OpenFOAM e Equações Constitutivas Diferenciais, p. 12, 127p. 